

BKTTHSONIAH OCEANO WTHEDO SORTING CEYTER

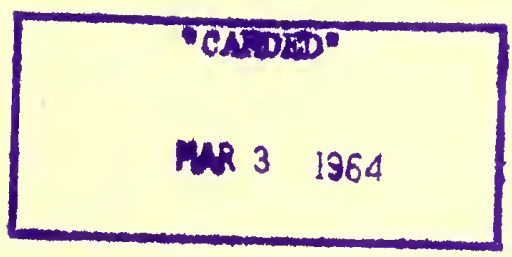




\title{
ENTEROPNEUSTA FROM THE SOUTH PACIFIC, WITH NOTES ON THE WEST INDIAN SPECIES.
}

\author{
By ARTHUR WILLEY, M.A., D.Sc.
}

[With Plates XXVI-XXXII.]

Noт more than five species of Enteropneusta have been described from the South Pacific up to the present time, and of these, no less than four have been definitely made known since the publication, in 1893, of Professor Spengel's Monograph of the group.

The five species are as follows:-Schizocardium peruvianum Spengel, Ptychodera australiensis Hill', Ptychodera flava Eschscholtz ${ }^{2}$, Ptychodera hedleyi Hill, and Spengelia porosa Willey.

In the present contribution I am able to add three new species to this list, namely, Spengelia alba n. sp., Ptychodera ruficollis n. sp., and Ptychodera carnosa n. sp. I also describe two new species of Ptychodera from the West Indies, specimens of which I owe to the kindness of Professor T. H. Morgan (see below p. 288).

Ptychodera flava was the first Enteropneust ever described, and was obtained from the Rumanzow Group in the Archipelago of the Marshall Islands, and described by Eschscholtz in 1825. The figure of the animal given by Eschscholtz was reproduced by Spengel in his monograph; and the general character of the species portrayed in this figure seemed to indicate that it was closely similar to the species which I found in great abundance at the Isle of Pines in 1896. But as Eschscholtz's figure did not admit of any detailed comparison with the form from the Isle of Pines, I deemed it advisable to give a provisional name to the latter, viz. Pt. caledonica.

I was subsequently informed by my friend $\mathrm{Mr}$ J. P. Hill that the same species occurs at Funafuti and I thereupon became doubtful as to the value of the name Pt. caledonica. Accordingly in a later publication ${ }^{4}$ s stated in a footnote that if the

1 J. P. Hill (1894), "On a new species of Enteropneusta (Ptychodera australiensis) from the coast of New South Wales," Proc. Linn. Soc. N. S. W. x. (2).

${ }^{2}$ A. Willey (1897), "On Ptychodera flava Eschscholtz," Q. J. M. S. Vol. xL. p. 165.

3 J. P. Hill (1898), "The Enteropneusta of Funafuti," Memoirs Aust. Mus. 11. pp. 205 and 335.

"A. Willey (1898), "Spengelia, a new genus of Enteropneusta," Q. J. M. S. Vol. xL. p. 623. W. III. 
species from the Marshall Islands should prove to be distinct, then its name (i.e. that given by Eschscholtz) would have to be changed. This, however, was a mistake on my part, since such a procedure would be contrary to the rules of priority in nomenclature. The present position of affairs with regard to this species is therefore, so far as I am concerned, the following. Until it is shown that the Northern and Southern species are different, Eschscholtz's name will apply to both. If, on the contrary, they should eventually prove to be distinct from one another, then the Southern species will be Pt. caledonica Willey and the Northern species alone Pt. fava Eschscholtz.

\section{TERMINOLOGY.}

Before proceeding further, I think it will be well to explain certain technical terms which it is necessary to introduce when treating of the Enteropneusta in one's mother-tongue. The combinations of native words which yield such impressive results in other languages are not possible in English; and, in any case, it seems only reasonable that technical words should be of such a nature, in respect of their etymology, as to be available for universal use.

I have already (loc. cit. 1897) translated Spengel's "Genitalflügel" into genital pleurae. More important is the rendering of Spengel's "Eicheldarm," since this involves matter of controversy. It was Bateson who first advocated the view that this structure is related to the notochord of the Vertebrates, and he, very naturally, called it notochord. The notochord of the Chordata is a structure with which we are all familiar and it is capable of exact definition. What has been called notochord in the Enteropneusta does not correspond with this definition except in its capacity of skeletal product of the gut-wall. A special designation is therefore necessary, and the name I propose for it is stomochord, the first half of the word indicating its relation to the buccal cavity, and the second half indicating its resistent, chord-like character (cf. Pl. XXVI. Fig. 4). This term involves no sacrifice of conviction whatever, since it leaves the question of the morphological relationships of the structure to which it refers quite open.

The stomochord is not the only skeletal product of the gut-wall in the Enteropneusta. Spengel described in Pt. minuta a "kielförmiger Fortsatz des Darmepithels" on the ventral side of the caudal region. Hill has found the same structure in $P t$. hedleyi, describing it as a "long and high keel-like process." I have found it in Pt. flava, Pt. carnosa n. sp., and in Pt. ruficollis n. sp. It is a very remarkable structure indeed and deserves to be called a pygochord.

Spengel's longitudinal "Grenzwiilste" which characterise the lines of demarcation of the branchial portion of the gut from the osophageal portion in Ptychoderidae are likewise structures to which I shall attribute a peculiar significance. They are the parabranchial ridges.

\section{TAXONOMY.}

Spengel indicated clearly in his Monograph that the Enteropneusta are divisible into three families, but he did not carry the matter beyond the point of naming one family, viz., the Ptychoderidae. The deficiency may be supplied by naming the three families as follows: I. Ptychoderidae, II. Spengelidae, and III. Balanoglossidae. 
The following tabulation may serve as a synopsis of the

\section{FAMILIES AND GENERA OF ENTEROPNEUSTA.}

\section{Family I. PTYChODERIDAE, Spengel.}

Proboscis usually shorter than collar; cornua of nuchal skeleton do not extend backwards beyond the middle of the collar; dorsal unpaired roots unite the medullary cord of the collar with the epidermis; efferent vessels of proboscis united in one transverse plane by a circular vessel with the ventral blood-vessel of the collar; peripharyngeal space containing circular muscles completely surrounds the wall of the throat continuously up to the level of the buccal orifice; perihaemal cavities do not contain transverse muscles; circular muscles outside the longitudinal muscles usually present in body-wall of trunk; genital pleurae well-developed or vestigial; lateral septa carrying the genital blood-vessels present; external liver-saccules present (except in Pt. ruficollis n. sp.).

GEnus. PTYCHODERA Eschscholtz, char. emend. Spengel.

With the characters of the family.

A. Gill-slits opening freely and directly to the exterior.

Subgenus i. Chlamydothorax, Spengel.

Genital pleurae with ventral origin.

Ex. Pt. flava Esch., Pt. erythraea Spengel, Pt. bahamensis Spengel.

B. Gill-slits opening into pouches which discharge to the exterior by dorsal gillpores.

Subgenus ii. Tauroglossus, Spengel.

Genital pleurae with dorsal origin.

Ex. Pt. aperta Spengel, Pt. clavigera (Delle Chiaje), Pt. gigas (Fr. Müller), Pt. aurantiaca (Girard), Pt. australiensis Hill, Pt. carnosa n. sp., Pt. biminiensis n. sp., Pt. jamaicensis n. sp.

Subgenus iii. Ptychodera, s. str., Spengel.

Genital pleurae vestigial, reduced to ridges.

Ex. Pt. minuta (Kow.), Pt. samiensis (Koehler), Pt. hedleyi Hill, Pt. ruficollis n. sp.

FAmily II. SPENGELIDAE, nov. fam.

Proboscis longer than collar; stomochord produced anteriorly into a long vermiform process; cornua of nuchal skeleton extend to posterior region of collar; roots absent or vestigial; efferent vessels of proboscis pass obliquely downwards to posterior end of collar to unite with the anterior end of the ventral vessel of the trunk; 
peripharyngeal spaces separate, vestigial or absent; perihaemal cavities contain transverse muscles; the layer of circular muscles in the body-wall lies inside of the longitudinal muscles; genital pleurae and lateral septa, absent; external liver-saccules present or absent.

A. Right and left peripharyngeal cavities present; synapticula present.

\section{Genus 1. SCHIZOCARDIUM, Spengel.}

Ventral septum of proboscis extends to end of vermiform process; external liversaccules present; medial gonads absent; pericardial auricles highly developed; œesophageal portion of branchial sac reduced to narrow hypobranchial band.

\section{S. brasiliense, Spengel. S. peruvianum, Spengel.}

\section{Genus 2. SPENGELIA, Willey.}

Ventral septum of proboscis does not extend to the vermiform process; external liver-saccules absent; medial gonads present or absent; pericardial auricles reduced; dermal pits in the genital region; œsophageal portion of branchial sac present as a deep groove.

\section{S. porosa, Willey. S. alba, n. sp.}

B. No peripharyngeal cavities and no synapticula.

\section{Genus 3. GLANDICEPS, Spengel.}

Ventral septum of proboscis, external liver-saccules and medial gonads, as in Spengelia; pericardial auricles rudimentary; œesophageal portion of branchial sac reduced to a broad hypobranchial tract.

G. talaboti (Marion), G. hacksi (Marion), G. abyssicola, Spengel.

\section{Family III. BALANOGLOSSIDAE n. n.}

It is not easy to define this family in terms similar to those employed in the definitions of the two preceding families, because the anatomical characteristics are chiefly of a negative nature.

The most important properties of the members of this family may be summed up as follows:-Boreal forms; with large eggs; developing directly (i.e. without a pelagic larva).

Stomochord without vermiform process; roots absent; cornua of nuchal skeleton, efferent vessels of proboscis and perihaemal cavities, as in Spengelidae; peripharyngeal spaces present or absent; no circular muscles in body-wall of trunk-region; synapticula absent; external liver-saccules absent. 


\section{Genus. BALANOGLOSSUS (Delle Chiaje).}

With the characters of the family.

Subgenus 1. Balanoglossus s. str. Spengel. present.

Proboscis short; proboscis-pores paired; peripharyngeal spaces absent; medial gonads

B. kupfferi v. Willemoes-Suhm. B. canadensis Spengel.

\section{Subgenus 2. Dolichoglossus Spengel.}

Proboscis very long; proboscis-pore unpaired; peripharyngeal spaces ${ }^{1}$ present; medial gonads absent.

B. kowalevskii A. Agassiz. B. mereschkowskii Nic. Wagner. B. sulcatus Spengel.

\section{SYSTEMATIC DESCRIPTION OF SPECIES 2 .}

\section{FAMILY. PTYCHODERIDAE.}

Genus. Ptychodera.

\section{Subgenus 1. Chlamydothorax.}

1. Ptychodera flava Eschscholtz.

Eschscholtz, Fr. ${ }^{3}$ (1825) Bericht über die zoologische Ausbeute der Reise von Kronstadt bis St Peter und Paul. Oken's Isis, p. 740.

Spengel, J. W. (1893), Die Enteropneusten (Monograph, p. 190).

Willey, A. (1897), On Ptychodera flava Esch., Q. J. M. S., Vol. XL., p. 165.

Hill, J. P. (1897-8), The Enteropneusta of Funafuti, Memoirs Aust. Mus. III. p. 205 and p. 335.

Spengel points out that this was the first Enteropneust that was ever mentioned in literature, the original description and name having fallen into complete oblivion until rescued by Carus in his "Prodromus Faunae Mediterraneae." My observations upon this form, as a result of which I showed that it belongs to the subgenus Chlamydothorax, were the first to be made since 1825. It is closely allied to its congeners, Pt. erythraea Spengel and Pt. bahamensis Spengel, from both of which it differs in certain minor details, especially in the matter of the proboscis-pores.

1 The peripharyngeal spaces, as described by Spengel in B. kovalevskii, contain both circular and longitu. dinal muscles. In all other cases where they occur, they contain only circular or transverse museles.

2 The species of Enteropneusta can usually be distinguished by external characters alone. When a species has once been recognised as distinct, its internal anatomy must be described for itself apart, because nearly allied species often differ very much in details of organisation. No two individuals of a species are exactly alike.

${ }^{3}$ For this reference I am indebted to Spengel's Monograph. 


\section{Colour, Measurements, and External Form.}

The colour is a nearly uniform dull yellow, sometimes with a tendency to a brownish tinge. By attentive examination in the fresh condition, it is often possible to distinguish the males from the females by the presence of true brown pigment in the integument covering the testes on the inner surface of the genital pleurae. The yellow monotone is relieved in the hepatic region. The anterior hepatic coeca have a dark, greenish-brown colour; the mid-hepatic coeca are light brown, passing posteriorly into the yellow ground-colour.

The average length of the entire animal, when extended, may be taken at about 5 inches, the larger specimens attaining a length of $7-8$ inches. It is a delicate, fragile species.

The most salient character of its external appearance is due to the presence of the enormous pleural lappets, the genital pleurae.

As is usual with Ptychoderidae, the proboscis is normally somewhat shorter than the collar; the latter measures on the average $6-7 \mathrm{~mm}$. in length.

Pt. flava exhibits remarkable variation in respect of the length of the branchial region. As a rule in the living animal the length of the perforated pharynx is about equal to that of the proboscis and collar taken together, but it may be both shorter and longer. Two extreme forms are met with, namely, brachybranchiate and macrobranchiate forms. The specimens which I obtained from the islet of Amédée (Isle du Phare), some ten miles out from Nouméa, inside the barrier reef, include a striking series of brachybranchiate forms. Those from the Isle of Pines are on the whole intermediate between the two extremes, while the macrobranchiate variety was found on the weather side of the island of Lifu ${ }^{1}$.

According to my measurements of numerous preserved specimens, those from the Isle of Pines range from about $6 \mathrm{~mm}$. to about $15 \mathrm{~mm}$. in length of branchial region. Specimens from Lifu range up to as much as $29 \mathrm{~mm}$. in length of branchial region, the combined length of proboscis and collar in this case measuring about $12 \mathrm{~mm}$. When the genital pleurae of such an individual are spread out nearly flat, so as to completely expose the long, perforated pharynx, it forms a most striking object (see Pl. XXVI. Fig. 2).

The length of the branchial region is of systematic importance in the case of other species, and the variation of Pt. flava in this respect is therefore of particular interest, since, according to the opinion which $I$ expressed in my previous account of this species, it appears, on the whole, to represent the most primitive Enteropneustic type at present known.

The postbranchial portion of the trunk intervening between the branchial and hepatic regions is, as a rule, somewhat shorter than the branchial region, very much shorter in the macrobranchiate forms. In most Enteropneusta this intermediate tract constitutes the genital region proper, but cannot be so designated in this and in allied species, because the gonads are entirely restricted to the genital pleurae.

1 Individuals which have regenerated the anterior portion of the body resemble the brachybranchiate variety. 
For some distance behind the branchial region, the annulations of the dorsal bodywall (apart from the genital pleurae) are obscure. Gradually, as we proceed backwards, these annulations become more pronounced until they form prominent ridges with deep interannular depressions. Passing still further backwards, the ridges become larger until they form pro-eminent lobes, which are the external hepatic saccules (Pl. XXVI. Fig. 1).

The anterior hepatic saccules, which are dark green in colour, have a smooth surface. The mid-hepatic saccules are the largest, are coloured a light brown, and their anterior and posterior faces are distinctly ribbed. The posterior saccules have, as already mentioned, the usual yellow ground-colour, and pass behind imperceptibly into the annular ridges of the abdominal region.

The caudal region can be readily distinguished from the abdominal region by the greater compactness and regularity of the annular dermal ridges, by its consequently smoother surface, and, above all, by its rigidity, which is no doubt in great part due to the presence of a remarkable skeletal derivative of the median ventral wall of the gut, which I have called the pygochord. In Plate XXVI. Fig. 1, the caudal end of the body is represented as bent at a sharp angle upon the flaccid abdominal region, a condition often met with in preserved specimens.

\section{PROBOSCIS.}

\section{Cavity of Proboscis: Dorsal and Ventral Proboscis-canals.}

In front of the basal and central organs of the proboscis there is a median cavity, which is sharply demarcated by the presence of a characteristic peripheral aponeurosis, formed by closely-felted fibres of connective tissue, which is more strongly developed on the dorsal than on the ventral side of the central cavity. This aponeurosis sends out interradial processes between the radially disposed bundles of the longitudinal musculature.

If the proboscis be tipped up so as to expose the ventral surface of its neck, a more or less lobulate or racemose organ, projecting freely into the buccal cavity, is brought into view. It is still better seen after opening the collar by a ventral incision, as shown in Pl. XXVIII. Fig. $1 a$.

This organ is a special development of the ventral coecal prolongation of the proboscis-cavity, the walls of which assume a characteristically lobed structure. In Pt. erythraea Spengel has described and figured a corresponding structure, the lobulation of which is much more complicated than in Pt. flava, the lobes being numerous and close-set, producing the appearance of a corymbose organ (blumenkohlähnlich).

Here it may be remarked that Pt. erythraea is altogether a larger species than Pt. flava.

The ventral coecum of the proboscis is produced by the union, behind the free edge of the ventral septum, of the two ventral proboscis-canals, which, in their turn, result from the subdivision of the proboscis-coelom into dorsal and ventral moieties by the transverse coecal expansion of the stomochord. The latter encroaches so much on 
the limits of the proboscis-cavity as to entirely displace the lateral portions of the cavity, thus giving rise to two pairs of canals, namely, the dorsal canals and the ventral canals (cf. Pl. XXX. Fig. 25). The former are associated with the proboscispores and the latter terminate in the ventral coecum of the proboscis (Pl. XXVIII. Figs. 2-3).

As indicated above, the partition between the ventral canals is formed by the ventral septum of the proboscis, which, as in most but not in all species of Enteropneusta, has free anterior and posterior borders ${ }^{1}$. The septum dividing the dorsal canals is formed by the dorsal wall of the pericardium (Herzblase) which reaches the basement membrane of the epidermis (cf. Pl. XXX. Fig. $25 h$ ).

The anterior border of the ventral septum is nearly vertical, usually with a slight backward inclination, but no doubt this inclination would vary under different conditions of contraction. The septum extends a short distance in front of the region of the coecal dilatation of the stomochord, but stops far short of the anterior end of the latter.

In front of the septum, the stomochord is held in position largely by the median dorso-ventral muscles of the proboscis.

\section{Proboscis-Pores.}

Pt. flava is distinguished by the constant occurrence of paired proboscis-pores ${ }^{2}$, which, however, differ from one another in their relations to the coelom of the proboscis. As I attach great importance to these structures I will describe my observations in some detail.

The proboscis-pores, by which the dorsal proboscis-canals discharge to the exterior, are interesting in this species on account of the variations which they exhibit ${ }^{3}$. It is important, however, to bear in mind the fact that a dorsal canal does not lead directly to the corresponding proboscis-pore, but communicates first with a terminal bladder-like dilatation lined by ciliated columnar epithelium. The communication between the canal and its terminal vesicle is effected by the intermediation of a narrow connecting tube, which proceeds from the posterior dorsal angle of the coelomic canal. There are, therefore, four structures to be considered, namely, (1) the dorsal coelomic canal, (2) the connecting tube (coelomic pore), (3) the terminal (ectodermal) vesicle, and (4) the proboscis-pore. The terminal vesicle is the Eichelpforte of Spengel, who identifies it with the ciliated excurrent canal or pore-canal of the anterior coelomic vesicle (Wassersack) of Tornaria.

I now pass on to a selected serial account of my observations on these structures, based on serial sections through different individuals.

1 Spengel has shown that there is no posterior free border of the ventral septum in Glandiceps and I find the same condition in Spengelia.

${ }^{2}$ Mr J. P. Hill, who has himself made some observations on Pt. flava to which I shall have occasion to refer, first saw the paired proboscis-pores of Pt. flava in preparations of his own made from material collected by $\mathrm{Mr}$ Charles Hedley in Funafuti.

${ }^{3}$ In some other species, e.g. Pt. minuta [Spengel] and Pt. australiensis Hill, the proboscis-pores vary greatly but not in the same way as those of Pt. flava. In Pt. hedleyi, Hill has described paired proboscis. pores which open nearly or quite coincidently in the middle line. 
Series i. The bulk of the right dorsal canal ends in the chondroid tissue in advance of the termination of the left canal. Before ending it gives off a connecting tube, which proceeds backwards as a solid cord of cells, finally expanding again into the hollow terminal vesicle which is like that of the left side, but smaller. This vesicle opens to the exterior, on the right side, by a small pore in the same transverse plane as the much larger pore of the left side (Pl. XXVIII. Fig. 2).

On the left side the connecting tube is not solid, the terminal vesicle being in free communication with the left dorsal canal.

Series ii. The right dorsal canal communicates with a wide terminal vesicle by a narrow connecting tube, whose lumen is occluded. The terminal vesicle opens to the exterior by the right proboscis-pore. On the left side there is no definite connecting tube at all. The left dorsal canal comes to an end in the chondroid tissue, into which it gives off numerous islets of cells, whose presence produces the cartilage-like appearance of the chondroid tissue. There is no cord of cells which can be selected from among these cellular islets as being the representative of a connecting tube. Nevertheless, there duly occurs, on the left side, a terminal vesicle which is not very much smaller than the corresponding structure on the right side, and opens to the exterior by a sinistral pore in the same transverse plane as the right proboscis-pore.

Series iii. The condition observed here resembles the preceding, except that the right vesicle is in open communication with the right dorsal canal. The left terminal vesicle is hardly any smaller than the right, but its connecting tube is drawn out into a solid or sub-solid cord.

Series iv. The right terminal vesicle is in open communication with the right dorsal canal. There is also a terminal vesicle and pore on the left side, but the vesicle is not in open communication with the left dorsal canal, the connecting tube being discontinuous and vestigial.

Series v. Both end-vesicles communicate with their corresponding dorsal canals of the proboscis-coelom, but the left vesicle is rather larger than the right.

Series vi. Both end-vesicles end solid internally towards the coelomic canals; the right vesicle is larger than the left.

From the above it will be seen that Pt. flava possesses paired terminal vesicles and paired proboscis-pores, but those of one side, eitber right or left, are larger than those of the other. The larger vesicle, whether it is on the right or on the left side, usually retains more or less of a functional communication with the corresponding dorsal canal. The smaller vesicle, on the contrary, shows a distinct tendency to become disconnected with or emancipated from the coelom of the proboscis.

Finally, it is to be noted that in this species the terminal vesicles of the dorsal canals do not open to the exterior by a narrow minute pore, but they usually open bodily by a wide orifice, equal in breadth to their own diameter. These pores can be easity seen in situ in uninjured specimens.

W. III. 


\section{Stomochord, Pericardium and Glomerulus.}

The behaviour of the stomochord at its distal free extremity, and its relations with the pericardium and glomerulus at this point, are of importance both morphologically and systematically. In Pt. flava the stomochord is attenuated at its distal end, being drawn out into a narrow, solid, cellular cord, with which the pericardium and glomerulus are exactly coextensive. The pericardium, like the stomochord, has a simple, pointed anterior extremity.

These three structures (stomochord, pericardium and glomerulus) constitute together the central complex of the proboscis. Corresponding to the ventral septum of the proboscis there is, as already mentioned, on the dorsal side a hollow septum, formed by the pericardium, reaching up to the dorsal integument. Its anterior point of union with the basement-membrane of the epidermis, or, in other words, the point (regarding from behind forwards) at which the pericardium ceases to reach the skin, and commences to stretch with a gently inclined free dorsal border to the anterior tip of the stomochord, is far removed from the distal end of the central complex, occurring slightly in front of the level of the anterior free edge of the ventral septum.

The cavity of the pericardium, in the preparations examined by me, is rarely completely filled up by proliferation of its endothelial lining, although the extent to which such proliferation has occurred varies in different specimens. Perhaps it varies at different ages or different periods. In one specimen the anterior end of the pericardium was practically filled with a spongy, reticulate tissue.

The median septum of the proboscis is principally formed by what Spengel has described as the dorso-ventral muscle-plate. Its relations to the central complex are of some systematic importance. In Pt. flava the median septum is essentially coextensive with the central complex, and does not extend in front of the latter.

The stomochord of the Enteropneusta may be resolved into three distinct regions, each of which may present features of diagnostic value. These are (1) the anterior or interglomerular region, (2) the middle or coecal region, and (3) the posterior or nuchal region.

In the Spengelidae the anterior portion is produced into a long, vermiform process, but in other Enteropneusta it is, generally speaking, coextensive with the glomerulus.

If we examine the stomochord of Pt. flava from before backwards we find that the anterior attenuated cellular cord passes gradually into a wider portion, with stellate lumen; the stomochord then gradually attains a certain thickness in the dorso-ventral direction, so that, in section, it appears oval or elliptical in shape; the lumen meanwhile becomes indefinitely subdivided. Farther back, near the commencement of the ventral septum, the lumen becomes single and well-defined, and the transverse diameter of the stomochord nearly equals its dorso-ventral diameter.

The coecal dilatation (i.e. the ventral "Blindsack" of Spengel) which characterises the middle region of the stomochord has no continuous transverse lumen in adult examples of Pt. flava, but there may be a trace of such a lumen in a more or less occluded condition. The lateral portions ${ }^{1}$ of the lumen appear as paired diverticula from the principal lumen.

1 In some species, rather more so than in Pt. flava (e.g. Pt. ruficollis and in Spengelia), the lateral portions 
Behind the coecal region the stomochord quickly loses its chorda-like character, and no doubt also its rigidity; its function as a supporting organ being, in this region, entirely usurped by the nuchal skeleton. It tends, at the commencement of the nuchal region, to diminish in size up to a certain point, always, however, maintaining its integrity and its lumen (Pl. XXVIII. Fig. 3). Its ventral wall becomes progressively thinner, and, some distance in front of the bifurcation of the nuchal skeleton, the stomochord begins to widen out into the characteristic flattened terminal portion, which finally opens freely into the buccal cavity.

\section{Nuchal Skeleton.}

This structure is sometimes referred to as the collar-skeleton, sometimes as the proboscis-skeleton, and Spengel calls it the Eichelskelet.

As the mass of it lies in the narrow neck which joins the proboscis to the collar, while the cornua lie in the collar and keep the mouth permanently open, the above seems to be the most appropriate designation.

There are at least six features of the skeleton to be taken into account, namely, (1) Cupule (Endscheibe or Trichter of Spengel), (2) Body, (3) Crest, (4) Alary processes, (5) Carina or Keel (Kiel or Zahn of Spengel), and (6) Cornua (Schenkel of Spengel).

The cupule embraces the posterior end of the ventral coecal dilatation of the stomochord (Pl. XXVIII. Fig. 2). In Pt. flava it is quite shallow, passing abruptly into the solid body of the skeleton. The body in its anterior portion is massive, laterally compressed, sub-rectangular, and produced along the dorsal middle line into a prominent acuminate crest, which projects into the ventral wall of the stomochord. The crest varies, however, in the degree of its development and is sometimes obsolete.

In the mid-region of the body of the skeleton, an accessory skeletal element is added to the main body in the form of a transverse arcuate bar produced at the sides into alary processes, and embracing the dorsal side of the ventral coecum of the proboscis.

In fact, in Pt. flava, as in Pt. erythraea described by Spengel, there is no keel along the ventral side of the nuchal skeleton, its place being occupied by the enlarged ventral coecum of the proboscis'. Behind the alary processes the body of the skeleton becomes subtriangular in section, the base of the triangle being directed dorsally and the apex ventrally (Pl. XXVIII. Fig. 3). Immediately in front of the orifice of communication between the stomochord and the buccal cavity, the body of the skeleton becomes bisected, and from this point the cornua begin to diverge.

As in all species of Ptychodera the cornua, which lie on each side in a fold of the epithelium of the throat, do not extend backwards beyond the middle of the collar-region.

of the dilated region of the stomochord appear as distinct lateral pouches and are described below under that designation (cf. Pl. XXX. Fig. 25).

1 For full treatment of the nuchal skeleton in its capacity of derivative of the basement-membrane, with proof of its dual origin from stomochord and epidermis as shown by the lines of stratification, etc., see Spengel's Monograph, p. 487 et seq. 


\section{COLLAR.}

\section{Collar Nerve-Cord and Roots.}

The dorsal nerve-cord in the collar of Pt. flava is a true medullary tube, possessing a continuous central canal which communicates with the exterior, in front and behind, by the anterior and posterior neuropores. In Pt. minuta and in many other species, the lumen of the collar nerve-cord is broken up into a large number of separate medullary cavities. The possession of a continuous axial canal is particularly characteristic of the subgenus Chlamydothorax, and I regard it as most certainly representing the more primitive condition. Such a continuous central or axial canal in the medullary tube of the collar-region, occurs exclusively among the Ptychoderidae, namely, in all the species of the subgenus Chlamydothorax, and in certain other isolated cases, e.g. Pt. sarniensis, Pt. hedleyi, Pt. aperta and Pt. ruficollis n. sp.

The collar nerve-cord is united at intervals with the epidermis by means of unpaired dorsal roots in all Ptychoderidae. These roots are either solid or contain a lumen communicating with the central canal.

I attach special significance to these roots, and will therefore give a serial account of my observations.

Series i. ${ }^{1}$ The first root arises shortly behind the orifice of the stomochord as a hollow diverticulum from the medullary tube to the right of the median line, and runs for some distance horizontally backwards, so that in transverse sections through the entire animal the root is also cut transversely to its long axis.

The second root is also hollow, and arises nearly in the median line in front of the point at which the first root meets the epidermis. It is also directed backwards, accompanying the anterior free edge of the dorsal septum of the collar. The first root maintains its calibre until it passes into the epidermis, while the second root becomes somewhat attenuated towards its distal end, although it retains its minute central lumen to the end.

The third root is obviously vestigial in its nature. It appears as a solid bud from the dorsal wall of the medullary tube in the middle line, lying in the dorsal septum. Immediately after its origin its calibre abruptly diminishes almost to vanishing point and in this attenuated portion there are no nuclei. This root likewise has a backward course. When nearly half-way between the medullary tube and the epidermis, its diameter resumes the normal size and a central lumen appears.

Series ii. The first root has a hollow origin and is very slightly oblique, running almost directly from inedullary tube to epidermis, so that in one section it is united to the former at its proximal and to the latter at its distal end. It is not a simple cylindrical root but is triangular in shape, the apex of the triangle being its insertion in the epidermis, and the base of the triangle its elongated origin from the medullary tube. The anterior side of the triangle is directed backwards and the

1 Series $\mathrm{i}-\mathrm{v}$ refer to series of sections through different specimens which do not necessarily correspond with those given on p. 231. 
posterior side forwards, reckoning from the base. Moreover, the posterior side coincides with the anterior free edge of the dorsal septum.

The second root is likewise hollow at the base and very slightly oblique in its course from medullary tube to epidermis.

Series iii. The first root is hollow and runs along the anterior cdge of the dorsal septum. The second root is hollow and arises close behind the first root from a common neural crest (Pl. XXVIII. Figs. $4 a-4 c$ ). The third root is hollow and smaller than the preceding. All are directed somewhat obliquely backwards. In describing these roots as hollow, I refer particularly to their origin as hollow diverticula from the medullary tube. In some cases the lumen appears to be broken up into discontinuous portions towards the distal end of the root.

Series iv. The first root is almost entirely solid at its origin, but there is a slight indication of pouching at its base. There are disconnected traces of a lumen in the root itself. This root is large and runs horizontally backwards for a relatively long distance. It is anterior to and independent of the dorsal septum and has not an extended neural crest for a base.

The second root is also solid, narrower and shorter than the first; it accompanies the anterior edge of the septum.

Series v. The first root has a median origin and is hollow, running obliquely backwards along the anterior free edge of the dorsal septum. The second root is also median and hollow like the first, and comes off from the medullary tube before the first root has reached the epidermis.

The above observations may be summarised by saying that in Pt. flava, the nerveroots of the collar are few in number but vary in number, length, course and calibre; sometimes they arise from a common neural crest ${ }^{1}$; sometimes they arise to one side of the middle line instead of being quite median; and, they are primarily hollow.

\section{Ventral Septum of Collar.}

There is no ventral septum in the collar of Pt. flava. Although the complicated longitudinal vascular plexus along the ventral side of the throat causes an extensive fold of the basement-membrane, it does not reach across the collar-cavity to the basement-membrane of the ventral epidermis. The two halves of the collar-cavity are therefore in free communication below the ventral vascular fold. In some cases the ventral septum persists through a great part of the collar-region as in Pt. sarniensis; in others it is restricted to a narrow tract at the posterior end of the collar as in Glandiceps talaboti. It is also largely persistent in Spengelia (see below). Spengel has pointed out that neither the dorsal nor the ventral septum of the collar is ever complete; but both septa, when present, always have a free anterior margin. Perhaps the vascular fold suspended from the basement-membrane of the throat-epithelium in

\footnotetext{
${ }^{1}$ In other cases, besides that mentioned above in connection with Series iii., successive roots come off from a common crest but not, as a rule, so strikingly as appears in that series.
} 
Pt. flava is to be interpreted as an incomplete ventral septum; but there is reason for supposing that it would be more correct to treat the ventral vascular complex and the ventral septum as two distinct structures which may or may not, coincide.

\section{Collar canals and Pores.}

The collar-canals (Kragenpforten) of Pt. flava vary so much in their length and in the character of the dorsal wall, that they are of little use for diagnostic purposes. The dorsal wall is folded into the lumen of the canal by a simple tongue-like plication. This dorsal fold is always deep, but is larger in some cases than in others and resembles roughly the condition described and figured by Spengel for Pt. minuta and Pt. aperta.

Each canal opens internally into the collar-coelom by a ciliated semilunar funnel. Sometimes the canal is so short that its ventral wall is fused with the epithelium of the first gill-pouch in the same transverse plane with the funnel. More usually a tube of some length with deeply infolded dorsal wall intervenes between the internal funnel and the external pore. The latter opens into a special dorsal section of the first gillpouch. The first gill-slit of all Enteropneusta (unlike Amplioxus) is complete, and provided with a tongue-bar like the rest. The first septal bar is therefore confluent with the epithelium of the throat or collar-gut. The collar-pore opens into the dorsal angle made by the first septal bar with the posterior edge of the collar, this angle being tucked in for some distance beneath the collar-rim (PI. XXVIII. Fig. 5).

There are therefore three portions of a collar-canal to be considered, namely, (1) the funnel, (2) the tube, and (3) the pore. The tube appears to be largely formed by intercalary growth, between the funnel and the pore, during the life of the animal.

\section{TRUNK.}

\section{Branchial Region.}

I hope by this time that the fact of the existence of Enteropneusta with a free, exposed pharynx, has sunk into the mind of the reader (PI. XXVI. Figs. 1 and 2).

In horizontal sections it appears that the first two gill-clefts do open into gillpouches owing to the protrusion of the anterior end of the pharynx within the posterior limits of the collar, but the bulk of the gill-slits open freely to the exterior, a fact which might also be expressed by saying that the gill-pouches are confluent.

In sections through this region Pt. fava is apparently distinguishable from the other two species of the subgenus Chlamydothorax, as described and figured by Spengel, in respect of the relative cubic capacity of the branchial and cesophageal portions of the pharynx. In Pt. erythraea the cesophageal division predominates over the branchial division; in Pt. bahamensis the two divisions are nearly equal; finally, in Pt. flava the branchial predominates over the osophageal division (PI. XXVIII. Fig. 6).

The line of demarcation between the bases of the gill-bars and the œsophageal epithelium is occupied, as in all Ptychoderidae, on each side by a prominent longi- 
tudinal ridge, which Spengel has called the "oesophageale Grenzwulst." These ridges are what I call the parabranchial ridges, and I am disposed to attach high morphological importance to them. They are certainly important structures anatomically, as may be best seen by simple dissection (Pl. XXVIII. Fig. 1a). They are co-extensive with the gill-slits, and, at the anterior end of the pharynx, they are seen to pass round into the median dorsal epibranchial band. As shown in Pl. XXVIII. Fig. 8, the parabranchial ridges are nothing else than the confluent thickened ventral walls of the gillclefts.

\section{Genital Pleurae and Lateral Septa.}

The genital pleurae of Pt. flava resemble those of the two species of the subgenus Chlamydothorax which were described by Spengel, in their extreme ventral origin. So low is their origin that they leave the pharynx quite free and exposed, so that the gill-slits open laterally in their entirety directly to the exterior. The pharynx remains erect owing to the rigidity of its walls, which is effected by the skeletal supports in the gill-bars. The latter are markedly arcuate with the convex side directed outwards so that the pharynx presents the appearance of a sub-cylindrical body with the annular septal branchial arches and intervening slits. The tonguebars lic far inwards towards the cavity of the pharynx, and so are not visible in external view in preserved specimens. In all Ptychoderidae the tongue-bars have a more internal position than the septal bars.

The gill-clefts are crossed by solid connecting rods or synapticula, so that the result is a branchial basket (Pl. XXVIII. Fig. 8).

The average number of synapticula on each side of a tongue-bar is 10-12; but there may be as many as 18-20 in the macrobranchiate forms. The plication of the outer wall of the tongue-bar, which has been noted in so many cases, is not a constant feature in Pt. flava. It not only varies in successive bars but at different levels in the same bar.

In most Enteropneusta the external openings of the gill-slits are reduced to small pores, which occur in linear series on the dorsal side of the animal, on each side of the middle line, at the base of a longitudinal groove known as the branchial groove; in such cases the gill-slits no longer open directly to the exterior but into special branchial pouches which, in their turn, discharge to the exterior by the aforesaid gill-pores.

The genital pleurae, in addition to their primary function of bearing the gonads, serve also the accessory function of protecting the branchial basket. They can be folded over the latter so as to meet and even overlap in the dorsal middle line, and, when so carried, they form a completc temporary peribranchial chamber, only open posteriorly where the pleural folds divaricate. On the other hand they can be spread out laterally in the plane of the ventral side of the body. They are extremely mobile structures, and attain their maximum development about the middle of the branchiogenital region.

Towards the hepatic region the pleurae diminish gradually in size and also attain a more dorsal position. They enclose the more anterior liver-saccules, and are finally 
continued as a low ridge immediately outside of and below the liver-saccules, through about four-fifths of the hepatic region (Pl. XXVIII. Fig. 1). This mode of termination of the genital pleurae is, in the main, characteristic of the subgenus Chlamydothorax. Inseparably associated with the genital pleurae are the lateral septa which carry bloodvessels to the gonads. So far as Spengel's account of them in Pt. erythraea goes they have the same proximal origin and distal insertion in Pt. flava (Pl. XXVIII. Figs. 6 and 7). But Spengel does not state the important fact that, whereas in most cases the lateral septa are limited in their anterior extension, in Chlamydothorax (judging by Pt. flava) they are coextensive, in front as well as behind, with the genital pleurae.

This fact explains the meaning of the lateral septa as vascular folds of the basement-membrane accompanying the pleural expansions or outgrowths of the body.

In the branchial region of Pt. flava the lateral septa arise from the basementmembrane of the epidermis on the medial side of and dorsal to the angle formed by the junction of the genital pleurae with the body-wall. Peripherally they are inserted again into the basement-membrane of the epidermis at the free edges of the genital pleurae. Behind the pharynx their line of origin is transfcrred from the basal membrane of the cpidermis to the basement-membranc of the wall of the gut. In the mid-hepatic region their line of origin occurs alternately in the side of the hepatic diverticula, and in the basement-membrane of the epidermis in the intersaccular intervals (Pl. XXIX. Fig. 14).

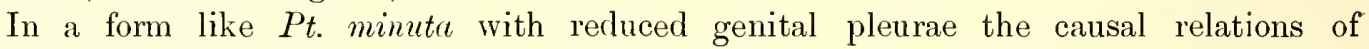
the lateral scpta and genital pleurae are obscured, and the portion of the coelom enclosed by the septa appears as a pouch on each side ending coccally in front and was so interpreted by Spengel. Pt. flava shows conclusively that the latcral septa belong to the pleural system, and no pouching whatever (apart from the pleural outgrowths) of the body-cavity has taken place. This should be particularly noted, as this is a tangible example demonstrating how that $P t$. minuta is a misleading form to take as a basis for the interpretation of the Enteropneustic organisation (cf. Spengel, Mon. p. 60).

\section{Branchiogenital Transition.}

The region of the body which lies between the branchial and the hepatic regions has been called the genital region by Spengel; but as the gonads generally extend for a greater or less distance into the branchial region, he also applies the term branchiogenital to the two regions taken in combination. The intimate relation between branchial and genital regions, which is expressed in this word, is probably of great significance, and will be dealt with in the portion of this memoir devoted to the morphology of the Enteropneusta.

There is no true genital region in Pt. flava in the sense in which it occurs in other forms, since the gonads are emancipated from the main body of the animal, being confined to the genital pleurae. It is only therefore in comparison with other forms that the short stretch of body which is intercalated between the posterior end of the pharynx and the anterior cnd of the hepatic region, can be spoken of as the genital region (cf. Pl. XXVIII. Fig. 2). 
Behind the last pair of gill-slits the gut still retains, over a distance of a few millimetres, its division into upper and lower moieties corresponding to the branchial and œesophageal portions. This fact has been already recorded for Pt. flava by Hill (loc. cit. p. 343). A similar condition has been described by Spengel in Pt. erythruea (Monograph, p. 181, Text-figure) and more recently by Hill (loc. cit.) in Pt. hedleyi. In Pt. erythraea Spengel describes the gut in this region as being divided "durch zwei seitlich einspringende Falten in zwei Halbcanäle, einen dorsalen und einen ventralen." In Pt. bahamensis Spengel found the division to be a very unequal one, the dorsal portion occurring as a rather deep furrow, while the ventral portion is much more extensive. In Pt. hedleyi the dorsal moiety is very pronounced and is described by Hill as a dorsal diverticulum possessing a transverse lumen and communicating with the ventral portion of the gut "by a short, laterally compressed stalk"; its high glandular epithelium is thrown into low foldis.

I shall refer to this dorsal portion of the gut at the anterior end of the postbranchial genital region as the postbranchial canal (Pl. XXVIII. Fig. 7). It is a structure of some diagnostic and morphological importance. In Pt. flava new gill-slits arise at the dorsal margins of the postbranchial canal at its anterior end. In Pt. hedleyi, as described by Hill, and in Pt. ruficollis n. sp. (see below) it is quite independent of, and dorsal to, the most posterior gill-slits.

In Pt. flava the postbranchial canal occurs in direct continuity with the branchial division of the gut. It is lined by a high, smooth deeply staining ciliated epithelium, which passes rather abruptly into the folded epithelium of the ventral division of the gut. Behind the last pair of gill-slits it possesses a narrow vertical lumen with a slight dorsal dilatation, the lumen opening below, throughout its entire extent, into the general cavity of the gut ${ }^{1}$.

With regard to the formation of new gill-slits at the posterior end of the pharynx, I observed in one series that the last gill-pouch of one side opens to the exterior, while the corresponding pouch on the other side is present as a blind diverticulum proceeding from the dorso-lateral margin of the gut, which has not yet come into contact with the epidermis. Nevertheless the tongue bar has commenced to grow down in the form of a slight vascular fold of the dorsal epithelium of the pouchlike diverticulum. This early appearance of the tongue-bar before the perforation of the gill-slit is a fact of importance and is in accordance with what Morgan ${ }^{2}$ has observed in Tornaria.

In fact, whereas in Amphioxus the tongue-bars of the gill-slits are of secondary origin and are therefore rightly referred to as the secondary bars, in the Enteropneusta they are of primary origin, and should never be spoken of as secondary bars.

\section{Gonads.}

The gonads are essentially confined to the genital pleurae, and consist of a great number of separate, more or less lobulated, genital glands, whose arrangement is on the

1 In one specimen I found the cavity of the postbranchial canal to be wide and its walls somewhat coarsely folded in contrast to the epithelial plications which occur in Pt. hedleyi and Pt. ruficollis.

2 T. H. Morgan, "The growth and metamorphosis of Tornaria," Journ. Morph. v., 1891, p. 407.

W. III. 
whole diffuse, although it may be observed that they are disposed in a more or less zonary manner roughly analogous to the epidermal annulations. Of course the gonads are not directly influenced in their topography by the epidermal annulations (although originally I believe the genital zones and epidermal annulations were topographically related), and in mature or sub-mature specimens their ramifications often extend over more than one epidermal zone. The principle of zonulation is directly suggested by the facts which were first described and figured by Spengel in Pt. erythraea and Pt. bahamensis, that the gonads are disposed in many superposed tiers and that the genital ducts occur in numbers in one and the same transverse section. I ought perhaps to explain that the principle of zonary distribution was not present to my nind when I first dealt with Pt. flava, but I have been led to adopt it by subsequent observations. The gonads extend in front to the anterior end of the genital pleurae up to the septum which divides the collar coelom from the truncal coelom, so that they are met with in the same transverse sections with the collar canals.

The shape of the gonads varies greatly in both sexes and also according to the state of contraction or extension of the animal. The fact that, in the male, the integument over the testes on the inner surface of the genital pleurae contains patches of dark brown pigment, has been already referred to (Pl. XXVIII. Fig. 10).

Each gonad is surrounded by a basement-membrane which carries blood-vessels between its inner and outer lamellae (in the manner shown by Spengel to be characteristic of the Enteropneusta), and at the same time serves as a tunica propria. Each gonad, accordingly, has its own duct which perforates the musculature of the inner wall of the genital pleurae, and so brings the tunica propria of the gonad into fusion with the basement-membrane of the epidermis.

The gonads contain actually or potentially a central cavity which may perhaps be regarded as coelomic in nature as opposed to being haemocoelic. It is important to emphasize the fact that in the Enteropneusta the genital coelom (i.e. the cavities of the gonads) is quite independent of, and at no time has any connection with the perivisceral coelom.

The gonads contain, in addition to the sexual elements, a large quantity of a fat-like substance consisting of masses of refringent globules of various sizes, which have a great attraction for eosin.

Normally both right and left genital pleurae are fertile and contain an equal complement of gonads. In one series of sections, however, through a male individual, I find that the gonads are only developed in the right genital pleura, the left pleura being sterile. On the left side the gonads, in this case, appear to be in an arrested state of development, being represented by inconspicuous hollow sacs lined by germinal epithelium. There are no fat bodies present, and we may conclude from that that a portion of the germinal epithelium becomes normally employed in the manufacture of nutritive material, while the rest goes to form ova or spermatozoa as the case may be. Such a differential behaviour of the two sides of the body is of interest as indicating a tendency to unilaterality in the matter of the gonads.

In Pt. minuta Spengel says that the fatty material in the gonads is finally quite replaced by ova and spermatozoa; and this is no doubt what takes place in every case, 
although in Pt. flava the eosinophile globules occur in great profusion in company with mature ova.

The mature eggs are small, round and subtransparent. They measure $06 \mathrm{~mm}$. in diameter $^{1}$ and, when freshly isolated from the body, are found to be contained in a double-contoured membrane between which and the ovum itself there is an intervening space. The size of the ova in Euteropneusta is particularly noteworthy since it enables us to determine whether any species will develop with or without metamorphosis.

With regard to the nature of the cells which contain and produce the eosinophile globules I cannot add very much to Spengel's observations. Spengel sought in vain for nuclei in these cells in Pt. minutc, but left it doubtful whether certain peripheral flattened nuclei belonged to them or not. In Pt. flava I think I can state detinitely that these cells do not contain normal nuclei, for the simple reason that the eosinophile globules themselves are apparently products of nuclear degeneration. The course pursued in this process of degeneration is apparently that of hypertrophy of the nucleolus to which must perhaps be added a multiplication of nucleoli. My interpretation of the appearances presented is that the entire original nucleus undergoes a nucleolar degeneration analogous to fatty degeneration. Spengel points out that these fat-like globules are not fat since they are unaffected by the usual fat-solvents and are also very resistent to caustic potash. He says that sometimes they stain very darkly with haematoxylin and at other times remain quite unstained. This would appear to indicate an ever-changing chemical constitution. Spengel does not seem to have treated them with eosin. In his Taf. XI., Fig. 23 Spengel figures these globules of various graded sizes filling up the cells which contain them. In the text (p. 656) he says, "Bisweilen nimmt eine grössere Kugel die Mitte ein und kleinere ungeben sie." What sometimes happens in Pt. minuta, happens as the rule if not invariably, in Pt. flava.

In this species the normal condition of these nutrient cells at a stage preceding that of their maximum development is slown in Pl. XXVIII. Fig. 11. The large central globule is surrounded on all sides by very much smaller, but otherwise similar, globules. Of course at different stages of growth the contrast in size is not so great as shown in the figure, and I am quite unable to say whether the globules increase in size entirely by intussusception or whether fusion takes place. Spengel could form no opinion as to the relation of these bodies to the sexual elements. As he saw in Pt. minuta and I have seen in female Pt. ruficollis n. sp., the globules disappear at the period of complete maturity. But the eggs retain their small size and, as mentioned above, in Pt. flave ripe eggs coexist in the ovaries with abundant eosinophile globules. In fact this substance appears to serve two functions. The first function, it would seem necessary to assume, would be the nutrition of the growing germ-cells. The second, which later becomes the principal function, is not that of actively nourishing the germ-cells, but of providing an albuminous medium to preserve the germcells under the best possible physiological conditions during the final crucial stages of maturation.

That these globule-containing cells, in their original quality of nucleated cells, are in a condition of degeneration, is merely a statement of fact. One of the chief reasons which led me to the above interpretation is that the large central globule is often seen to contain clear refringent inclusions, closely resembling, on a larger scale, analogous inclusions which

${ }^{1}$ In my former paper, by a lapsus calani, the diameter was stated to be $006 \mathrm{~mm}$. although the correct magnification was given in the explanation of the plate. 
I have observed, in every case, in the normal nucleoli of the germinal vesicles of the mature ova of Pt. ruficollie n. sp. (Pl. XXX. Fig. 34).

The number of eosinophile globules whose chemical nature is unknown is alarmingly on the increase.

If the interpretation which I have suggested at all approaches the truth the globules now under consideration would be composed of a substance allied to pyrenin. It must be added that $I$ have made no observations on the processes of maturation of the gern-cells themselves. This is a subject which presents great difficulties and probably necessitates the employment of a special and elaborate technique.

\section{Genito-hepatic Transition.}

The genital pleurae with their contained gonads encroach for a considerable distance upon the hepatic region. The first few hepatic diverticula are internal and do not cause elevations of the integument; they are characterised by their much elongated epithelium consisting of closely packed cells with basal nuclei in an approximately even layer, and containing peripheral yellowish-brown intracellular granular deposits ${ }^{1}$.

As they approach the hepatic region the genital pleurae begin to diminish in size and to become more and more dorsal, until at the beginning of the hepatic region they are quite dorso-lateral in origin. They maintain their integrity for some distance, but when the hepatic diverticula commence to cause projections of the integument between the genital pleurae, the latter are, at these successive points, greatly reduced in size, widening out again in the intervals between the saccules. Finally, when the latter become more massive, the genital pleurae are reduced to zero at the level of the saccules and only reappear in the intervals as ridges bounding the interannular depressions between the hepatic lobes (Pl. XXIX. Fig. 14).

The hepatic diverticula of the gut have a very rich blood-supply, the vessels forming a rete mirabile on their walls.

\section{Ciliated Grooves of In'testine.}

These are longitudinal grooves in the wall of the gut in the hepatic and abdominal regions, which Spengel found to be especially characteristic of the Ptychoderidae. They consist on each side of a narrow tract of richly ciliated epithelium more or less overhung or protected by an epithelial covering-pad developed on the medial side of the groove.

In Pt. flava they are not simple longitudinal grooves but possess metameric sacculations corresponding in the hepatic region to the intersaccular valleys (Pl. XXIX. Figs. 12-14). They commence at the extreme anterior end of the hepatic region, in the region of the genito-hepatic transition, and they extend backwards to the posterior end of the abdominal region. In some places the sacculations of the ciliated grooves approach very close to the epidermis, almost touching the basement-membrane of the latter.

1 The blood in the vessels round the hepatic epithelium is sometimes coloured a bright refringent yellow. 
Sometimes the continuity of the grooves appears to be lost or obscured in the interval between two sacculations.

The covering-pad is especially prominent in the sacculations, and less so in the intervening tracts.

A similar sacculation of the ciliated grooves has been described by Spengel in Pt. erythraea (Mon. p. 183), where it gives rise to special nodal prominences of the bodywall external to the liver-saccules. These nodal prominences are continued behind the hepatic region.

In Pt. minuta [where there is a ciliated groove on the left side only (Spengel)], Pt. australiensis Hill and Pt. hedleyi Hill, the ciliated grooves lie close to the epidermis, and corresponding with each groove there is a longitudinal epidermal band characterised by the absence of gland-cells.

In Pt. flava the ciliated grooves show through the skin during life but, as Hill has pointed out, there are no glandless epidermal stripes.

In Pt. sarniensis Spengel has described a ciliated groove (Wimperapparat) on the left side only, which however has no relation to, and in fact is far removed from the vicinity of, the epidermis.

\section{Caudal Region.}

This region is above all characterised by the presence of a longitudinal, solid, supporting band, derived from and in continuity with the epithelium forming the median ventral portion of the gut-wall.

This is what I propose to call the pygochord. It is probably of some economic importance to the animal as it is of diagnostic importance to us.

This structure was first described by Spengel in Pt. minuta as a remarkable "kielförmiger Fortsatz des Darmepithels," and has since been described by Hill in Pt. hedleyi as "a long and high keel-like process, the slightly enlarged ventral end of which overlies the minute ventral vessel."

In Pt. flava it commences at the anterior end of the caudal region as a simplc thickening of the ventral wall of the hind-gut which is soon drawn out into a flattened band with dilated distal (ventral) border (Pl. XXIX. Fig. 15b). As a rule the pygochord retains its connection with the gut-epithelium, but at irregular intervals the basementmembrane is continued across the line of junction so as to completely separate the pygochordal tissue from the wall of the gut. The dilated distal end is sometimes similarly shut off from the rest of the band, and the band itsclf is sometimes constricted by transverse fusions of the basement-membrane.

Sometimes the band presents a remarkable moniliform appearance due to this fusion of the basement-membrane at different levels (PI. XXIX. Fig. 15a).

The pygochord ceases at the anus.

The hind-gut of Pt. flava is surrounded by a very feeble muscularis, while the anus is provided with a light sphincter formed by the circular muscles of the body-wall. 


\section{OECOLOGY.}

Pt. fava occurs in clean loose coral-sand between the tide-marks. It does not burrow to any great extent but frequents the superficial layer of sand, and the meshes formed by the roots of seaweeds and crevices in stones. I have found it in three localities, viz. at the Isle du Phare opposite Nouméa, at the Isle of Pines, and at Lifu. Hill has recorded it from Funafuti and Mr J. Stanley Gardiner bronght back a few specimens from the same locality. It is a gregarious species and is usually to be obtained in considerable numbers. As a rule, Pt. flava seems to prefer the weather side of the islands, that is to say the side which is exposed to the prevailing wind. This preference is clearly shown at Lifu, the lee side of which forms a large inlet known as Sandal Bay. I never found Pt. flava on the shores of Sandal Bay, but had to cross over to the opposite side of the island, which is bounded by a continuous fringing reef, to obtain my material.

In a small percentage of specimens there is found a parasitic Copepod which lives in the genital pleurae causing a prominent tumour or gall. I gave a figure of an infected specimen in my former paper on this species (loc. cit.). A similar parasite was found by Spengel in Pt. minuta and named Ive balanoglossi Paul Mayer. In Pt. uustraliensis Hill found that a similar parasite infested a large proportion of the individuals of the species.

The intimate association of quite distinct species of Enteropneusta is an interesting feature in their distribution. At Funafuti Pt. flava and Pt. hedleyi were taken together by $\mathrm{Mr}$ Charles Hedley. At Lifu I took Spengelia porosa in company with Pt. flava and in New Britain Pt. ruficollis n. sp. inhabits the same burrows with Pt. carnosa n. sp.

Pt. flava does not practise autotomy in the same way as this takes place in Pt. carnosa and Sp. alba (cf. Pl. XXVII. Figs. 6 and 9) but it is fragile and excessively prone to laceration. The wall of the hind-gut is well vascularised and the anal orifice may be seen to open and close periodically irrespective of defæcation, thus suggesting anal respiration. 


\section{REGENERATION IN PT. FLAVA.}

Like Pt. minuta (cf. Spengel, Taf. xxvi. Figs. 14--18) Pt. flava possesses extraordinary powers of regeneration, and the processes involved in the regeneration of the proboscis and collar are unusually instructive, especially if, as Barfurth ${ }^{1}$ and others think, regeneration is sometimes (not always) accompanied by atavistic phenomena. Of course the phenomena of regeneration will vary according to the region in which it takes place. For example, if it occurs behind the genital pleurae (Pl. XXVI. Fig. $5 C$ ) the appearances presented are different from those which are exhibited when the regeneration occurs in the region of the pleural folds. It is these latter cases to which I desire to draw particular attention.

The chief facts observed are evident in the figures on Plate XXVI., and it will suffice to point out the principal conclusions derived therefrom. I have confirmed these conclusions as far as possible by sections, some of which are reproduced on Plate XXXII.

1. When regeneration occurs in the region of the genital pleurae the collar is regenerated from the pleurae.

2. The collar nerve-tube is formed by the fusion of true medullary folds which are differentiated from the pleural folds (Pl. XXVI. Figs. $5 A$ and $5 B$ ).

3. The zones of the collar are differentiated from the annulations of the body-wall (Fig. $5 E$ ).

4. In regenerating individuals the right and left proboscis-pores are approximately equal. In the specimen shown in Fig. $5 A$ they were quite equal.

5. In regenerating individuals the lumen of the stomochord is, at first, entire.

For my part I am persuaded that the above facts have an atavistic significance. I do not think there is any reason for regarding the collar as being anything more than a differentiation of the anterior portion of the trunk associated with the cephalisation and regional differentiation in general, which is such a prominent characteristic of the Enteropneusta. This remark refers simply to the collar as such, and not to the pair of body-cavities which form the collar-coelom. These cavities may possibly date much farther back than the collar itself, which is a purely Enteropneustic structure.

As MacBride $^{2}$ has shown, homologous coelomic pouches occur in Amphioxus where there is no collar. It is important not to confound the collar with the collar-coelom.

'Dietrich Barfurth, "Regeneration und Involution" in Merkel u. Bonnet's Ergebnisse der Anat. u. Entwickgesch. Bd. Iv. 1894.

2 E. W. MacBride, "The early development of Amphioxus," Q. J. M. S., Vol. xL. 1897-8, p. 589. 
In possessing, in such a high degree, the faculty of regeneration, the Enteropneusta differ radically from Amphioxus, which does not regenerate after fracture.

The possibility of regeneration revealing facts of atavistic significance is a matter of great suggestiveness. At the same time, the assertion that any particular process of regeneration is atavistic is always liable to be dismissed as arbitrary. It is very important to bear in mind that regeneration at different regions of the body may be accompanied by different appearances and will yield different information. The atavistic phenomena associated with regeneration carry us farther back than do the phenomena of ontogenetic recapitulation. Although Morgan has found that in Tornaric the collar nerve-cord arises by the depression and closure of a medullary groove, yet it could not there be recognised that the medullary folds are metamorphosed derivatives of preexisting pleural folds. It is practically certain that Pt. flava develops through a Tornaria stage. No Tornaria has ever been secn having two water-pores. On the other hand in a regencrating Pt. flava we find a restoration of what must have been the primordial condition, viz. equal paired proboscis-pores.

In the regenerating individual shown in Fig. $5 A$, Pl. XXVI., the medullary folds are seen to be widely separated in front and less widely separated behind (cf. Pl. XXXII. Figs. 66-67); in Fig. $5 B$ the medullary folds are closely approximated and transverse sections reveal the fact that they are actually fused together over a short stretch at the extreme anterior end of the collar (Pl. XXXII. Fig. 68) behind which they arc still unfused, the narrow superficial groove leading directly into a wide medullary canal. At this and at the preceding stage there is no free collar-flap in front. In the stage of regeneration shown in Fig. $5 D$ a median dorsal groove is seen to occupy the posterior two-thirds of the collar region, and in front of the groove is a smooth tract which represents the anterior frce collar-flap ${ }^{1}$.

After the closure of the medullary folds the collar continues to grow in length and to project forwards as a free circular fold (collar-flap). The medullary tube must also be involved in the general growth in length and so we find that it extends forwards in front of the dorsal septum which, as in the normal adult, has an anterior frec border. Thus although in this specimen (Fig. $\check{\delta} D$ ) the dorsal septum is not coextensive anteriorly with the medullary tube, it is so posteriorly and it presents clearly the appearance of resulting from and representing the raphe of fusion of the medullary folds². Inside this dorsal septum there are cellular remains of the solid plate or keel of ectoderm which is produced by the fusion of the folds (cf. Pl. XXXII. Fig. 68 and Text-fig. 1). Sometimes these remains are in the form of disconnected

1 Reference is made below to the anterior "Epidermistasche" which Spengel describes in place of the anterior neuropore. In the specimen of Pt. flava shown in Fig. $5 D$ there is no question of an "Epidermistasche" which in other cases may coincide with the neuropore. In this case there is only the true neuropore at the anterior end of the fused medullary folds. The collar-flap projects above and beyond it, but there can be no confusion between the angle formed by the collar with the neck of the proboscis and the neuropore, such as is possible in certain cases.

$\approx$ The dorsal septum which, when present, unites the collar nerve-cord with the epidermis, should not be confounded with the dorsal mesentery which primarily separates the two collar-cavities from one another at an early stage. This mesentery is represented in the adult by the median partition between the right and left perihaemal cavities, which carries the dorsal blood-vessel. 
débris, while others approximate to the character of roots, of which the first accurately coincides with the anterior free border of the septum. This root is massive and solid at its base and attenuated distally; it occurs in the region of the buccal orifice of the stomochord. The second root is slender, solid at its origin and sub-solid through-

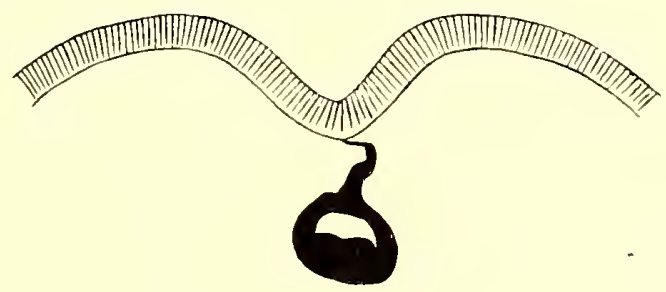

FrG. 1. Portion of transverse section through the middle of the collar of the specimen drawn on Pl. XXVI. Fig. 5D. The section shows the fourth root passing from the dorsal side of the medullary tube to the basement membrane of the epidermis and illustrates the interpretation of the root and the septum in which it lies, as a product of the raphe of fusion of the medullary folds. The superjacent epidermal groove presumably represents what is left of the medullary groove after the closing-in of its lower portion to form the medullary tube (ef. Pl. XXXII. Fig. 68).

out, and does not fuse with the epidermis. The third root is similar except that it meets the epidermis; the fourth root does not fuse with the cpidermis, neither does the fifth and last, which is massive and presents disconnected traces of lumen.

These observations may throw a partial light on the origin of the roots as successive differentiations from the raphe of fusion of the medullary folds, but they throw no direct light upon their character of hollow tubes passing from the medullary canal to the cpidermis. 


\section{Subgenus 2. Tauroglossus.}

2. Ptychodera carnosa n. sp.

Colour, Measurements and External Form.

This is a giant Enteropneust like Pt. gigas and Pt. robinii, the latter according to Spengel being the Atlantic form of the Mediterranean Pt. clavigera ${ }^{1}$.

Table of Colour and Measurements (in mm.).

\begin{tabular}{|c|c|c|c|c|c|c|c|c|}
\hline $\begin{array}{l}\text { Speci- } \\
\text { men }\end{array}$ & Colour & Proboscis & $\begin{array}{l}\text { Collar } \\
\text { length }\end{array}$ & $\begin{array}{l}\text { Branchial } \\
\text { region }\end{array}$ & Genital region & $\begin{array}{c}\text { Inter- } \\
\text { mediate } \\
\text { tract }\end{array}$ & $\begin{array}{c}\text { Hepatic } \\
\text { region }\end{array}$ & $\begin{array}{l}\text { Abdominal } \\
\text { and caudal } \\
\text { region }\end{array}$ \\
\hline 1 & \begin{tabular}{|c|} 
Rich yellow \\
throughout, faint \\
salmon tinge in \\
genital pleurae
\end{tabular} & 6 & $17 \cdot 5$ & & & & & \\
\hline 2 & $\begin{array}{l}\text { Pale yellow } \\
\text { throughout }\end{array}$ & 8 & 16 & & & & & \\
\hline 3 & $\begin{array}{l}\text { Prevailing colour } \\
\text { of branchiogenital } \\
\text { region, dark sal- } \\
\text { mon or purplish }\end{array}$ & 10 & $\begin{array}{c}22.5 \\
\text { [Max. } \\
\text { width } \\
\text { behind 16] }\end{array}$ & 92 & $\begin{array}{c}160-170 \\
\text { [Width across } \\
\text { outspread genital } \\
\text { pleurae behind } \\
\text { pharynx 35] }\end{array}$ & 10 & 106 & $\begin{array}{l}\text { About } \\
1 \text { foot }\end{array}$ \\
\hline 4 & $\begin{array}{c}\text { Genital pleurae } \\
\text { with salmon- } \\
\text { coloured gonads }\end{array}$ & & $\begin{array}{c}14 \\
\text { [Width } \\
9-10]\end{array}$ & $\begin{array}{c}26 \cdot 5 \\
{[\text { Width }} \\
10--12]\end{array}$ & & & & \\
\hline 5 & $\begin{array}{l}\text { Salmon-coloured } \\
\text { gonads; collar } \\
\text { creamy yellow, } \\
\text { darker in centre }\end{array}$ & . & 12.5 & $29 \cdot 5$ & 64 & & & \\
\hline
\end{tabular}

The immature eggs are purple and are surrounded by orange-coloured fat-globules, the combination of the two colours producing the salmon tone. As the eggs ripen the pronounced purple coloration is lost and the fatty matter seems also largely to lose its colour, so that the result is a dull neutral tint. Sometimes the prevailing colour of the genital pleurae is dark with a violet tone.

The posterior zone of the collar is sharply differentiated from the other zones. In paler specimens it is intensely white, while in the more richly coloured individuals it is not so conspicuous but always to be recognized.

1 If Spengel is right in regarding $P t$. robinii as a giant variety of $P t$. clavigera, it furnishes an interesting analogy with the large Amphioxus $(8 \mathrm{~cm}$. long) of the coasts of France as compared with the smaller Mediterranean form. 
In the largest specimen whose measurements are given in the above table, the hepatic region commenced with about a dozen brown hepatic coeca, which were followed by a long stretch of foliaceous, dull yellowish saccules, and these again by a still longer gradually decreasing series of brown lobes. The larger saccules are finely digitate or crenulate at their free margins and are quite lamelliform, like the leaves of a book, being extraordinarily flattened antero-posteriorly and closely crowded together.

On the inner surface of the genital pleurae, especially towards the base, are often to be observed numerous white rounded dermal islets.

In some cases the gill-pores may be observed to be surrounded by a rim of brown pigment, and fine lines of the pigment radiate out from the gill-pores to the submedian line ${ }^{1}$ in which the genital pores occur.

The proboscis is remarkable for its small size relatively to the capacious collar (Pl. XXVII. Fig. 6). It is probably liable to frequent injury owing to the excessive boring propensities, deep down in heavy volcanic sand, which this species exhibits. Specimens are often obtained in which the proboscis is quite concealed within the collar without betraying any pronounced lacerated surface; so that it probably regenerates very quickly.

The most distinctive external feature of this species is the abrupt ending of the genital pleurae some distance in front of the hepatic region (Pl. XXVII. Fig. 6).

The maximum development of the genital pleurae is behind the branchial region. In fiont they become much lower as they approach the posterior rim of the collar, and converge towards the middle line. The gonads commence some distance behind the anterior end of the pleurae. The genital pleurae can not only meet one another in the middle line so as to close in the dorsal nerve-cord and the branchial tract, but they can effect a mucous junction with one another. When the animals are preserved during such a mucous junction (which normally is only temporary) the mucus coagulates into a dense leathery band, which is untearable. If one tries to separate the pleurae by force the body-wall ruptures but the mucous coagulum remains entire. No such mucous junction of the genital pleurae is effected in Pt. flava.

Sometimes the gonaducal (submedian) line is marked out behind the branchial region by a brown-pigmented groove running along the inner base of the genital pleurae; and there may also be observed fine interannular lines of brown pigment.

The ventral middle line is conspicuous in external view by its bright red colour, presumably due to the ventral blood-vessel showing through ${ }^{2}$.

The dorsal blood-vessel is less conspicuous in external view.

A colour-variation which $\mathrm{I}$ think is directly traceable to difference in habitat and nutrition is worthy of mention. The remarks already recorded as to the colour of the hepatic saccules referred to specimens obtained from the volcanic island of Matupi in Blanche Bay, New Britain. Those which I obtained from a small coral island (Pigeon Island) midway between Cape Gazelle and Blanche Bay had dark green liver-saccules.

1 This is not an appropriate designation, and I think it should be replaced by some such term as gonaducal line.

2 The blood of the Enteropneusta is an oxyphile non-corpusculated fluid, as shown by its intense affinity for eosin. Hence it seems probable that the red colour often observed in the region of the vascular trunks in living specimens is due to a substance like haemoglobin if not to haemoglobin itself. 


\section{PROBOSCIS.}

In the anterior portion of the proboscis there is a small central cavity surrounded by a feeble aponeurosis. The cavity is not empty but contains a cellular conglomerate. Similar cell-débris have been observed by Spengel in the central cavity of the proboscis of Pt. minuta and elsewhere.

Farther back, but still in front of the central complex, the central cavity disappears ${ }^{1}$, its place being taken by the decussating and radiating bundles of connective tissue fibres. Immediately in front of the central complex the cavity again opens out, only to become nearly filled up once more by the extraordinarily abundant splanchnotheca in which the glomerulus (and central complex generally) is imbedded.

The anterior end of the glomerulus projects beyond the stomochord and pericardium but, in the main, the three principal components of the central complex are coextensive. The stomochord ends bluntly in front and does not taper as it does in Pt. flava. The pericardium ends simply, with no sign of bifurcation in front.

There is no well-defined lumen in the most anterior portion of the stomochord, but I will not undertake to deny its existence. The reason why I cannot speak certainly on this point in this case $^{2}$ is due to the fact that the cells of the stomochord are here inflated, more or less bladder-like, and decidedly more like chordatissue than I have seen in some other species.

The cavity of the pericardium is almost entirely filled by flocculent tissue resembling the splanchnotheca and containing minute granules, like the latter.

Dorso-ventral muscle-fibres accompany the central complex as usual.

The central blood-space attains enormous dimensions, far outstripping the subjacent stomochord. It is surrounded on all sides, except below, by a strong muscularis, derived, as usual, from the endothelium of the ventral wall of the pericardium, as is shown by the fact that no basement-membrane intervenes between the muscularis and the pericardial tissue.

The ventral septum is of less extent, both longitudinally and vertically, than in Pt. flava. It has a posterior free border, behind which the ventral canals fuse together to form a median tube, which dilates somewhat before terminating in the keel of the nuchal skeleton.

On nearing the nuchal region the musculature of the proboscis becomes more and more reduced in bulk, persisting for the longest distance in the ventral walls of the ventral canals. There is no circular thickening of the circular musculature at the base of the proboscis such as Spengel has described for Pt. clavigera, agreeing therefore in this respect with Pt. aurantiaca.

Accompanying the termination of the muscular fibres, the lateral walls of the dorsal canals and the dorsal walls of the ventral canals acquire a ciliated columnar epithelium. The right dorsal canal ends blindly in the feebly developed chondroid

1 This reduction of the coelomic cavity of the proboscis should be remembered in connection with the behaviour of the proboscis-pore described below.

2 There is usually no doubt one way or the other. My material of the present species is quite faultlessly preserved. 
tissue, while the left canal opens widely into a median end-vesicle terminating in an ill-defined pore which may open into the base of the medullary tube somewhat behind the anterior neuropore $1 \mathrm{Pl}$. XXIX. Fig. $17 a-c)$. Behind the proboscis-pore, the ventral angles of the end-vesicle are continued for a short distance below the medullary tube as a pair of coecal pockets which may be separate or united. The association, here described, of the proboscis-pore and medullary tube, suggests morphological relationships of great significance and complexity of which I had previously no idea. The pore does not form a gaping orifice but is narrowed or even subdivided by a reduplication of the wall of the end-vesicle. The meaning of this reduplication will be apparent when we come to consider the West Indian species. In a younger specimen I find a simple undivided median end-vesicle opening to the exterior by a median pore in front of the anterior neuropore. The reduplication of the end-vesicle would therefore appear to be secondary in an ontogenetic sense-a fact of some interest.

\section{STOMOCHORD.}

The coecal dilatation of the stomochord is remarkable for the feeble development of the lateral pockets, and, comnected therewith, its relatively small transverse expansion. The expansion in the dorso-ventral direction is approximately normal; in the transverse direction it is less than usual. There are both dorso-lateral and ventrolateral subdivisions of the stomochordal lumen (Pl. XXIX. Fig. $17 a$ ).

Tracing the stomochord in section from before backwards, its lumen is seen to be in a vestigial condition (reduced to zero or interrupted and broken) until near the posterior end of the coecal dilatation. Here the lumen widens out and the cells composing its dorsal wall are densely ciliated. This is an unexpected result, and the reason for the occurrence of cilia in this position is not very apparent, since the continuity of the stomochord is interrupted some distance in front of its buccal orifice.

Behind the coecal region the stomochord becomes abruptly reduced in bulk and continues to decrease in size until it reaches a point where it positively splits up into three minute portions separated from one another by processes from the dorsal edge of the nuchal skeleton (Pl. XXIX. Fig. 18). Finally these fragments of the stomochord unite with, and are absorbed into, the ventral wall of the wide terminal division of the stomochord, the dorsal wall of which is again finely ciliated. A similar, but more extensive fragmentation of the stomochord in the nuchal region, through its being traversed by bridges of skeletal substance is described by Spengel in Bal. kupfferi (Spengel, Mon., Taf. XV. Figs. 24-26).

\section{Nuchal Skeleton.}

The dorsal edges of the cupule of the nuchal skeleton are produced forwards as two thickened skeletal bands lying above the ventro-lateral pockets of the coecal dilatation of the stomochord (Pl. XXIX. Fig. 17 a). The body of the skeleton is produced dorsally into a high crest which is instrumental in effecting the fragmentation of the stomochord

1 Similar observations are recorded by Spengel in Bal. canadensis and Gl. talaboti. [Spengel, Mon. Taf. 17, Fig. 13, and Taf. 19, Fig. 6, page 607.] 
described above. The alary processes are produced in front of the keel and bound the dorso-lateral sides of the ventral coecum of the proboscis-cavity, behind which they unite to form the keel. In the anterior region of the keel, the body of the skeleton is reduced to a thin flattened vertical band which becomes, for a short distance, absorbed into the substance of the keel, being almost entirely replaced by the latter. Farther back, the body again seems to assert itself, and the keel becomes reduced until the point of bifurcation is reached.

\section{COLLAR.}

\section{Collar Nerve-cord and Roots.}

At its anterior end the collar nerve-cord possesses a simple transverse lumen proceeding from the anterior neuropore. This soon ceases and the central canal is thereafter represented by a large number of separate minute medullary cavities, until the neighbourhood of the posterior neuropore is approached, when a large median lumen again occurs.

The first root is hollow throughout the greater part of its free course, but it is solid at its origin from the dorsal wall of the nerve-cord. It arises in front of the buccal orifice of the stomochord and has a long, oblique, forwardly directed course. The layer of peripheral nerve-fibres (Punktsubstanz) accompanying the root is relatively thick.

After fusing with the epidermis the lumen of the root, surrounded by an epithelial layer of cells, is continued for some distance forwards as an intra-epidermal canal lying within the thickness of the epidermis above the nervous layer. I have not observed this feature in any other species.

Immediately below the origin of the first root there is an indication of a small cavity in the nerve-cord, which however is quite filled up by a drop of deeply staining mucus like that which will be described below as occurring at the distal end of the vestigial root of Spengelia porosa.

The second root accompanies the anterior border of the dorsal septum of the collar. It is likewise hollow throughout its course, but solid at its origin and its central canal also runs for some distance $(30-40 \mu)$ within the epidermis above the nervous layer. I do not think there is an actual opening to the exterior between the epidermal cells, but the latter are grouped round the distal end of this canalicular prolongation of the root in such a manner as to strongly suggest that at one time the root opened at the surface by a pore (Pl. XXIX. Fig. $19 \alpha$ and $19 b$ ).

The origin of the second root lies exactly at the level of the buccal orifice of the stomochord. Its course, like that of the first, is directed obliquely forwards.

In another specimen the first root is short and band-like, and its central canal vestigial, but the intra-epidermal canal into which it is produced in front possesses a continuous lumen and is remarkable for its great length-about $180 \mu$.

The second root is short, mostly solid and without intra-epidermal canal. A vestigial third root is present which is reduced at origin and insertion to little more 
than a cylinder of basement-membrane; the cellular contents expand in the tract of the root which intervenes between the points of origin and insertion.

Finally, in the specimen now under consideration, the dorsal septum of the collar is lacking.

\section{Collar-canals and Pores.}

The collar-canals have a characteristically folded epithelium (Pl. XXX. Fig. 20). They open, on each side, into the first gill-pouch dorso-laterally with respect to the first gill-pore. It is a striking fact that the first gill-pore itself opens, together with the collar-pore, into the posterior end of the medullary tube immediately in front of the posterior neuropore, and in front of the posterior commissural ring-nerve of the collar (Pl. XXX. Fig. 21).

In another specimen these relations were not so striking, the opening of the first gill-slit occurring slightly farther back at the level of the posterior neuropore'.

It is probably not a matter of very great importance whether the first gill-pore occurs a few thousandths of a millimetre in front of or behind the level of the posterior neuropore; and the same remark applies to the proboscis-pore in its relation to the anterior neuropore. What is perhaps of some importance is to take note of the fact that while the proboscis-pore may be intimately associated with the anterior neuropore, the collar-pores and first gill-pores may be similarly associated with the posterior neuropore.

\section{TRUNK.}

\section{Branchial Region.}

The genital pleurae become reduced in height as they approach the posterior rim of the collar, and they converge towards the middle line. The gonads do not extend to the anterior end of the genital pleurae but commence some distance behind the collar, as, indeed, is frequently the case (Spengel).

Spengel has shown that in those species in which the gill-clefts open into gillpouches (i.e. in the majority of Enteropneusta) the gill-pouch is exactly as deep (dorso-ventrally) and as broad (longitudinally) as the corresponding gill-slit, except in Pt. gigas and Pt. clavigera, where the gill-pouches are produced ventrally below the base of the gill-slits into deep coecal diverticula. In Pt. carnosa such ventral coeca of the gill-pouches are also present and of great depth anteriorly, becoming shallower posteriorly (Pl. XXX. Fig. 22). At the posterior end of the branchial region the gillpouches are very capacious in the transverse direction.

The tongue-bars are united to the corresponding septal bars by more than 30 synapticula on each side.

1 It might be said with equal justice and perkaps even with more accuracy that, in the specimen referred to, the posterior neuropore oceurred at a slightly more anterior level. 


\section{Branchiogenital Transition.}

The external features of the branchiogenital transition are shown in Pl. XXVII. Fig. 6. The branchial tract assumes an elevated or vaulted form and the dorsal nerve-cord causes a crest-like projection.

The pharynx is succeeded by a thick-walled postbranchial canal similar in all essential respects to the corresponding structure in Pt. flava (Pl. XXX. Fig. 23). This structure has not previously been recorded in a member of the subgenus Tauroglossus. Its walls are formed of high, closely-packed, ciliated columnar cells, with nuclei at different levels, but especially crowded in the central portion of the epithelium. This postbranchial canal has a narrow lumen open continuously below into the main cavity of the gut. The last pair of gill-slits occurs at its dorsal borders as in Pt. flava. In front it constitutes a high median crest or duplication of the gut-wall which, posteriorly, becomes lower and lower until it disappears, and its place is then taken by an ordinary duplication of the gut-wall lined by normal gastral epithelium consisting of low, cubical, ciliated cells with basal nuclei.

The lateral septum arises on each side of the postbranchial canal behind which it arises from the dorso-lateral borders of the gut. In front of the postbranchial canal, that is, in front of the last gill-slit, both the origin and the insertion of the lateral septum occur in the basement-membrane of the epidermis. Its insertion marks the position of the gonaducal line which lies on the inner side of the genital pleura near the base, but separated by a wide interval from the branchial groove. Contrary however to what takes places in Pt. flava, the lateral septum only extends for a short distance into the branchial region and is by no means coextensive with the genital pleurae. In front of the lateral septum the gonaducal line is denoted by a fold of basement-membrane carrying a lateral blood-vessel; and moreover, this lateral blood-vessel occasions or is associated with the same interruption of the longitudinal musculature which accompanies the insertion of the lateral septum itself. Although, as mentioned above, the gonads do not, in this species, extend to the anterior end of the genital pleurae but commence two or three millimetres behind the posterior rim of the collar, nevertheless the gonaducal line, as defined by the presence of a lateral vessel and by the interruption of the longitudinal musculature, is continued beyond the anterior limit of the gonads to the anterior extremity of the genital pleurae.

Thus, although neither the gonads nor the lateral septa are coextensive anteriorly with the genital pleurae, the gonaducal line is. We have here, therefore, evidence of a recession of the gonads from the anterior end of the trunk.

In immature specimens the medial and lateral branches of the gonads, in the posterior branchial and genital region, abut simply upon the lateral or gonaducal line as shown in Fig. 23, Pl. XXX. In a mature female such as the one represented in Fig. 6, Pl. XXVI. accessory genital ducts occur laterally from the main series. It seems quite certain that the subdivision of the gonads which accompanies the appearance of accessory ducts, in Pt. carnosa, is simply due to growth and constriction from the original gonad; not to the formation of independent accessory gonads. There are no accessory ducts mediad of the gonaducal line, but the inedial branches of the gonad 
have become quite independent and their ducts occur a short distance removed from the line of insertion of the lateral septum. The mature gonads do not exhaust the entire capacity of the genital pleurae, but the distal fiee portion of the latter is left free from gonads. The eggs are quite small, as they are in all Ptychoderidae, and measure $15 \mathrm{~mm}$. in diameter in the preserved state.

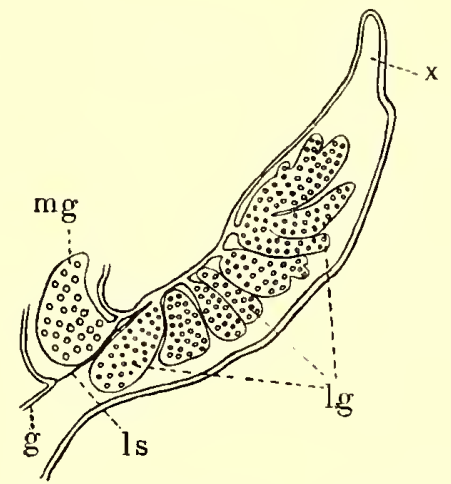

FIG. 2. Portion of transverse section through genital region of adult $P t$. carnosa $q$; showing lateral accessory genital ducts.

g. Gut-wall. lg. Lateral divisions of the gonad. ls. Lateral septum. mg. Medial branch of gonad with independent duct. $x$. Sterile border of pleural fold.

\section{Genito-hepatic Transition.}

The most characteristic feature of this transition, namely, the abrupt termination of the genital pleurae (including the lateral septa), leaving a marked interval between them and the anterior hepatic saccules, has been already mentioned and is clearly shown in Fig. 6, Pl. XXVII.; this interval was even more pronounced in the living animal.

In this species therefore the gonads do not encroach upon the hepatic region. The wall of the gut in this region is thrown into a large number of folds arranged with some regularity. In the anterior portion of the hepatic region there are two specialised tracts of high, folded, ciliated epithelium, with basal nuclei and clear periphery, placed symmetrically at the ventro-lateral borders of the gut. Whether these remarkable tracts have any special significance I cannot say. I have not been able to find in this region any ciliated apparatus like that described above in Pt. flava. But I have (with difficulty owing to the extraordinarily folded wall of the gut) ascertained the existence of the two ptychoderoid ciliated intestinal grooves in the posterior hepatic and abdominal region.

\section{Caudal Region; Pygochord.}

The abdominal and caudal regions of this species are extremely flaccid, and there is no external manifestation of the presence of a pygochord in the latter region.

W. III. 
Nevertheless, one is present. As shown in Pl. XXIX. Fig. 16, it is a very high, thin band with slightly dilated distal edge abutting upon the ventral vessel. It consists of ordinary cells as in Pt. flava. It probably does not possess great staying power in the present species. A pygochord seems to be of very general occurrence among the Ptychoderidae and affords a useful specific character.

\section{OECOLOGY.}

Pt. carnosa burrows deeply in the sand and can draw itself along with astonishing rapidity. Its presence is betrayed by massive castings, which sometimes occur in such numbers as to form an important feature in the landscape at low tide. It lives at a depth of from one to two feet in the sand, both volcanic and coral, and may be taken anywhere between Cape Gazelle and the island of Matupi in Blanche Bay, New Britain. I first found it in Matupi.

In the same burrows another smaller species is to be found, namely, Pt. ruficollis n. sp.

It breaks up into longer or shorter lengths upon slight provocation. I do not know whether or not fragments of the trunk would regenerate a head. There can be no doubt however as to the ability of the animal to regenerate its proboscis, which is often found more or less injured.

Often in the process of defæcation the caudal end of the body is thrown off with the castings. An isolated piece, two or three inches long, of the abdominal region will always turn itself inside out.

The enormous size of the collar in this species, in some individuals more than in others, suggests that it not only assists the proboscis in the acts of burrowing and progression but even tends to supersede the proboscis. In other words, the collar of this species, and probably of some others, is more important than the proboscis as an essential organ of progression. This is therefore an indication of modification of function of the proboscis, and all such indications, however slight, should be carefully recorded. 


\section{Subgenus 3. Ptychodera s. str.}

\section{Ptychodera ruficollis n. sp.}

I was at first inclined to create a new subgenus for this well-marked species. When a Ptychodera has no genital pleurae, like Pt. hedleyi, the only obvious external character by which it can be recognised as a Ptychodera, is the presence of external hepatic saccules. The present species differs from all other Ptychoderidae, in the absence of these structures. This character, combined with-the absence of pleural folds and with the small dimensions and triangular shape of the branchial tract ${ }^{1}$, renders this species as well-defined as could be wished. But it could hardly be identified as a Ptychodera from its external features alone, and I am still in some doubt as to the wisdom of not making a separate subgenus for it. Only two other Enteropneusta have been described with a triangular branchial tract, namely, Pt. minuta and $P t$. sarniensis, from both of which Pt. ruficollis differs greatly.

\section{Colour, Measurements and External Form.}

Like other species of Enteropneusta the present form is characterised by a peculiarity in its colour. There is a strong crimson element in the collar which suggested the specific name. The colour of the proboscis in the living animal is light opaque yellow; that of the collar is dark reddish yellow, or yellow strongly tinged or shot with crimson. This combination of yellow and crimson gives the general effect of the colour known as Indian-red or Orange-red.

The crimson colour of the collar is chiefly confined to its anterior free portion and to the posterior region. The mid-region, which has the form of a circular cushion, seen in front of the broad dark-coloured groove in Fig. 7, Pl. XXVII., is generally without the crimson and is dark yellowish. The extrcme posterior marginal band or so-called fifth zone of the collar is also free from crimson and is plain yellow.

The ground-colour of the trunk is a dull subtranslucent yellow except in the hepatic region, which is distinguished by a bright brown colour.

The proboscis is small and obtusely subconical in shape during life; it measures, in maximum extension beyond the rim of the collar, 4-4.5 min.

The collar is much longer than the proboscis; its length is 6.5 to $7 \mathrm{~mm}$, with maximum breadth in its hinder region of $5 \mathrm{~mm}$. The branchial region is remarkable for its shortness, being sometimes even shorter than the collar; length $6-8 \mathrm{~mm}$.

The genital ridges, whitish in colour, commence at the posterior end of the branchial region and extend back for some $50-60 \mathrm{~mm}$., their maximum development occurring close behind the branchial region. The genital region is therefore many times longer than the branchial region-a good diagnostic feature. In Pt. hedleyi, with

1 This is the "Kiemenfeld" of Spengel and "gill-area" of Hill. 
which Pt. ruficollis seems to be more closely allied than with any other species, the genital region is less than half the length of the branchial region (Hill).

The hepatic region occupies approximately the third quarter of the body reckoned from the front. The rich brown colour which characterises this region is concentrated along parallel lines which run diagonally in two directions, decussating and so producing a striking lattice-work pattern. This condition could also be expressed by saying that the dermal annulations are broken up into diamond-shaped islets.

In the branchial region the dorsal vascular trunk is distinct and coloured red; otherwise the dorsal vessel is inconspicuous from outside. The ventral vessel on the contrary is very conspicuous with its deep red colour; it is bounded on each side by a longitudinal clear neutral-tinted area.

The general shape of the body is subcylindrical with a diameter of about $4 \mathrm{~mm}$.

\section{PROBOSCIS.}

The layer of circular muscles which lies next below the basement-membrane of the epidermis is thin, as is usual in Ptychodera, while the longitudinal muscles of the proboscis are arranged in radial bundles. The central cavity of the proboscis is not surrounded by a feltwork of conjunctive fibres.

\section{Central Complex.}

The anterior or distal extremity of the central complex of the proboscis in Pt. ruficollis differs greatly from the condition met with in the two species described above. The stomochord is not attenuated in front but terminates bluntly; the lumen extends practically to its distal end, and there is thus no solid prolongation.

The pericardium is bifid anteriorly, being produced forwards into two blind pouches, each of which is accompanied by the corresponding half of the glomerulus, for a short distance beyond the anterior limit of the stomochord ( $\mathrm{Pl}$. XXX. Fig. 24). This condition is comparable to what takes place in the Spengelidae, where, as was first described by Spengel in Schizocardium and Glandiceps, the pericardium is produced anteriorly into a pair of pericardial auricles (Herzohren).

The cavity of the pericardium is quite filled up by loose spongy tissue over a short stretch at its posterior end.

The ventral septum of the proboscis extends almost to the anterior extremity of the stomochord, its anterior free edge passing very obliquely downwards and backwards. It will be remembered that in Pt. flava the ventral septum ceases shortly in front of the dilated region of the stomochord, remote from the anterior end of the central complex.

At the front part of the coecal dilatation of the stomochord the lateral portions of the ventral coecum are seen to be projected forwards as paired lateral pouches (Pl. XXX. Fig. 25). It is clear that in many species of Enteropneusta the lateral pouches have to be considered equally with what Spengel las described as the ventral coecum only. In Pt. australiensis, Hill (loc. cit.) describes and figures the lateral 
pouches of the stomochord. "From the transverse lumen of the blind sac," says Hill, "there passes forwards laterally a short horn on each side; a section passing through the proboscis neck just anterior to the passing down of the ventral blind sac lumen thus shows three cavities in the notochord," namely, two ventro-lateral and one dorsomedian.

In Pt. hedleyi a similar condition has been described also by Hill. Here, in the region of the ventral blind sac the stomochord is transversely extended and "somewhat dorso-ventrally compressed. From the lumen of the blind sac there pass forwards two short lateral horns" as in Pt. australiensis.

In the mid-coecal region of the stomochord the latter has a characteristic helmetshape in section, the ventro-lateral corners arching downwards over the ventral coelomic canals. In the median dorsal division of the helmet-shaped stomochord are numerous mucous gland-cells (Pl. XXX. Fig. 26).

Behind the coecal region, the character of the stomochord changes entirely. It is greatly reduced in bulk and its walls become thin and are apparently in a condition of mucous degeneration. In fact, the function of the stomochord as a supporting structure, a function which it undoubtedly serves in its anterior moiety, is, in the nuchal region, quite superseded by the nuchal skeleton.

The nuchal region of the stomochord is therefore in a retrograde condition, and we are prepared for the fragmentation described above in Pt. carnosa and by Spengel in Bal. kupfferi; and for the entire resorption of the nuchal portion of the stomochord which Spengel has described in old examples of Sch. brasiliense and in Bal. canadensis.

\section{Proboscis-Pore.}

The dorsal proboscis-canals occur above the middle or coecal region of the stomochord, being separated from the ventral canals by the lateral pockets of the dilated stomochord and from each other by the dorsal wall of the pericardium, which meets the basement-membrane of the epidermis, as in other species (Pl. XXX. Fig. 25).

There is only one proboscis-pore, namely, that on the left side (Pl. XXX. Fig. 27). The left dorsal canal leads into an end-vesicle which lies in a median position above the pericardium, the apex of which is therefore shifted over to the right side.

The pore is coterminous with the end-vesicle, or, in other words, there is no coecal extension of the end-vesicle behind the pore. In different specimens there is great variation in the topographical relations of the various organs in the neck of the proboscis. Thus, in one case the left dorsal coelomic canal opens into the endvesicle at the commencement of the coecal dilatation of the stomochord, i.e. at the commencement of the lateral pouches of the stomochord. The medianly placed endvesicle accompanies the pouched region of the stomochord throughout its length, and opens by a sinistral pore at the transition from the coecal to the nuchal portion of the stomochord or, what is the same thing, at the transition from the cupule to the body of the nuchal skeleton; the pore therefore occurs well in front of the alary processes of the skeleton and in front of the posterior edge of the ventral septum, which, in this case, extends back into the free lobe described below. 
In another specimen the left dorsal canal opens into the end-vesicle at the posterior end of the pouched or coecal region of the stomochord; the vesicle accompanies the body of the nuchal skeleton behind the cupule and opens by the sinistral pore at the level of the alary processes and posterior to the ventral septum which does not extend into the free lobe (Pl. XXX. Fig. 27).

In spite of these differences, however, the posterior border of the proboscis-pore is, in both cases, equally close to the insertion of the neck of the proboscis into the dorsal wall of the collar, and hence, equally near to the anterior neuropore.

Beyond the point of communication with the end-vesicle, the rest of the left canal breaks up into the islets of the chondroid tissue; and the right canal does the same. The chondroid tissue which was first described by Marion in 1885 and is called by Spengel the secondary skeleton, is one of the most remarkable elements in the organisation of these animals. In the present species it is poorly developed, as is usual for Ptychoderidae. It attains its maximum development in the Spengelidae. It needs little perspicacity to predict that when the theory of chondrification is better understood, the importance of this chondroid tissue in the Enteropneusta will be more fully appreciated.

The end-vesicle opens widely, like an exposed pit, as do the end-vesicles of Pt. flava. In Pt. hedleyi, Hill has shown that both sinistral and dextral pores are present, opening close together or by a common median aperture.

\section{Ventral Coecum of Proboscis.}

The affinities which bind together the different species of Enteropneusta intertwine and overlap in the most perplexing manner. Thus, Pt. ruficollis differs from the other species of its subgenus and agrees with those of the subgenus Chlamydothorax in the mode of termination of the ventral coecum of the proboscis.

This coecal prolongation of the proboscis-coelom is continued far behind the posterior free edge of the ventral septum, and forms a large pro-eminent lobe which projects into the buccal cavity like the racemose organ of Pt. flava (PI. XXVIII. Fig. 1 c, and Pl. XXX. Fig. 27). In Pt. hedleyi, the ventral coecum of the proboscis is stated by Hill to end blindly "in what appears to be simply the thickened basementmembrane of the epidermis" below the body of the nuchal skeleton.

In Pt. minuta it extends for a very short distance beyond the ventral septum as a flattened sac (Spengel, Mon., Taf. III. Fig. 30).

\section{Nuchal Skeleton.}

The anterior cupule of the nuchal skeleton in which the stomochordal coecum rests, presents no reliable features of diagnostic importance. The body of the skeleton following upon the cupule has, on the contrary, definite features characteristic of the species. It has a triradiate form closely resembling in outline the mitre-shaped stomochord which lies in front of it. It sits like a cap upon the ventral proboscis-canals 
over which its lateral portions arch. The dorsal median portion projects into the base of the reduced stomochord, and may be described as cristate ${ }^{1}$.

Behind the level of the posterior edge of the ventral septum the body of the skeleton begins to alter its form. Its basal angles cease and their place is taken by the adventitious skeletal elements which constitute the alary processes (Pl. XXX. Fig. 27). Farther back these come together and unite to form the prominent keel which coexists in this species with the projecting lobe formed by the ventral coecum of the proboscis (Pl. XXX. Fig. 28).

\section{COLLAR.}

In respect of musculature and vascular system of the collar, the present species conforms to the Ptychoderoid type.

\section{Collar Nerve-cord and RoOts.}

There is a continuous merlullary canal in the collar nerve-cord of Pt. ruficollis which agrees therefore in this respect with Pt. hedleyi Hill. The dorsal wall of the neural canal is, as a rule, sharply delimited towards the lumen, while the inner surface of the ventral wall is sometimes quite irregular and without a clear line of demarcation. The central canal contains débris (Pl. XXX. Fig. 29).

Pt. ruficollis is remarkable for the large number of roots which may be present.

Series i. The first root (I) arises as a solid outgrowth from the dorsal wall very close behind the anterior neuropore; it is a slender root and has a winding course backwards at the anterior edge of the dorsal septum; it is doubtful whether this root contains any nerve-fibres, although it reaches up to the epidermis.

The sccond root (II) follows close upon the first and has also a long and winding course, but is much stouter than the first.

Root III arises at the level of the fusion of II with the epidermis. It runs horizontally backwards for a short distance, separated from the medullary cord by its own basement-membrane and by that of the cord itself, as well as by a thin layer of mesenchymatous tissue. As it proceeds backwards its calibre increases until finaliy it becomes connected for a second time with the wall of the medullary tube, and from this point it has a direct course to the epidermis. This remarkable condition would perhaps be more correctly expressed by saying that III does not approach the epidermis but runs backwards and fuses with IV. This at least is my interpretation of the matter. The fourth root, thus defincd, is a broad sagittal band, not cylindrical.

After an interval, root $\mathrm{V}$ is given off; it has a direct, vertical course to the epidermis and is a normal cylindrical root, solid like the rest. Root VI resembles V in all respects. It is followed by another still longer interval, and then a stout root

1 Few of these statements are absolute. In one case the body of the nuchal skeleton between the cupule and the alary processes presents in outline an exact replica of the preceding triradiate stomochord as seen in section (Pl. XXX. Fig. 26). In another specimen the dorsal crest-like portion was barely represented, the dorsal side of the skeleton being concave with a very slight median crest. 
(VII) unites the nerve-cord directly with the epidermis. VIII is band-like. IX is slender and arises a moderate distance behind VIII.

As the medullary tube nears the posterior portion of the collar-region it approaches the epidermis more and more, and the dorsal mesentery becomes progressively shorter. The consequence is that root $\mathrm{X}$ is very short and amounts to little more than a direct fusion of the nerve-tube with the epidermis. XI is quite slender and runs obliquely backwards, being followed by a twelfth root (XII) of similar character.

Series ii. The first root is band-like in its basal half and subcylindrical distally. It commences in front of the bifurcation of the nuchal skeleton, while its radical portion extends backwards in continuity with the nerve-cord beyond the bifurcation. It has a winding course in the dorsal septum shortly behind the free anterior margin of the latter.

The second root (II) has a band-like or crest-like origin; III is inclined forwards; IV has the vestige of an axial lumen at its base; $V$ also has the vestige of an axial canal in continuity with the central canal of the medullary tube; VI has the merest trace of a basal diverticulum from the central canal; VII, VIII, and IX arise in close succession and are quite solid; a long interval occurs before $\mathrm{X}$ closely followed by XI is given off; XII has a horizontal course backwards, and is apparently without fibres.

About this region (i.e. in the hinder third of the cord) the central canal of the medullary tube has very irregular walls in the specimen under consideration. After another long interval a small root XIII occurs. XIV has interrupted vestiges of an axial lumen, but I could not trace this root continuously to the epidermis, and in fact I think it anastomoses with $\mathrm{XV}$, which in its turn does not reach the epidermis but passes back to XVI which does. A much reduced root XVII occurs but does not reach the epidermis. There is a somewhat doubtful vestige of an eighteenth root which is immediately followed by the fusion of the nerve-cord and epidermis at the lip of the posterior neuropore.

\section{Collar-Canals AND pORES.}

This species is particularly interesting in respect of its collar-canals in that it appears to afford a clue as to the origin of the dorsal plication which is such a frequent feature of the canals. In section this dorsal plication looks temptingly like a tongue-bar and the possibility of the collar-pores being modified gill-slits has been referred to by Morgan. It is therefore a matter of some importance to show conclusively that the dorsal plication is in no sense comparable to the tongue-bar of a gill-cleft. It is in fact simply due to the fusion of the infolded edges of the collarfunnel; a distinct raphe is discernible throughout almost the entire extent of the lappet.

The external aperture of the collar-canal, i.e. the collar-pore, opens as usual into the first gill-pouch. The dorsal plication projects beyond the limits of the collar-pore as a valve-like structure overhanging the branchial groove as far back as the second gill-pore (Pl. XXX. Fig. 30). 


\section{TRUNK.}

\section{Branchial Region.}

The character of this region is shown in Pl. XXVII. Fig. 7, and in section in Pl. XXX. Fig. 31.

The chief feature about it, namely, its shortness, has been already alluded to. Each half of a gill-cleft is crossed by $10-12$ synapticula.

The lateral septa only extend for a short distance into the posterior portion of this region, namely, to the anterior border of the posterior depression of the branchial grooves, described below.

\section{BRANCHIOGENITAL TRANSITION.}

At the posterior end of the branchial region, the branchial grooves undergo an abrupt and deep depression at the base of which the posterior gill-clefts open ( $\mathrm{Pl}$. XXVII. Fig. 7, and Pl. XXX. Fig. 32). A similar depression of the branchial grooves has been described by Hill in Pt. hedleyi. In Pt. ruficollis the depression is localised in the posterior end of the branchial region. In its deepest portion it bears a strong resemblance to the dermal pores which I have described in Spengelia porosa (see below, p. 275) into the base of the most anterior of which the posterior gill-slits likewise open.

At the posterior end of the branchial region the dorsal wall of the pharynx, i.e. the epibranchial ridge or band, sinks deeper below the surface and the height of the dorsal mesentery is correspondingly increased (Pl. XXX. Fig. 32). By this sinking inwards of the epibranchial ridge, the branchial division of the pharynx is reduced to zero, and the last pair of gill-pouches appear as small diverticula on each side of the epibranchial ridge, continuous with which a longitudinal ciliated groove passes back for some distance into the anterior portion of the genital region at the base of the postbranchial canal (Pl. XXX. Fig. 33).

The postbranchial canal of $P$ t. ruficollis differs greatly from the corresponding structure of Pt. flava and Pt. carnosa, both in its relations to the gill-slits and in its general character. In the two last-named species we have seen that the postbranchial canal is in direct continuity with the branchial portion of the gut, and that the terminal gill-clefts occur at its summit.

In Pt. ruficollis, on the contrary, the branchial division of the gut comes to an abrupt end, and the postbranchial canal appears as an independent diverticulum of the gut, while the terminal gill-clefts together with the longitudinal grooves continued behind them in the dorsal wall of the gut, lie at the base, instead of at the summit of the postbranchial canal. The relations here described are not only important in providing a clue as to the meaning of the postbranchial canal, but they are perhaps of even greater interest in furnishing a striking example of readjustment of topographical relations of gill-clefts.

The postbranchial canal of Pt. ruficollis projects forwards for some distance beyond the region of its communication with the gut, as a coecal tube, resembling, in this respect, the condition described by Hill in Pt. hedleyi. With regard to the latter species Hill says (loc. cit. p. 342):-_" At its anterior end the dorsal diverticulum W. III. 
projects forwards over the last pair of gill-pockets as a very short, free, blindly-ending tube."

Here the resemblance ends, for in Pt. ruficollis the walls of the diverticulum instead of being slightly folded as they are in Pt. hedleyi [Hill, l. c. Pl. XXII. Fig. 11], are thrown into the most complicated folds, so that the cavity is greatly subdivided and, in section appears as a multiple lumen (Pl. XXX. Fig. 33). Its communication with the gut extends over a comparatively short distance, in fact there is little more than an elongated orifice of communication behind which it is again produced backwards, for a relatively long distance, as a coecal tube tapering slightly towards its posterior extremity. The lumen ceases some distance in front of its posterior end, and the structure is then a solid mass of densely nucleated tissue.

In mature specimens, the gonads actually penetrate into that portion of the perivisceral cavity which occurs between the attenuated free posterior end of the postbranchial canal and the dorsal wall of the gut.

The postbranchial canal of Pt. ruficollis, as here described, appears to me to present the characters of a vestigial structure for which I will at once proceed to offer an explanation, a certain amount of repetition being unavoidable.

\section{PT. Flava.}

1. The pharynx varies greatly in length.

2. The postbranchial canal is the direct continuation of the branchial portion of the gut; it is neither produced anteriorly nor posteriorly as a coecal tube.

3. The terminal gill-clefts occur, and new ones arise in normal succession at the dorsal sides of the postbranchial canal.

4. The walls of the postbrauchial canal are smooth, and its cavity is throughout in free communication with the ventral division of the gut.

PT. RUFICOLLIS.

1. The length of the branchial region is approximately constant, as shown by a dozen specimens; and it is characteristically short.

2. The postbranchial canal is not in direct continuity with the branchial portion of the gut; it is produced anteriorly and posteriorly, as a coecal tube, beyond the region of its communication with the cavity of the gut.

3. The terminal gill-clefts do not communicate with the postbranchial canal, but are quite separated from it, occurring in the dorsal wall of the ventral division of the gut below and beside the postbranchial canal.

4. The walls of the postbranchial canal are thrown into complex folds, by which its cavity is subdivided; it only communicates over a short stretch with the gut, and even then the orifice of communication may be interrupted; towards the posterior end of its free backwardly produced portion the lumen is obliterated, and replaced by a solid mass of tissue with densely packed nuclei. 
My deduction from the foregoing data is, that the postbranchial canal represents what was formerly a greater posterior extension of the pharynx; that it is, in fact, the more or less metamorphosed relic of a portion of a primitively more extensive perforated pharynx. In Pt. flava, as well as in Pt. carnosa, it is still the seat of origin of new gill-clefts in the normal position. But in Pt. ruficollis, as well as in Pt. hedleyi, it is emancipated from any connection with the gill-clefts.

\section{Genital Region.}

In Pt. ruficollis there is a true genital region in a sense in which it is not present in Pt. flava. In the latter we saw that the gonads were emancipated from the main body of the animal. In the present species the gonads are incorporated into the body.

The species is remarkable for the great length of the postbranchial genital region, a peculiarity which it shares with Pt. sarniensis. There are no genital pleurae, but the dorso-lateral margins of the body are squared off sharply behind the branchial region and are continued backwards as longitudinal ridges between which the median dorsal region is sometimes depressed. But often the body is subcylindrical in shape, the prominence of the genital ridges no doubt depending upon the condition of the gonads and also upon the state of muscular contraction of the body.

The gonaducal lines (submedian lines of Spengel) in the genital region are seen in the living animal to be continuous with the branchial grooves.

The gonads encroach upon the branchial region, extending forwards (as shown in one series) to the level of the first gill-pouch on one side, and to that of the second gill-pouch on the other side. This difference of level of the anterior gonads is merely due to differences in the amount of their lobation, since the gonads of the first pair open approximately in the same plane between the fifth and sixth pairs of gill-pores.

The succession of the anterior seven genital ducts and their relation to the gillpores is shown in the following table; a simple Roman numeral indicates that the genital duct occurs beside the corresponding gill-pore; two numerals connected by a hyphen indicates that the genital duct occurs between two gill-pores.

\begin{tabular}{|c|c|c|c|}
\hline $\begin{array}{l}\text { Genital } \\
\text { ducts. }\end{array}$ & \multicolumn{3}{|c|}{ Gill-pores. } \\
\hline 1 & $\begin{array}{l}\text { Righte. } \\
\mathrm{V}-\mathrm{VI}\end{array}$ & . & $\begin{array}{l}\text { Left. } \\
\mathrm{V}-\mathrm{VI}\end{array}$ \\
\hline 2 & VIII & … & VI-VII. \\
\hline 3 & IX & 다. & VIII-IX. \\
\hline 4 & $\mathrm{X}$ & 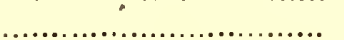 & $\mathrm{X}$ \\
\hline 5 & $\mathrm{XI}$ & 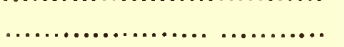 & XII. \\
\hline 6 & XII-XIII & 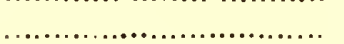 & XIII. \\
\hline 7 & XIII & 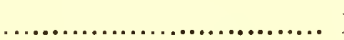 & $\mathrm{XIV}-\mathrm{XV}$. \\
\hline
\end{tabular}


The fact that the first pair of genital pores occurs between gill-pores V. and VI. again illustrates what $I$ shall speak of later as the recession of the gonads from the anterior end of the trunk.

Ova.

I was fortunate in obtaining a quite mature female, whose gonads contained vast numbers of ripe ova. The eggs are enveloped in a stout vitelline membrane which closely hugs the unfertilised ovum. The ovum is round and small, and its contents are finely granular.

The germinal vesicle contains a large, usually marginal nucleolus, which has great attraction for eosin, and contains, one or many, fatty inclusions in its centre. In the unstained condition these refringent inclusions in the nucleolus are exceedingly prominent.

The diameter of these eggs is $09 \mathrm{~mm}$., and this is a measurement of great importance because it is sufficient to inform us, I think with certainty, that the species (like all Ptychoderidae) develops indirectly through a Tornaria-stage.

The mode of oviposition of the Enteropneusta does not seem to be perfectly understood [cf. Spengel, Mon., p. 658], and observations which I have made on Pt. ruficollis are therefore of interest. Although the gonads are connected to the skin by so-called ducts, Bateson thought that the eggs were discharged by rupture of the body-wall as they are in many Annelids. As shown in Plate XXXII. Fig. 69, at the time when the ova are ready to be discharged the genital duct, in this species, becomes properly hollowed out, and gapes widely enough for the passage of the ova without any squeezing.

\section{Genito-hepatic transition.}

Sometimes the genital ridges can be traced for some distance into the hepatic region; sometimes they stop short some distance in front of the hepatic region. The noteworthy point abont the transition internally, is the occurrence of a longitudinal ciliated tract on the left side about midway between the dorso-lateral margin of the body and the ventral nerve-cord. This ciliated band is partly overhung by a fold of intestinal epithelium, and appears to be comparable to the ciliated apparatus in the gut of other Ptychoderidae.

I was not able to ascertain how far this band extended into the abdominal region. The post-genital portion of the body of this species is almost impossible to preserve intact as the body-wall is very thin and brittle. Only the caudal region always preserves its integrity.

The wall of the gut in the hepatic region is thrown into numerous sacculations throughout its entire circumference. These do not normally produce lobes of the bodywall which would be visible externally.

1 Possibly the discharge of the large eggs in the Balanoglossidae may be accompanied by rupture. 


\section{Abdominal-CaUdal transition.}

The ventral nerve-cord in the abdominal region lies at the base of a groove which comes to an abrupt termination at the junction of the abdominal and caudal regions (Pl. XXVII. Fig. 7).

The surface of the body in the caudal region is smoother than in the abdominal region, and the dermal annulations more regular.

The body-wall in the abdominal region is flaccid and highly collapsible, while the caudal region is always well distended. The rigidity of the caudal region is no doubt partly due to the circular musculature, and partly to the presence of a stout pygochord (Pl. XXX. Fig. 35). The ventral dilated edge of the pygochord consists of a cord of large cells, each with a central nucleus from whose neighbourhood radiating strands of protoplasm pass to the periphery of the cell, strongly reminding the observer of the axial cells of the tentacle of a Campanularian hydroid. Similar cells with stellate contents occur in the superjacent constrictions of the pygochord.

\section{Musculature of BoDy-wall.}

Pt. ruficollis agrees with $P t$. hedleyi Hill in the absence of circular muscles from the body-wall of the trunk except in the caudal region. At the anal extremity they combine with the muscularis of the gut-wall to form a sphincter ani.

\section{OECOLOGY.}

Pt. ruficollis lives commensally with $P t$. carnosa in so far that it inhabits the burrows of the latter. At the volcanic island of Matupi in Blanche Bay (New Britain) when one investigates the Enteropneustic castings with the aid of a spade it is almost an even chance whether one will unearth the one species or the other, although Pt. carnosa is the predominant form. At the coral islet known to the local whites as Pigeon Island and to the native blacks as Palakuvur Pt. ruficollis is the predominant form or at least it is the one which is easier to procure.

Both these species are victims of autotomy; but whereas Pt. carnosa is thick and fleshy, Pt. ruficollis is thin and brittle. 


\section{FAMILY. SPENGELIDAE.}

\section{Genus. Spengelia.}

4. Spengelia porosa Willey.

A. Willey. Spengelia; a new Genus of Enteropneusta. Q. J. M. S. Vol. XL. 1898, p. 623.

\section{Colour, Measurements and External Form.}

Proboscis, rich yellow; collar, bright orange; body, dull yellow. The distinctive feature in regard to the colour of this species is the bright orange of the collar.

The length of the proboscis, in the fresh condition, greatly exceeds that of the collar. During extension it measured up to $10.5 \mathrm{~mm}$. in length; the collar under the same conditions measured $6.25 \mathrm{~mm}$. After preservation the proboscis contrasted to $5 \cdot 25 \mathrm{~mm}$. and the collar to $4 \mathrm{rnm}$. firm.

The general shape of the body is subcylindrical and the body-wall is stout and

In the branchial region the body is quite cylindrical and faintly annulated. The diameter of the body, in this region, alike in the vertical and transverse directions, measures $5 \mathrm{~mm}$. The gill-area, i.e., the dorsal tract bounded by the branchial grooves, is long and band-like, measuring, in the living animal $30 \mathrm{~mm}$. in length. The gillpores are visible externally in each branchial groove (Pl. XXVII. Fig. 8).

Only twenty millimetres of the postbranchial genital region were present in the single available specimen, the posterior half of the body being lost.

The genital region is characterised on its dorsal side by the presence of a double series of very extraordinary dermal pits which dip down into the body for a relatively great depth. They may be defined as special intergonadial depressions of the interannular grooves of the body-wall. The mouth of each pit measures about $1 \mathrm{~mm}$. in diameter, and the pits taper towards their internal extremities which, except in the case of the most anterior pits, end blindly near the wall of the gut (Text-fig. 3).

\section{PROBOSCIS.}

All that need be noted here about the musculature of the proboscis is that the longitudinal muscles are not disposed in radial bundles as they are in the Ptychoderidae, and that the circular muscles are strongly developed. 


\section{VERMIFORM PROCESS OF STOMOCHORD.}

The stomochord is produced in front into a long vermiform process like that described by Spengel in Schizocardium and Glandiceps. This process consists of a generally solid cord of undifferentiated cells lying in the median septum of the proboscis. It is coextensive with the median septum extending with the latter through about one-third of the length of the proboscis (Pl. XXXI. Fig. 36, and Pl. XXVII. Fig. $8 \mathrm{~A}$ ). In front of the median septum the central cavity of the proboscis is an undivided well-defined space.

The vermiform process is surrounded by a stout basement-membrane but is of unequal calibre. It serves, in great part, for the insertion of the median dorso-ventral muscles of the proboscis; but often the muscular fibres pass across the centrum of the proboscis apparently without being inserted into the basement-membrane of the vermiform process.

The economic importance of the vermiform process appears to lie in its capacity for producing basement-membrane.

The dorso-ventral muscles are quite distinct in the median septum itself; but outside the latter the fibres soon appear to alter their course and are lost in the general longitudinal musculature. On the dorsal side of the median septum the fibres may be observed to pass through the aponenrosis formed by the closely felted connective-tissue fibres which surround the central cavity of the proboscis. This aponeurosis is interrupted at intervals along the ventral edge of the median septum and is never so strongly developed ventrally as dorsally (Pl. XXXI. Fig. 36).

On issuing from the median septum, the dorso-ventral muscles form, both dorsally and ventrally, two divergent bundles; and it is these bundles which farther back, bound the lateral surfaces of the dorsal ${ }^{1}$ and ventral septa of the proboscis.

At some points the vermiform process may be reduced to the basement-membrane which surrounds the axial cord of cells, no cell-elements being visible at such places.

At the bifurcation of the ventral bundles of the dorso-ventral muscles, there is a longitudinal blood-vessel which rises from the basement-membrane of the ventral epidermis about at the level of the anterior end of the vermiform process. This vessel arches upwards from its point of origin until it reaches the position just described when it runs backwards parallel with the vermiform process. It probably connects the ventral dermal vessels of the proboscis with the central blood-space although I was not able to trace its actual connection with the latter. In accordance with Spengel's nomenclature it is to be defined as the ventral recurrent dermal vessel of $S$. porosa and the characteristic feature is that it occurs entirely in front of and independent of the ventral septum of the proboscis'. The afferent dermal vessel, as in other Enteropneusta [Spengel, Mon., p. 81], occurs dorsally much farther back near the posterior end of the pericardium approximately at the junction of the dorsal truncal vessel with the central blood-space, i.e. in the nuchal region.

The aponeurosis round the central cavity of the proboscis dwindles out posteriorly in front of the glomerular region.

1 The dorsal septum of the proboseis, as already mentioned, is formed by the dorso-lateral wall of the pericardium.

${ }^{2}$ The dermal vessels of the proboscis are much clearer in the species next to be described, Spengelia alba. 


\section{Central Complex.}

The pericardium is bifurcated in front and the right and left halves of the glomerulus are likewise produced for a short distance in front of the body of the stomochord, but the pericardial auricles (Herzohren) are not long, definite structures as described by Spengel in Schizocardium but moderately developed (Pl. XXXI. Fig. 37). Of the two anterior horns into which the glomerulus is produced the left is larger and longer than the right in my preparations, and in correspondence with this condition the right pericardial auricle is feebly developed, the bulk of the pericardium and central blood-space passing over to the left division of the glomerulus. The left auricle can be traced through about half the course of the left horn of the glomerulus.

The ventral septum of the proboscis commences at the junction of the vermiform process with the body of the stomochord. The latter is somewhat flattened transversely in front and contains a multiple, interrupted lumen. In addition to the usual elongated fibre-like interlacing cellular tissue, there are numerous deeply staining gland-cells in the neighbourhood of the lumen. At some points the lumen is reduced to the merest trace and the stomochord is then, to all intents and purposes, solid.

The cavity of the pericardium contains a mass of loose cellular tissue chiefly derived by proliferation from the ventral wall. The dorsal wall of the pericardium is flat in front but soon becomes elevated into a hollow crest which meets and fuses with the basement-membrane of the epidermis shortly in front of the coecal region of the stomochord.

The character of the stomochord changes in the vicinity of the coecal dilatation. Its dorsal wall becomes elevated into a broad, rounded crest which projects into the ventral wall of the pericardium. The lumen widens out in the centre of the dorsal crest and gives off a median ventral diverticulum which forms the cavity of the thickened ventral half of the stomochord. The cavity of this so-called ventral coecum soon loses its integrity and is represented by numerous small disconnected cavities which occur between the lateral pouches of the stomochord.

The lateral pouches of the stomochord are very distinct structures. Each contains a spacious cavity lined by well-defined columnar epithelium (except mesially where the cavity is bounded by the body of the stomochord). The pouches tend to project forwards for a short distance as coecal pockets lying in a sheath of chondroid tissue. In their middle portion the lateral pouches are separated by the sub-solid body of the stomochord; but more posteriorly their cavities communicate transversely, thus forming the posterior portion of the ventral coecum which projects backwards into the cupule of the nuchal skeleton (cf. Pl. XXXI. Fig. 38).

\section{Nuchal Skeleton.}

The ventral proboscis-canals come to an end posteriorly in the chondroid tissue, without fusing together. This is another of the many points in which Spengelia shows relationship to Glandiceps. By their ending in this manner they make way for the enormous keel of the nuchal skeleton. Thus their behaviour in this species is the exact converse of what has been described above for Pt. flava. The large keel and 
the intimate relation between the substance of the nuchal skeleton and the chondroid tissue, are the salient features in the nuchal skeleton of this species (Pl. XXXI. Fig. 39). The cornua of the skeleton, as already mentioned in the classification, extend to the posterior region of the collar (Pl. XXVIII. Fig. $1 d$ ). The keel diminishes posteriorly, ceasing entirely some distance in front of the point of bifurcation; the body of the skeleton has then (i.e. behind the keel) a cubical shape with rounded edges.

\section{Proboscis-PORE.}

The right dorsal canal ends blindly, while the left communicates with an endvesicle which opens to the exterior by a narrow pore on the left side (Pl. XXXI. Fig. 39). The pore is very long, slit-like and approximately co-terminous with the end-vesicle; in both of which features the present species differs from S. alba. The right canal has a narrow dorsal canalicular extension corresponding to the place where it would communicate with an end-vesicle, were one present on that side. In the vicinity of the point of communication between the left canal and its end-vesicle, there are muscular fibres about the base of the vesicle which appear as if they would act as a sphincter.

\section{COLLAR.}

\section{Collar Nerve-Cord.}

The medulla of Spengelia porosa does not contain a continuous central canal but a large number of small disconnected medullary cavities arranged quite irregularly $(\mathrm{Pl}$. XXXI. Fig. 41).

The anterior neuropore leads into a broad, transverse, median lumen which soon gives place to a series of lateral cavities at each side of the nerve-cord. In addition to these lateral cavities there are other smaller cavities scattered about in the substance of the cord. Here and there cavities seem to be entirely absent and the cord at such places appears quite solid in section.

In the neighbourhood of the medullary cavities there occur numbers of deeply staining mucous cells, not unlike those found in a similar position in relation to the fragmented lumen of the stomochord.

The nerve-fibre layer is confined to the ventral side and to the lateral margins of the cord, but is absent from the median dorsal tract.

The collar cord of the present species is remarkable for the presence of at least one vestigial root. It is no new thing for a root not to reach the epidermis but it is new for it to behave as it does in S. porosa (Pl. XXXI. Figs. $40 a-40 \mathrm{c}$ ).

The vestigial root which claims special attention occurs in the region of the bifurcation of the nuchal skeleton. It arises from the non-fibrous dorsal side of the cord slightly to the right of the middle line. It bends first to the right and then runs forward for an appreciable distance, without however reaching the basement-membrane of the epidermis. On the contrary, it abuts upon and terminates in a relatively dilated vesicle, the walls of which are crowded with some mucoid substance W. III. 
which stains black with haematoxylin. The end-vesicle of this vestigial root would in fact seem to be in a condition of mucoid degeneration. The root itself contains a well-marked, though interrupted vestige of an axial canal, which however does not communicate with any of the medullary cavities of the cord, although immediately behind and at the base of the root there occurs a comparatively large medullary cavity.

The posterior portion of the collar nerve-cord, like the anterior, contains a broad continuous lumen and it is at the commencement of this posterior lumen that a low hollow pouch-like diverticulum arises to the right of the middle line. It is quite short and does not appear in section separate from the nerve-cord. It is open to anyone to regard this structure as a second vestigial root, to which, however, no special interest attaches.

\section{Peripharyngeal Cavities.}

In my preliminary diagnosis of this species I stated that there were no peripharyngeal cavities. Having since been so fortunate as to obtain a second species of the genus, my examination of it led me to re-investigate $S$. porosa in respect of this quality and I find that there is a pair of peripharyngeal cavities in a vestigial condition.

Their vestigial nature is clearly established by the fact that they are closed behind as well as in front and thercfore do not communicate with the body-cavity of the trunk.

In Schizocardium, Spengel has shown that the right and left peripharyngeal spaces are triangular in shape, the apex of the triangle being directed forwards and reaching to the level of the point of bifurcation of the nuchal skeleton; the base of the triangle lies at the posterior end of the collar where the cavity enters into free communication with the truncal coelom.

This condition is indeed met with in Spengelia alba n. sp. In the present species, however, the peripharyngeal cavities are pointed at both ends, sharply pointed in front and bluntly behind. The anterior extremity reaches to a point shortly behind the level of the bifurcation of the nuchal skeleton. As the cornua of the latter divaricate, the dorso-ventral extension of the peripharyngeal cavity (on each side) increases, until a maximum is reached in the mid-region of the collar. Then reduction commences; the dorsal edge of the cavity, which is always separated by an interval from the edge of the perihaemal cavity of its side, recedes further and further from the vicinity of the latter, the ventral extension of the cavity becomes likewise reduced until the entire cavity ceases some distance in front of the termination of the nuchal skeleton. The posterior end of the cavity lies against the throat-epithelium half-way between the dorsal and ventral sides of the latter (Pl. XXXI. Fig. 44).

\section{Collar-coelom and Pores.}

There is no dorsal septum in the collar, except the fold of basement-membrane associated with the first vestigial root, which is probably to be regarded as a vestige of the dorsal septum. On the other hand, the ventral septum has an unusual forward 
extension, commencing a short distance behind the region of bifurcation of the nuchal skeleton; it is a much folded membrane containing blood-spaces.

The collar-canals have the usual semilunar funnel opening into the posterior dorsal portion of the collar cavity. The ciliated columnar epithelium of the canals has a striated inner portion free from nuclei, and a basal two-thirds, with densely crowded nuclei which stain nearly black with ordinary haematoxylin. The dorsal wall of the canals is lightly plicated, but there is no definite tongue-like fold such as occurs in many other species (Pl. XXXI. Fig. 42).

\section{Perihaemal Cavities and Canals.}

The perihaemal cavities, as is known, are prolongations from the truncal coelom into the collar. In Spengelia, as in all Enteropneusta except the Ptychoderidae, they contain transverse muscles below the longitudinal muscles. Their most noteworthy feature in S. porosa, however, is die to thc presence of a pair of canals, analogous to the collar canals, which open like the lattcr, into the first pair of gill-pouches from which they are derived (Pl. XXXI. Fig. 44). These structures also occur in S. alba, n. sp. In the present species they lie imbedded in the spongy connective-tissue which is abundant in the posterior region of the perihaemal cavities. They are long canals, and perfectly definite, and I knew of their existence long before realising their probable significance. Their epithelium is of a spongy nature, and contains mucous cells. The lumen is to a large extent occluded in my preparations, so that it is not possible to assert positively that these canals open into the perihaemal cavities. The latter are cavities only in name, being filled up by muscular and connective tissue, so that there could hardly be an effective opening into the cavities. Nevertheless in the following species which I have to describe, the conditions are more favourable for observation, and there is more reason to suspect the existence of an internal pore in that case.

In the present species, at least in the adult, my impression is that these structures are not of great functional importance, they are in fact vestiges of a former coudition of which we know nothing definitely. I regard them as truncal pores homodynamous with the collar pores and the proboscis pores, and the true homologues of the atrio-coelomic funnels (brown funnels) described by Lankester in Amphioxus. These latter structures have fallen into desuetude phyletically, since the evolution, and historically since Boveri's discovery, of the nephric tubules ${ }^{1}$.

\section{Splanchnic layer of Nerve-fibres.}

There is a well-defined layer of "Punktsubstanz" at the base of the throat epithelium. It is thicker in front than behind. It also occurs at the base of the epithelium of the cesophageal portion of the pharynx.

Spengel has also described such "Punktsubstanz" in places where one might not have expected to find it. I have seen it at the base of the branchial epithelium of the septal bars in Pt. flava.

\footnotetext{
1 For further remarks, see below p. 310 et seq.
} 


\section{TRUNK.}

\section{Branchial REgron.}

The present species is characterised by the presence of a paired series of medial gonads, mediad of the branchial grooves, in addition to the main lateral series (Pl. XXXI. Fig. 45).

This is a feature which it possesses in common with the genus Glandiceps; while the fact that the branchial bars are united together by synapticula or crossbars (of which there are about ten in a vertical row) removes it from Glandiceps and approximates it to Schizocardium and the Ptychoderidae.

It is a fact of topographical interest which is exhibited in horizontal sections through the pharynx-such sections cutting the gill-bars transversely-that whereas in the entire genus Ptychodera, the tongue-bars project into the cavity of the pharynx beyond the septal bars, in Spengelia these relations are reversed, the septal bars projecting into the pharynx beyond the tongue-bars. In other Enteropneusta the conditions appear, judging from Spengel's figures, to differ according to the species.

The lateral gonads appear in section at the level of the first gill-pore, but the first genital duct occurs at the level of the fourth gill-pore; the medial gonads commence at the level of the fourth gill-pore. The genital ducts of the lateral series open at the outer sides of the branchial grooves, while those of the medial series open at the inner sides of the grooves. Apart from the medial genital ducts there are no accessory ducts in the branchial region. Mediad of the lateral ducts may be found a lateral (genital) blood-vessel.

The gut in the branchial region is provided with a well-developed lower œsophageal portion in the form of a deep groove, and the parabranchial ridges are nearly as definitely demarcated as in the Ptychoderidae.

The circular musculature of the body-wall is internal to the longitudinal musculature, instead of being external as it is in the Ptychoderidae; it agrees in its disposition with that described by Spengel in Glandiceps, namely, the fibres arise at the peripheral margins of the dorsal and ventral septa, and pass between the dorsal and ventral sides of the body applied to the inner surface of the longitudinal musculature, the muscularis of the gut being independent of the dermal musculature. In Schizocardium, Spengel has shown that the muscularis of the gut, at least in the branchial region, is derived from the dermal musculature.

\section{Genital Region.}

This region is characterised on the dorsal side by a right and left series of very remarkable dermal pits which dip deep down between the gonads and actually penetrate to some degree amongst them. They probably serve for the irrigation of the gonads, as suggested in my preliminary account of this species, and in this capacity are to be compared physiologically with the subgenital pits of Discomedusae, and the funnel-like depressions of Lucernariidae. 
The dermal pits of this species are so deep that they extend through more than half the thickness of the body as shown in Text-figure 3. They lie in the

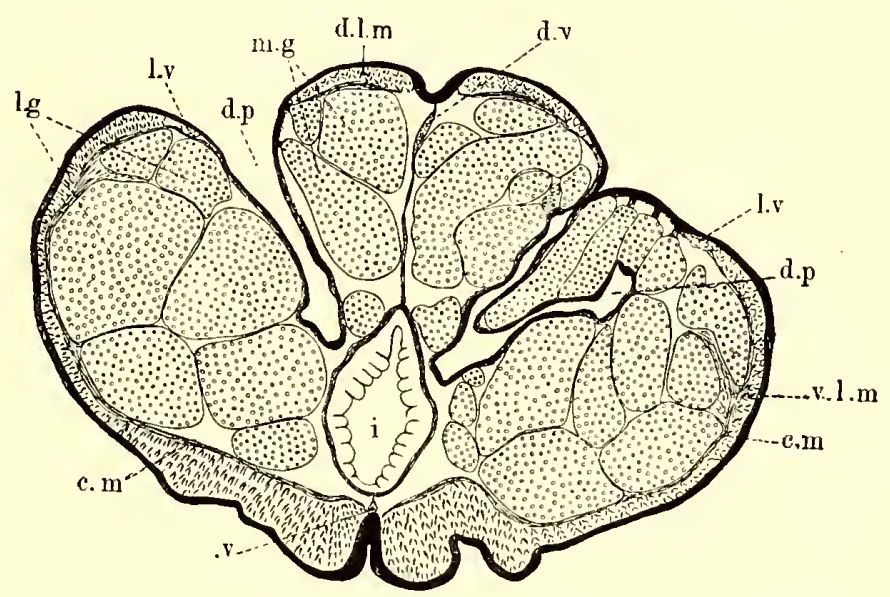

Fig. 3. Transverse section throdgh genital region of Spengelia porosa showing deraial pits and pores.

On the left of the figure a dermal pit is cut through the middle of its external orifice; on the right it is cut tangentially.

c.m. Circular muscles. d.l.m. Dorsal longitudinal muscles. d.p. Dermal pits. d.v. Dorsal vessel. l.g. Lateral gonads (accessory genital ducts shown on the right). l.v. Lateral vessel. m.g. Medial gonads. v. Ventral vessel. v.l.m. Ventro-lateral longitudinal muscles.

submedian line, in direct continuation from the branchial groove on each side. They are roughly but not exactly paired, no more than are the gill-clefts themselves. The mouth of each pit is about $1 \mathrm{~mm}$. in diameter. The most anterior pits invade the posterior extremity of the branchial region, in consequence of which a number of the outer pores of the posterior gill-slits do not open near the surface of the body, but deep down at the base of the dermal pits. Apart from their connection with the gut by means of the posterior gill-slits, the dermal pits do not communicate with the intestine, although they extend very near to the wall of the latter.

In the fresh condition the sides of the genital region were occupied by elongated, somewhat pyriform bodies, which caused definite ridges on the external surface. These projections were caused by the gonads.

In the genital region accessory genital ducts occur both laterally and medially from the dermal pits, so that several may be met with in a single transverse section. The accessory pores of the lateral gonads do not perforate the longitudinal musculature, but all occur within the interval, which is a very wide one, between the dorsal longitudinal musculature, and the upper margin of the ventro-lateral longitudinal muscles (Textfigure 3).

The post-genital portion of the body was lacking from the single specimen which was available for microscope examination. The individual was a mature male. 


\section{OECOLOGY.}

I found this species in company with Pt. flava in rock-pools, which contained sand between the tide-marks on the weather side of Lifu. I had two specimens, only one of which was available for cutting into sections, the other was overlooked until my arrival home, when it was found to be macerated, but not useless (see Pl. XXVII. Fig. $8 a$ and Pl. XXVIII. Fig. 1d).

My former account of Sp. porosa (loc. cit.) was illustrated by a sketch drawn from the living animal which showed the dermal pits in the genital region in dorsal view. These pits introduce us to a new category of structures in the Enteropneusta.

Besides the truncal canals of Spengelia there is another ancient structure which occurs in the Spengelidae and nowhere else among the Enteropneusta. I refer to the vermiform process of the stomochord. Apart from what is stated near the end of this memoir I shall not attempt to offer an explanation of this organ, although I believe one is possible. Suffice it to say that, for my part, I am convinced that the vermiform process is to be regarded as an integral constituent of the stomochordal complex, but that it has only been retained by the members of this family. As I have just intimated, I think it is possible to arrive at the probable approximate explanation of the vermiform process, but it would be difficult, at present, to make it convincing. 


\section{Spengelia alba n. sp.}

\section{Colour, Measurements and External Form.}

This species is remarkable on account of its almost uniformly dull white colour. During life the proboscis and collar were opaque white; the anterior free portion of the collar was plain white, and was followed by a watery white zone; then came a white ridge, followed by another watery white zone, which was separated by the usual circular groove from the posterior white band of the collar. In the hepatic region there were green and brown tints.

The proboscis when extended attained a length of $10-11 \mathrm{~mm}$. (after preservation $8 \mathrm{~mm}$.), and was cylindrical in shape. The collar under the same conditions attained a maximum length of $6.5 \mathrm{~mm}$. (after preservation $4 \mathrm{~mm}$.).

Behind the branchial region the trunk appeared to have a ventral curvature impressed upon it, and the ventral side of the body in the hepatic and abdominal regions was distinctly carinate, the median tract being marked off, on each side, by a deep longitudinal groove, from the rest of the body (Pl. XXVII. Fig. 9).

The branchial region, $18 \mathrm{~mm}$. in length, is characterised by the elongated, even, band-like gill-area. The body in this region has a transverse diameter of $3.5 \mathrm{~mm}$., and a vertical diameter of $4.5 \mathrm{~mm}$. The entire body of the animal may be described as long and slender.

The genital region, $25.5 \mathrm{~mm}$. in length, is characterised externally by the presence of dermal pits which are very similar in superficial appearance to the corresponding structures in S. porosa; but in section they are found to be much shallower.

The hepatic region, characterised by its green and brown coloration, had according to my notes a length of $14-15 \mathrm{~mm}$. The effect of preservation was to cause this region to lengthen rather than to contract and in the preserved condition I should put the length of it as nearer $20 \mathrm{~mm}$. There are no external liver saccules although, when fresh, the annular ridges were found to be turgid and to present the appearance of rudimentary saccules, an appearance which was almost entirely lost after preservation. Nevertheless even in the spirit specimen some of the dorsal annular ridges of the anterior portion of the hepatic region tend to be more pronounced than the ordinary ridges.

The hepatic region is above all characterised by the presence on each side of the body of a smooth glandless epidermal tract lying nearer to the ventral than to the dorsal side of the body. It commences in front, at the posterior end of the genital region as a wide area quickly narrowing down to a narrow streak, which widens out again to a breadth of about $1.25 \mathrm{~mm}$. in the mid-hepatic region. From the region of maximum breadth it gradually narrows down posteriorly and is continued for some distance into the abdominal region (Pl. XXVII. Figs. $9 \mathrm{~B}$ and $9 \mathrm{c}$ ).

In the fresh state I observed brown loculi showing through this ventro-lateral tract in its wide portion, due presumably to the local turgidity of the gastral wall. 
There is no such glandless tract over the greater part of the abdominal region (60 mm. in length), but its place is taken on each side by a shallow groove which is not associated with absence of glandular ridges. The effect of these grooves is to raise the median ventral tract into a prominent rounded keel. The caudal region (about $14 \mathrm{~mm}$.) is slightly swollen and is only distinguished externally by the flattening out of the above-described grooves and the consequent absence of a ventral keel.

\section{PROBOSCIS.}

The central cavity is sharply defined and extends nearly to the tip of the proboscis. Anteriorly it is surrounded by a uniform layer of felted fibres and it is difficult to distinguish the dorsal and ventral sides of the cavity. Farther back the decussation of the fibres denotes the dorsal side. But from the extreme front end of the proboscis the ventral middle line is defined by the presence of the ventral recurrent vessel which lies immediately inside the layer of circular muscles and communicates at frequent intervals with the epidermal system of blood-vessels (i.e. the blood-spaces in the basement-membrane of the epidermis) by perforating the circular musculature. A similar recurrent vessel is present in $S$. porosa, where it rises up to a more dorsal position below the vermiform process. In the present species the recurrent vessel retains its ventral position adjacent to the circular musculature until it passes up along the free edge of the ventral septum (Pl. XXXI. Figs. 46-47).

The dorsal recurrent dermal vessel runs, as is its wont, along the anterior edge of the pericardium in front of which its distal portion forms a vascular complex. (Pl. XXXI. Fig. 47).

The circular musculature of the proboscis is generally thicker than the nervous layer of the epidermis.

The vermiform process of the stomochord is of varying calibre and in its anterior portion there is, in one or two places, an actual discontinuity, as if a certain amount of fragmentation had taken place. It is solid and its cells are undifferentiated in the anterior two-thirds, becoming vacuolar as the body of the stomochord is approached. The vermiform process is supported in the thin median septum of the proboscis, and the dorso-ventral muscles are inserted into the basement-inembrane surrounding it (Pl. XXXI. Fig. 46). The vermiform process passes quite gradually into the body of the stomochord and it is impossible to say where one begins and the other ends.

The pericardial auricles are very minute, almost non-existent, but the glomerulus projects beyond the anterior limit of the pericardium for a moderate distance as paired glomerular horns at the sides of the stomochord.

The ventral septum has a forwardly directed free edge and does not extend to the base of the vermiform process or to what might be considered as such but falls somewhat behind the anterior legion of the main body of the stomochord.

In the coecal region of the stomochord the lateral pouches are extremely wellmarked and tend to project slightly forwards as independent pouches. Unlike S. porosa, their cavities do not communicate across the middle line but remain separate until 
they die out (Pl. XXXI. Fig. 48). Other minute cavities or vestiges occur in the body of the dilated stomochord in addition to the main lumen, which is also interrupted.

The ventral canals terminate in the chondroid tissue without communicating with each other, as in Glandiceps.

Of the dorsal canals only the left communicates with an end-vesicle which is sinistral in position (not quite median) and opens by a short narrow sinistral pore to the exterior (Pl. XXXI. Fig. 49). Behind the proboscis-pore the basement-membrane surrounding the vesicle closes in once more and the end-vesicle is continued for a relatively long distance (about $100 \mu$ ) as a coecal tube, the posterior end of which actually projects into the anterior end of the left perihaemal cavity (Pl. XXXI. Fig. 50).

The prae-trematic, post-trematic and trematic behaviour of the end-vesicle of the proboscis canals is of the very greatest importance to anyone willing to penetrate into the morphological tangle surrounding these structures. The post-trematic prolongation of the end-vesicle of $S$. alba is therefore worthy of particular note as being one of the most striking characters of the species.

The nuchal skeleton resembles that of $S$. porosa in the main. Its principal characters are sufficiently shown in the figures to obviate a detailed verbal description (Pl. XXXI. Figs. 49-51).

\section{COLLAR.}

Not only is the collar musculature (inner longitudinal muscles and perihaemal muscles) projected into the neck of the proboscis but the anterior neuropore also occurs at the posterior end of the nuchal region and is independent of the duplicature of the collar (Pl. XXXI. Fig. 51). In most other species the two structures coincide (see below p. 304). The central canal leading backwards from the neuropore only extends for a short distance, after which the medullary cord is nearly solid, with numerous disconnected vestiges of medullary cavities mostly ill-defined. There may be distinguished two main lateral series of cavities with irregular intervening vestiges. The posterior central canal leading to the posterior neuropore is much longer and more capacious than the anterior canal. There are no roots of any kind.

The dorsal septum extends to the anterior end of the collar nerve-cord appearing immediately behind the anterior neuropore and joining the cord with the basementmembrane of the epidermal involution which is associated with the collar-duplicature (Pl. XXXI. Fig. 51). Posterior to this involution the septum is present but does not reach the epidermis until the level of the buccal orifice of the stomochord is reached, after which its course is uninterrupted to the posterior end of the collar.

The collar canals have the usual semilunar funnel behind which the dorsal wall is invaginated into the lumen of the canal. The dorsal plication is characterised by its tenuity due to the low cells composing it; the remaining walls of the canals consist of high columnar epithelium. The canals opeu into the first gill-pouch in the normal manner.

1 The perihaemal cavities project forwards for a short distance into the neck of the proboscis. W. III. 
In the region of the collar funnels there is a pair of remarkable tubes lying in the perihaemal cavities and opening like the collar canals into the first gill-pouch. These are in fact perihaemal, i.e, truncal canals analogous to, and in all probability homodynamous with the collar canals (Pl. XXXII. Fig. 52).

As a rule, as mentioned above, the perihaemal spaces do not contain cavities since they are quite filled up with muscular and connective tissue. In the present species however, while the perihaemal tracts are solid in their anterior two-thirds, posteriorly they develop a cavity which lies between the longitudinal and transverse muscles of the perihaemal coelom (Pl. XXXII. Figs. 52-54). This in itself is an interesting fact, but it becomes still more interesting when, on tracing the cavity backwards, the reason for its existence comes into view in the form of a genuine, canalicular extension of the first gill-pouch into the perihaemal coelom on each side. According to Spengel, the collar canals themselves appear to arise as canalicular extensions of the first gill-pouch, and, so far as I can gather, the observations of Bateson and Morgan do not run counter to this view, in essentials.

The truncal canals are smaller both in calibre and in extent than the collar canals and they are not provided with semilunar funnels, and I am not prepared to assert positively that they open into the perihaemal cavities (see, however, Pl. XXXII. Figs. 53-54). But in their quality of canals they are absolutely definite and so far as is known are peculiar to the genus Spengelia. No truncal pores have hitherto been described in Enteropneusta, and it is safe to add that none exist in previously known species.

That they existed at one epoch seems likely enough. We have already seen, in the species described in this paper, how that vestiges of different structures crop up in different species.

One species may possess the vestige of a certain structure and another allied species may be without it. It is not probable that truncal canals are essential to one genus and non-existent in any other.

For such reasons as the above I regard the truncal canals of Spengelia as being functionally in a vestigial condition and comparable in this and in other respects with the atrio-coelomic funnels described by Lankester in Amphioxus.

The peripharyngeal spaces of $S$. alba commence anteriorly as in $S$. porosa, but they do not end blindly behind as in the latter, neither do they communicate with each other across the ventral middle line; each space passes separately into the trunk coelom, as in Schizocardium (Spengel).

The ventral septum only occurs in the posterior. region of the collar, commencing a short distance (nearly half a millimetre) in front of the posterior termination of the cornua of the nuchal skeleton.

\section{TRUNK.}

\section{Branchial REgion.}

The gill-pores of the first pair open coincidently with the posterior neuropore, perforating the posterior commissure of the collar. 
The epibranchial band is markedly cristate, the epithelium being thickened in the median line; on the inner surface of the band there is a shallow median longitudinal groove opposite to the crest. The groove flattens out and the crest becomes broader at intervals corresponding with the breadth of a gill-cleft.

The gill-bars are only slightly arcuate. At the medial dorsal angle of every gillpouch there is a very small diverticulum (Pl. XXXII. Fig. 55). This minute diverticulum of the gill-pouch occupies a position corresponding to that of the large truncal canals described above. It is of course not peculiar to this species, but is particularly well-defined here. It is in such a position that the nephric tubules occur in Amphioxus; and it is possible that at the dorsal angles of the gill-pouches of Enteropneusta we have the makings or the primordia of nephric tubules.

The first gonad on the right side is quite unripe, and I am unable to say whether it is in an incipient or in an arrested state of development; it is connected with the ectoderm between the gill-clefts $\mathrm{V}$ and VI.

The second gonad is fully formed and contains ripe spermatozoa; its duct occurs between VII and VIII; the third genital duct is between VIII and IX, and so forth. On the left side there is no unripe anterior gonad like that on the right; the first duct is between VI and VII, the second at the level of VIII, the third between IX and $\mathrm{X}$, and so on.

I have estimated that there are approximately 80 gill-pores on each side. Each half of each gill-cleft is traversed by 10-11 synapticula.

The branchial groove commences in front as a narrow sulcus which gradually widens out posteriorly so that the gill-pores are plainly visible with a simple lens (Pl. XXVII. Fig. 9 A). At its hinder end the groove is as much as $75 \mathrm{~mm}$. in breadth; the gill-pores lie close against the submedian ridge leaving a smooth epidermal tract to form the floor of the branchial groove between the line of pores and the upper margin of the lateral annulations.

\section{Branchiogenital Transition and Genital Region.}

Behind the branchial region the branchial groove is continued into the genital region, not however as a continuous groove but as an interrupted groove traversed by dermal bridges. In this way there is produced the appearance of a series of dermal pits which, as already noted, present externally the same aspect as the dermal pores of $S$. porosa with which they are evidently homologous, though they are much shallower than the latter (Pl. XXXII. Fig. 59). There are upwards of 25 of these dermal pits on each side (Pl. XXVII. Fig. 9).

In the branchial region there are no medial gonads, i.e. no gonads mediad of the gill-pores, and in the anterior moiety of this region the gonads form a simple lateral series on each side. In the posterior part of the branchial region where the branchial groove widens out, as described above, accessory gonads begin to appear in the space which lies between the main series of lateral gonads and the gill-pores. There may be as many as three accessory gonads in one plane, but they are irregular 
in their distribution. Accessory gonads may be observed in various stages of formation, and they certainly appear, in this case, to have an ectodermal origin, being, so far as one can see, primarily in connection with the epidermis.

Bateson also thought it possible that the gonads were ectodermal in origin, while Spengel considered it probable that the germ-cells arise in the first instance in the mesenchyme. Morgan" states that "the gonad is formed from the mesoderm." It seems not impossible that the gonads of the primary series may have a different origin from the accessory gonads when the latter can be shown to be distinct neoformations, as in the present species.

The last gill-slits are quite dorsal in position (Pl. XXXII. Fig. 56) and are followed by a tract comparable to the postbranchial canal of species of Ptychodera but not so well-defined.

The dorsal submedian dermal tract below which the accessory gonads occur is characterised both in the posterior branchial and in the genital regions by the attenuation of the subjacent muscular layers. The circular muscles are not interrupted but pass continuously across the tract; the longitudinal muscular bundles are distinctly interrupted, but at the same time straggling fibres are present in greater or less numbers in the tract intervening between the dorsal and the ventro-lateral longitudinal musculature; so that the accessory genital ducts in this species may be said to perforate the longitudinal musculature.

\section{Genito-hepatic Transition.}

This crucial region is characterised in the present species by the occurrence of intestinal canals and pores (Darmpforten of Spengel). Although there are nine pores on each side they occupy a very short tract of the body because they tend to overlap (Pl. XXXII. Fig. 57).

They lie in the submedian tract, i.e. in the line of the gill-pores, although separated from the latter by the whole length of the genital region; their superficial resemblance to the last two or three pairs of gill-clefts is very striking.

Each canal consists of an ectodermal involution which meets and fuses with an outgrowth of the wall of the gut. The lumen of the canal appears more virtual than actual (like that of the genital ducts).

The first pore lics close against the submedian ridge and the succeeding pores occur more and more lateral to this point until a maximum lateral deviation is attained; then the remaining pores successively approach once more the submedian ridge until the last pore is in the same line with the first. The line of pores thus describes an arc which is not in any way due to muscular contraction but is a genuine anatomical feature. The pore-tract occurs at the posterior end of the genital region immediately preceding the hepatic region. It lies a few millimetres in front of the point denoted by an asterisk in Pl. XXVII. Fig. 9, in fact it lies almost in the middle of the sharp curvature which intervenes between the mid-hepatic region (denoted by the asterisk) and the posterior dermal pits shown in the figure. The pore-tract

1 T. H. Morgan, "The development of Balanoglossus," Journ. Morph. Ix. 1894. See p. 60. 
may be still further defined as occurring at the level of the anterior dilated end of the ventro-lateral glandless epidermal tract shown in Figures $9 \mathrm{~B}$ and $9 \mathrm{c}$ on Pl. XXVII.

Similar pores, in varying numbers, occur in the same region in Bal. mereschkowskii (Schimkewitsch), Bal. kowalevskii (Spengel), Sch. brasiliense (Spengel) and $G l$. hacksi (Spengel). In addition to these paired pores belonging to the posterior end of the genital region Spengel has described a number of similar structures following close behind the branchial region, i.e. at the anterior end of the genital region. These anterior pores may be either paired or unpaired and have been found by Spengel in Sch. brasiliense, Gl. hacksi and Gl. talaboti.

Although generally limited in distribution, in the last-named species they occur in 9 groups distributed at unequal intervals over the anterior four-fifths of the long genital region.

In Sp. alba the intestinal canals are not provided with a special ring-shaped thickening of basement-membrane such as Spengel has described in Bul. kowalevskii, nor with a sphincter muscle such as occurs in Sch. brasiliense. I have not found any pores other than those here described at the posterior end of the genital region.

Having now become personally acquainted with these remarkable structures, I agree with Schimkewitsch ${ }^{1}$, who was the first to record their existence, in regarding them as vestigial gill-clefts (see below p. 298).

The hepatic region follows immediately behind the intestinal canals. It is characterised by the presence of internal hepatic saccules having essentially the same topographical relations to the wall of the gut as the hepatic saccules of the Ptychoderidae and Schizocardium, but they are quite internal and are not associated with permanent external sacculation of the body-wall. This is all the more striking because the internal saccules are of large size and perfectly definite; a fact which serves to distinguish this species, and perhaps the genus, from other Enteropneusta.

Although no dermal elevation (or at most a slight arching) accompanies the hepatic saccules we nevertheless find remarkable intersaccular involutions of the epidermis, the walls of which sometimes present complicated corrugations (Pl. XXXII. Fig. 58).

The occurrence of these intersaccular epidermal involutions would seem to indicate that the external hepatic saccules of the Ptychoderidae are not merely due to the mechanical effect of the hepatic diverticula causing elevations of the skin but have a more fundamental physiological causation. Because it seems probable that the involutions in question are related to the intersaccular, i.e. interannular intervals in the Ptychoderidae.

If, as I believe, the Ptychoderidae are relatively primitive, we ought to find vestiges of their hepatic saccules in less primitive forms, and from this point of view we might regard the internal saccules and intersaccular involutions of Spengelia as such vestiges.

The ventro-lateral epidermal tract shown in Plate XXVII. Fig. 9 B, 9 c has been referred to above. It is characterised in general by the absence of gland cells and by low cubical or flattened ectoderm similar to that which forms the floor of the dermal

1 W. Schimkewitsch, "Über Balanoglossus mereschkowskii Wagner," Zool. Anz. xi. 1888, p. 280. 
pits. In fact, in section, it appears as a replica of the dorsal submedian tract. Below it the layers of longitudinal muscles is thinner than in the neighbouring tracts and posteriorly this layer thins out almost entirely at this place (Pl. XXXII. Fig. 58). Opposite to the glandless epidermal tract a tract of thickened columnar intestinal epithelium may be observed at the region of the hepato-abdominal transition.

Throughout the entire length of the hepatic region there is a pair of large lateral splanchnic vessels lying against the wall of the gut at the outer base of the internal hepatic saccules and at a corresponding level in the anterior abdominal region (Pl. XXXII. Fig. 58). They occupy the position in which a large vessel is often to be seen in Ptychodera flava (and doubtless in others) at the base of the lateral septum (cf. Pl. XXIX. Fig. 13). In the Spengelidae there is no lateral septum. A similar pair of vessels has been described by Spengel in Sch. brasiliense, Gl. hacksi and Bal. kowalevskii (Spengel, Monograph, p. 575).

\section{Caudal Region.}

The caudal region of $S$. alba has no very striking characteristics. The longitudinal muscles become feeble and the circular muscles do not suffer any change, there being no special sphincter round the anal opening. There is no band-like or keelshaped pygochord, but the median ventral epithelial tract of the hind-gut consists of enlarged columnar cells with clear vacuolar contents; it is therefore no doubt to be regarded as a pygochord which has retained its epithelial position in the wall of the gut (Pl. XXXII. Fig. 60).

\section{OECOLOGY.}

The complete unique male specimen which I obtained of this specimen was taken by me from a submerged hillock of sand (resembling a truncated mole-hill) at low water off Vulcan Island (Rakaiya) Blanche Bay, New Britain. It broke itself into three pieces but nothing was lost. The species appeared to resemble $S p$. porosa in its mode of life. It is not a burrowing species like $P t$. carnosa, but lives in the superficial loose layers of (volcanic) sand like Sp. porosa and Pt. flava.

On account of the length of the proboscis one might suppose, from its external characters, that it was a Balanoglossus s. str. It was quite alone although Pt. carnosa occurs in the same locality. 


\section{TORNARIA.}

A Tornaria which I obtained in the tow-net in Blanche Bay and off the small coral island (Pigeon Island) referred to above, belongs to the group of Tornariae in which the longitudinal ciliated bands are drawn out into tentacular processes.

Spengel calls all such tentaculated Tornariae T. grenacheri, and speaks of their circumtropical distribution (circumterrane Verbreitung) since they have been found in the tropical regions of all the great oceans, Atlantic, Indian and Pacific.

Spengel does not speak in terms of absolute certainty as to the identity of all the forms designated by the common name T. grenacheri, but gives it as his impression that they are so. In this impression I think he is certainly in error. The name $T$. grenacheri obviously implies that the forms included under that name are the larvae of one species of Enteropneusta. As a matter of fact there is reason for supposing that Tornaria does not voluntarily migrate far from the habitat of its parent, those which are found at great distances from home having been carried away by currents and doomed to destruction ${ }^{1}$. An instructive example of this is furnished by Agassiz' Tornaria ( $T$. agassizii Spengel) which is sometimes taken off the coast of Massachusetts, and was thought to belong to the Balanoglossus (B. kowalevslii) which occurs on the same coast, until Morgan ${ }^{2}$ showed that the latter had a direct development and was in fact identical with the species whose development had been worked out by Bateson.

T. agassizii very possibly belongs to Pt. aurantiaca and is liable to be carried up north by the Gulf Stream.

Pt. biminiensis n. sp. (see below), whose development has been studied by Morgan, possesses a Tornaria of the tentaculated type.

From the small size of the egg it is, I think, quite certain that all Ptychoderidae develop indirectly with a Tomaria larva, and it is probable that the Spengelidae do the same ${ }^{3}$. On the contrary there is no room for legitimate doubt, in consideration of the size of their eggs, that all Balanoglossidae develop directly without a Tornaria.

The Tornaria from New Britain which is here figured most probably belongs either to Pt. carnosa or to Pt. ruficollis, but it is impossible to say which, because, although I obtained at least one specimen immediately after the metamorphosis, it is notoriously impossible to identify newly metamorphosed larvae of Enteropneusta.

No doubt the differences between the Tornariae of some species are very trifling, but it is a great mistake to imagine that all tentaculated Tornariae belong to one species.

1 This has also been found to be the rule for Echinoderm larvae (Th. Mortensen, Die Echinodermenlarven der Plankton-Expcdition, 1898).

2 T. H. Morgan, "Balanoglossus and Tornaria of New England," Zool. Anz. xv., 1892, p. 456.

3 The diameter of the ripe eggs of Glandiceps hacksi is about $1 \mathrm{~mm}$. (Spengel). 
Among the external points of difference between my Tornaria and the T. grenacheri figured by Spengel may be mentioned those connected with the position of the
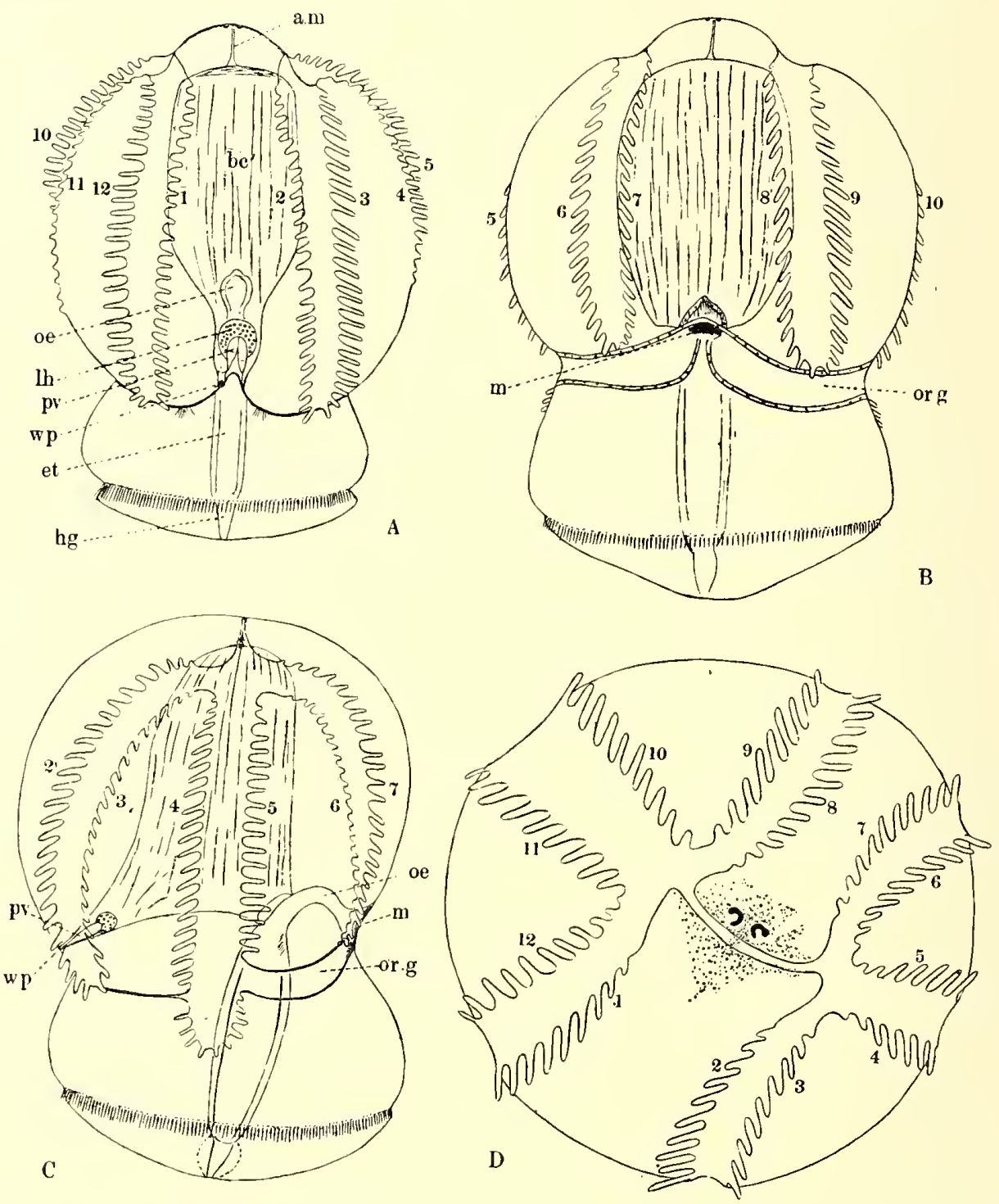

Fig. 4. Tentaculated Tornaria from Blanche Bay, New Britain. Drawn from living larva (January 1895 ) $\times$ about 12. Seen in dorsal view in $A$, ventral in $B$, lateral in $C$, and apical in $D$. The numbers serve for the identification of the ciliated bands in the different views. The eyes in $D$ are seen to lie within the limits of the ventral area bordered by the ciliated band. In other species they tend to lie centrally between the dorsal and ventral areas.

a.m. Apical muscle-band. $b c^{\prime}$. Anterior body-cavity. et. (for st.) Larval stomach. hg. Hind-gut (which contracts and expands as in $C$ ). $l h$. Larval heart (central blood-space). $m$. Mouth. oe. Larval oesophagus (to which the anterior body-cavity adheres at two points). or.g. Oral groove. $p v$. Pulsating vesicle (Pericardium, Herzblase). Note its $\wedge$-shape. wp. Water-pore (Sinistral proboscís-pore). 
eyes and the inferior dorsal lobe of the ciliated band (Text-figure 4). In my Tornaria there is no such sharply defined lobe, but a groove passes continuously round from the lateral lobe of the ciliated band across the dorsal middle line. This groove is overhung by the anterior body of the Tornaria, and appears in fresh surface view as little more than a line.

In Morgan's Tornaria the dorsal edge of the lateral lobe is entire, there being no inferior dorsal lobe proceeding from it.

The egg of $B$. kowalevslii $(375 \mathrm{~mm}$. in major diameter [Bateson]) is more than six times as large as the egg of Pt. flava and more than four times that of $P t$. ruficollis. The egg of Peripatus capensis is not more than five times as large as that of $P$. novae-britanniae, and the difference in the development of these two species of Peripatus is precisely the difference between direct and indirect development ${ }^{1}$.

Thus both in the Enteropneusta and in the Onychophora the forms whose anatomy leads us to believe are the most primitive are those whose development is indirect, and in both cases it is the indirect development which instructs us as to the proximate affinities of these comparatively isolated groups; while from the direct development we are apparently able to gather information as to the primordial significance of their organisation (e.g. blastopore of $P$. capensis and coelomic pouches of $B$. kowalevskii).

1 The fact that we can distinguish between direct and indirect development in an intra-uterine environment is one of very great interest. 


\title{
WEST INDIAN ENTEROPNEUSTA.
}

\author{
(Pt. biminiensis n. sp. and Pt. jamaicensis n. sp.)
}

Only one species of Enteropneusta from the West Indian Islands is described by Spengel, namely, Pt. bahamensis.

Being anxious to ascertain the identity of the species at Bimini which at one time engaged the interests of Professors T. H. Morgan and E. A. Andrews, I wrote to both these gentlemen for information on the subject, and received valuable replies from them which I gratefully acknowledge. Furthermore, Prof. Morgan sent me the collection of adults which still remained to him. The material was, on the whole, in good condition and has been of great use in elucidating the mystery of the proboscis-pore about which I was greatly concerned. Unfortunately the hepatic region was lacking from all the specimens and the diagnostic characters afforded by the genito-hepatic transition are therefore not available. Nevertheless I feel justified in naming two species, although the diagnoses must be imperfect for the present.

The material comprised portions of three species from as many localities, namely, (1) Pt. aurantiaca (Girard) from Beaufort N. C.; (2) Pt. biminiensis ${ }^{1}$ n. sp. from Bimini ; (3) Pt. jamaicensis n. sp. from Jamaica. They are all Ptychoderidae (this being the information $I$ was at first most anxious to obtain) belonging to the subgenus Tauroglossus; Pt. bahamensis Spengel was not included in the collection.

I am informed by Professor Morgan that the specimens which he generously placed at my disposal were collected by members of the Johns Hopkins Marine Laboratory.

Although the specimens were fragmentary it will be easy to differentiate the two new species from any other known species as well as from each other. If, for convenience, we divide the Enteropneusta into small, large and giant species, then Pt. biminiensis belongs to the category of large forms, while Pt. jamaicensis is a giant species.

Before proceeding to cut this valuable material into sections I experienced great difficulty in finding external differences between the fragments of $P t$. biminiensis and those of Pt. aurantiaca, and I accordingly wrote to Prof. Morgan asking whether, in consideration of his personal acquaintance with the living animals, his impression was that the Bimini species was distinct from the Beaufort species. His reply was that he considered the species from the two localities named to be quite distinct, adding the following important point of difference:- "The smell from the Beaufort form is

1 This is presumably the species whose Tornaria development was described by Morgan (Journ. Morph. Ix. 1894, p. 1). 
overpowering and very persistent even after years in alcohol. The Bahama [i.e. Bimini] worm has quite a bearable stench, very much fainter." In section the difference of the two species is at once evident. follows :-

The species of the subgenus Tauroglossus may be arranged into two groups as

A. Gill-pouches with ventral coeca.

Pt. clavigera, Pt. gigas, Pt. carnosa, Pt. biminiensis and Pt. jamaicensis.

B. Gill-pouches without ventral coeca.

Pt. aperta, Pt. australiensis and Pt. aurantiaca,

or again according to the presence and absence of accessory gonads in the genital region :-

A. With accessory gonads in the posterior branchial and in the genital region.

Pt. aurantiaca, Pt. biminiensis and Pt.jamaicensis, Pt. carnosa (in old animals ${ }^{1}$ ).

B. Without accessory gonads.

The remaining species named above, with the exception of Pt. gigas which must be left doubtful in this respect.

\section{Pt. biminiensis, n. sp. ${ }^{2}$}

The collar has a length of $10 \mathrm{~mm}$. and the proboscis $375 \mathrm{~mm}$. in two specimens. The branchial region was much contracted and wrinkled measuring about $40 \mathrm{~mm}$. in length; in the larger fragment about $24 \mathrm{~mm}$. of the genital region remained. In comparison with the following species the most useful measurement which I can state is the width across the expanded genital pleurae, which did not exceed $12 \mathrm{~mm}$. in the alcoholic specimen.

\section{PROBOSCIS.}

Both this and the following species are without the special thickening of the circular muscles at the base of the proboscis which is, according to Spengel, a distinctive feature in Pt. clavigera.

\section{STOMOCHORD.}

The region which has been referred to in the preceding pages as the coecal dilatation of the stomochord is, in Pt. biminiensis, remarkable for its exceedingly massive development. It recalls somewhat the condition met with in Pt. carnosa, especially in regard to the occurrence of dorso-lateral pockets in connection with the dorsal or main division of the lumen of the stomochord (cf. Pl. XXIX. Fig. $17 a$ and Pl. XXXII. Fig. 65). The dorsal wall of the stomochord in the coecal region is

1 The accessory genital ducts described above in old examples of Pt. carnosa do not necessarily and, I think do not in fact, imply the independent origin of additional gonads.

${ }^{2}$ For the habits of this species see the following:-T. H. Morgan, "The development of Balanoglossus," Journ. Morph., Vol. Ix. 1894, p. 1. 
densely packed with mucous cells and at the outer periphery (i.e. the base) of the cells there is a layer of fibrous matter or "Punktsubstanz" like that which underlies the epidermis (Pl. XXXII. Fig. 64). This is a peculiar feature of some importance; it has the same kind of importance as the observation of cilia in this portion of the stomochord of Pt. carnosa, namely, a vestigial significance.

In contrast to the massive or sub-solid condition of the stomochord in the coecal region, the anterior portion of the stomochord of this species is distinguished by the spacious cavity which it contains (Pl. XXXII. Fig. 62). The walls surrounding the large cavity are correspondingly thinner than usual, especially the dorsal wall. The central cavity buds off a large number of minute cavities which lie in the thickness of the walls. As we approach the coecal region we find the dorsal wall of the stomochord drawn up into the form of a crest protruding into the central bloodspace; the internal basal angles of the crest fuse together so as to constrict off a smaller dorsal portion of the lumen from the wider ventral portion. Farther back the ventral cavity decreases in volume, the walls becoming proportionately thicker until the massive mid-coecal region is reached. When the ventral cavity of the stomochord comes to an end in the anterior part of the coecal region, the stomochord consists of a nearly solid mass of vacuolar reticulate tissue with, however, a small dorsal lumen and minute scattered cavities (Pl. XXXII. Fig. 63).

In its anterior nuchal region the stomochord appears as a flattened transverse band with linear lumen, lying above the body of the skeleton; its dorsal wall is still crowded with mucous cells and the punctate matter is continued.

In the mid-nuchal region, the stomochord is greatly reduced; the mucous cells and fibrous matter disappear and, near the commencement of the wide posterior or buccal portion of the stomochord, the latter is invaded by skeletal substance to such an extent as to cause an interruption of continuity, at least so far as the lumen is concerned. In the posterior nuchal region the walls of the stomochord consist entirely of mucous epithelium, the dorsal wall being much thicker than the ventral. It duly opens into the buccal cavity at the point of bifurcation of the nuchal skeleton.

\section{Nuchal Skeleton.}

The cupule of the skeleton sends out irregular digitiform processes which penetrate into the substance of the stomochord. One of these processes is shown in Fig. 65, Pl. XXXII. From the dorsal side of the massive body of the skeleton, digitiform processes also project into the anterior nuchal portion of the stomochord; by the cross-fusion of such processes, portions of the stomochord become enclosed within the skeleton. In addition to these stomochordal inclusions, which are confined to the anterior end of the skeleton, there are extensive cellular inclusions within the body of the latter.

There are massive alary processes and a massive keel. The ventral septum of the proboscis ceases close behind the level of the proboscis pore, and the ventral coecum, produced by the confluence of the ventral canals, terminates at the front border of the keel. 
Proboscis-Pore.

Only the left dorsal canal communicates with an end-vesicle; the latter, however, does not end simply at the pore but becomes subdivided by a duplication of the wall into two unequal portions, a smaller right and a larger left moiety. Thus the effect is produced of two pores opening by a common median orifice (Pl. XXXII. Fig. 64). It seems quite obvious that the smaller dextral portion of the end-vesicle corresponds with the dextral vesicle of Pt. flava. The slit-like pore of the left portion is longer than that of the right, but both portions of the end-vesicle have long posttrematic coecal extensions (the left rather longer than the right) which lie on either side of the forward extremities of the perihaemal cavities. The smaller dextral portion maintains a more dorsal position than the bulk of the larger sinistral portion. The latter extends backwards beyond the region of the anterior neuropore.

Thus there is, in effect, a dextral end-vesicle and a dextral pore without any vestige of connection with the right dorsal proboscis canal. The pronounced subdivision of the end-vesicle in this species throws light upon the less complete subdivision observed in Pt. carnosa. The peculiar conditions here described are still more clearly established in the species next dealt with.

\section{COLLAR.}

\section{NERVE-CORD.}

There is no median anterior neuropore in this species; the medullary cord closes in solid in the anterior median tract but there are two short lateral cavities bounded by numerous mucous cells (Pl. XXXII. Fig. 65). These paired cavities open in front and are essentially due to the backward continuation of the dorso-lateral angles made by the union of the neck of the proboscis with the collar flap. This is a clear and instructive example of the way in which a median structure can assume a paired form.

The main body of the collar nerve-cord is practically solid, the medullary cavities being reduced to the merest vestiges. It is also characterised, in its anterior third, by the presence of a large quantity of yellowish flocculent tissue, the bulk of which forms a tract on each side of the middle line. In front, the cord is sub-triangular in section, the ventral angles being produced downwards so as to form bold projections into the perihaemal cavities; behind the orifice of the stomochord, these ventral horns of the medulla flatten out and the cord then becomes a transversely elliptical band.

The first and only root is massive and sub-solid; it has a backward course along the anterior free edge of the dorsal septum and occurs in front of the orifice of the stomochord.

The dorsal septum only extends for a short distance behind the root, when it becomes interrupted and finally disappears only to reappear near the posterior end of the collar in the region of the well-defined wide posterior central cavity of the nervecord which duly opens by the posterior neuropore. 


\section{TRUNK.}

All that need be said, and indeed in view of the fragmentary character of the material, the most that can be said as to the peculiarities of the truncal region of Pt. biminiensis, relates to points which have been already mentioned, namely, the occurrence of ventral diverticula of the gill-pouches and the presence of accessory gonads in the posterior branchial and genital regions.

It is only necessary to add, with regard to the accessory gonads, that they do not occur mediad of the main series, but only laterally, and they lie entirely within the genital pleurae ${ }^{2}$. This is an important difference between this species and Pt. aurantiaca where, as Spengel has shown, the accessory gonads occur both laterally and medially, i.e., on both sides of the main series. In front the gonads commence some distance behind the posterior rim of the collar.

I think it has been made sufficiently clear that this is quite a distinct species. Should the opportunity present itself to any naturalist visiting the Bahamas, particularly the Bimini Lagoon, to make further observations, it is desirable to note the external character of the genito-hepatic transition, the proportionate lengths of branchial and genital regions and, in section, the nature of the pygochord, if one occurs.

\section{Pt. jamaicensis, n. sp.}

In the single specimen at my disposal, the proboscis was nearly concealed within the collar-flap. The collar was much wrinkled and contracted to a length of about $1 \mathrm{~cm}$; the width was greater than the length in the contracted state.

The width of the body in the branchial region, with closed genital pleurae, was $11 \mathrm{~mm}$., and the vertical height, under the same conditions, was $17 \mathrm{~mm}$. The width across the expanded genital pleurae was $29 \mathrm{~mm}$. This species therefore belongs to the category of giant forms.

Professor E. A. Andrews has kindly supplied me with notes as to the appearance of this species during life together with some sketches, from which I gather the following details. "Balanoglossus very abundant in sandy cove on north [side] of Drunken Man Cay, off Harbour of Kingston." It lives in coral sand. "Only tail end usually cut off by spade; two $q$ heads taken in 3-4 hours." "Colour, yellowish white, with conspicuous transverse bands of red-brown arranged alternately" on the two sides of the body.

On one side of the body (? dorsal) these pigmented bands end sharply at the sides of the median groove; on the opposite side they bend forwards (or backwards) and their ends break up into a number of spots on either side of the median line. On the side on which the pigment-rows break up into spots, the body is "covered by numerous rounded, blunt papillae [dermal islets]; each [papilla] shows, under lens, minute white specks," probably due to mucous glands.

1 of course this statement does not refer to the normal medial branch of the lateral gonads which always occurs on the mesial side of the lateral septum. 
"Proboscis small, collar large; with no colour, except uniform yellow and fleshy." The pigmented bands were visible in some of the pieces of the abdominal region in the preserved condition.

Apart from the differences in size and colour-markings there are but few characters which can be definitely stated to establish a specific distinction between the present species and Pt. biminiensis. The impression produced upon the naturalists who collected both species was that they were distinct, and I have thought it would serve the interests of the subject best, under the circumstances, to give them separate names. It is only necessary to remember that Pt. jamaicensis may stand in a similar relation to Pt. biminiensis to that which Pt. robinii (Giard) bears to Pt. clavigera (Delle Chiaje), or Bal. mereschkowskii Nic. Wagner to Bal. kowalevskii Agassiż.

It is true that there is a striking difference in the matter of the proboscis-pores, but such as it is, it is only due to an exaggeration of the condition observed in Pt. biminiensis. In the present species there are two distinct end-vesicles and two proboscis-pores. At the level of the pores, the vesicles are nearly equal, but the prae-trematic portions of the vesicles are unequal, the bulk of the left exceeding that of the right. Only the left vesicle is in communication with the proboscis coelom; the right vesicle is blind at both ends. I say at both ends advisedly because in the case of both right and left vesicles, there is a long coecal post-trematic extension, stretching a considerable distance beyond the level of the anterior neuropore, and hence underlying the medullary cord.

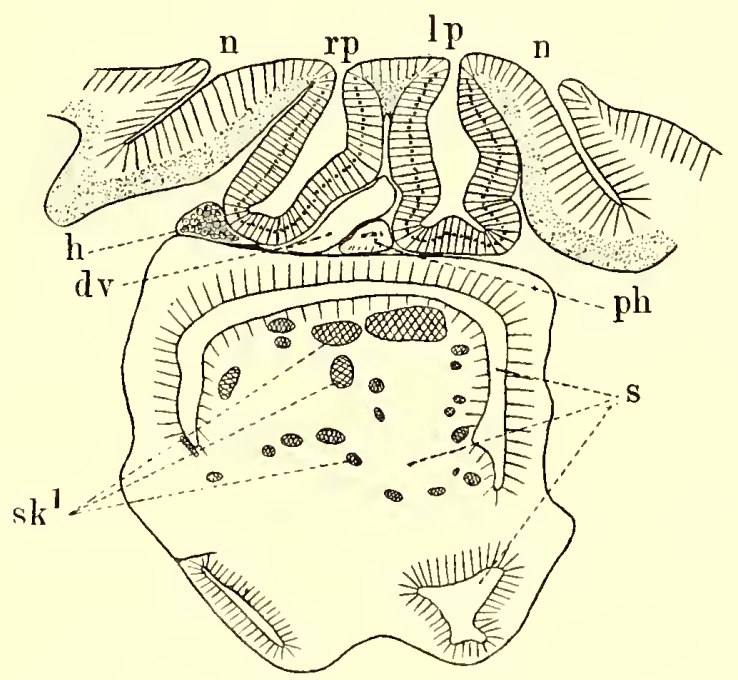

Fig. 5. Transverse section through the proboscis-pores and neuropore of Pt. jamaicensis.

$d v$ Dorsal vessel (at the point where it passes into the central blood-space and gives off the advehent dermal vessel of proboscis). $h$ Pericardium (solid posterior extremity). Ip Left proboscis-pore. $r p$ Right proboscis-pore. $n$ The two halves of the neuropore. $p h$ Perihaemal space (anterior extremity). $s$ Stomochord. $s k^{l}$ Skeletal inclusions in the stomochord (due to digitiform processes from the cupule of the nuchal skeleton). 
As shown in the text-figure, the proboscis-pores occur approximately at the level of the neuropore, although the latter is subdivided in this species in the same way as in Pt. biminiensis.

The digitation of the cupule of the nuchal skeleton is also more extensive in the present than in the preceding species. The stomochord undergoes fragmentation in its nuchal region by the invasion of strands of skeletal substance, very much as in Pt. carnosa.

The collar nerve-cord in its middle portion consists of a sub-solid transversely flattened band. There is a single root arising from the cord immediately in front of the buccal orifice of the stomochord; it passes directly to the epidermis with which it unites by a long anteriorly directed apical border. There is no dorsal septum near the root; it is limited to the posterior quarter of the nerve-cord.

As already mentioned, the gill-pouches are produced ventrally into coecal prolongations. The gill-clefts are traversed by upwards of 50 pairs of synapticula.

In the portion of the body which is characterised by the presence of the lateral septa, namely, in the posterior branchial and genital regions, accessory genital ducts occur laterally from the main series. The accessory gonads are arranged in a radial manner in the genital pleurae and entirely fill the latter. The genital region of the preserved animal was very brittle and the layers of the body-wall were in a disrupted condition, but I have been able to satisfy myself, with reasonable certainty, that this species agrees with Pt. biminiensis in having only lateral accessory gonads.

The specimen at my disposal was a mature female. The ova were tightly packed together, causing them to assume polygonal shapes, and they measured $\cdot 11 \mathrm{~mm}$. in diameter.

As at least two kinds of Tornaria have been recorded from the West Indies it is important to note that, so far as known, all the Enteropneusta inhabiting the shores of these islands belong to the family of the Ptychoderidae. 


\section{MORPHOLOGY OF THE ENTEROPNEUSTA.}

In his monumental monograph of the Enteropneusta, Professor Spengel was led to negative conclusions as to the outside affinities of the group. This result may be partly accounted for by the fact that he was handicapped in being obliged to make use of an unsuitable form, namely, Ptychodera minuta (the common species of the Bay of Naples), as the basis of his work. I cannot help thinking that the theoretical aspect of his labours might have assumed a different complexion if he could have started with such a form as Ptychodera flava.

As a treasury of facts it would not be easy to overestimate the value of this, the eighteenth monograph issued by the management of the Zoological Station at Naples; and I hope I have made it clear in the foregoing pages, how much later workers, like myself, are indebted to Professor Spengel for the great work which he has accomplished.

The result of my own observations, which have, intermittently, extended over the best part of three years ${ }^{1}$, has been not only to confirm my belief in the theory of the Chordate affinities of the Enteropneusta, which was first definitely advocated by Bateson, and has been accepted by most, if not all subsequent naturalists who have dealt with the group, with the exception of Spengel, but, to carry to my own mind the conviction that the Enteropneusta stand much nearer the direct line of Chordate descent than has generally been supposed.

Perhaps it may be admitted that I have brought forward a sufficient number of new facts to justify a restatement of the case for the Enteropneusta.

The views contained in Bateson's standard work on the direct development of Balanoglossus (published during the years 1883-1886) were naturally and properly based upon similarity of structure and origin. Spengel denied this similarity since it fell short of identity. It now remains to found the theory upon change of function. Such a theory not only dispenses with the necessity of the identity of structures, in widely separated forms, which are supposed to be genetically related, but it requires that they should be different.

I think it right to assume that it would be quite out of place for me to attempt the formidable task of discussing Dr Gaskell's Theory of the Origin of Vertebrates². I have quite enough on my hands in stating the case for the Enteropneusta. I may be permitted to say that I, for one, regard Dr Gaskell's work as an important contribution to the history and theory of the subject. Dr Gaskell has himself spoken of his theory as an "earthquake hypothesis," and it may probably be regarded as the culmination of that line of thought (namely, the reference of the Vertebrata to an Articulate ancestry) which originated with Ét. Geoffroy St. Hilaire and has numbered

1 I made the acquaintance of Pt. flava in July 1896.

2 W. H. Gaskell, "On the origin of Vertebrates, deduced from the study of Ammocoetes," Journ. Anat. and Physiol., Vol. xxxir., p. 513 and Vol. xxxiII., p. 154.

W. III. 
among its adherents Leydig, Semper, Dohrn, Eisig and many other distinguished names.

Without presuming to characterise the present contribution as a culmination of any kind whatever it may nevertheless be said, with truth, that it falls into line with the work of Johannes Müller, Kowalevsky, Hatschek, Huxley, Lankester and others.

\section{Theory of Gill-SLits ${ }^{1}$.}

In submitting the theory of gill-slits at which I have arrived during the course of my work on the Enteropneusta I definitely assume, at the outset, that whatever be the true approximate explanation of gill-clefts, it must, at all events, be sought for in free-living animals possessing a straight alimentary canal and not in sedentary forms, nor in purely pelagic forms, which possess a U-shaped alimentary canal. The theory suggested by Harmer based upon the anatomy of Cephalodiscus and by Brooks on the basis of Appendicularia, which has recently been further elaborated by Masterman², does not, in my opinion, account satisfactorily for the primordial origin of gill-slits, but it probably does explain the retention of a single pair of gill-clefts in the above-named animals. This is a point of great interest and some importance, because, the Pterobranchia probably bear the same sort of relationship to the Enteropneusta as that in which the Urochorda stand to the Cephalochorda.

In the Enteropneusta, as in Amphioxus, we observe the very remarkable phenomenon of the coincidence of the branchial and genital regions.

Whereas in the craniate Vertebrates the gonads have absolutely nothing to do with the branchial region, in these primitive groups of the Enteropneusta and the Cephalochorda, gonads and gill-slits are, roughly speaking, coextensive.

The intrinsic importance of gill-slits is abundantly evident from one of their most fundamental properties, namely, their persistency. Whereas teeth, limbs, limb-girdles, digits, etc., after having been once acquired, have been secondarily lost, over and over again, without leaving so much as a trace in the individual ontogeny, gill-slits persist throughout the whole series of craniate Vertebrates, into the human foetus.

The Memoria technica given below serves to illustrate the position of the Enteropneusta in the natural system; and also the dual propensities of this group towards the Echinoderms on one side and the Chordata on the other. The only liberties I have taken are firstly to introduce two new collective names, one of which, Branchiotrema, is to include all animals which possess gill-slits at any time in their life-history; and secondly to apply the name Bilateralia of Metschnikoff somewhat differently from what was originally intended. It is a poor word in any case to apply to a limited group of animals ${ }^{3}$, but its retention recalls the fact that Metschnikoff first discovered the

1 The substance of the remarks which follow under this heading was given in a paper read before the Cambridge Philosophical Society on Nov. 14th, 1898 (see Proc. Camb. Phil. Soc. Vol. Ix., 1899, p. 37.)

${ }^{2}$ A. T. Masterman, "On the further anatomy and the budding processes of Cephalodiscus dodecalophus M'Intosh." Trans. Roy. Soc. Edinb., Vol. 39, 1898, p. 507.

3 Metschnikoff called the Enteropneusta, Bilateralia, and included them with the group of the Echinoderma under the phylum or sub-phylum Ambulacralia. 
metamorphosis of Tornaria and that he, like his successors Bateson, Morgan (loc. cit.), MacBride ${ }^{1}$ and others, believed in the special though remote genetic relationship of the Enteropneusta and Echinoderma; the name is also useful as a reminder of the supposed bilateral ancestry of the Echinoderms.

The other collective name which I have suggested, viz. Hydrotrema, will be justified in the sequel.

With regard to the introduction of the name, Branchiotrema, I will say that there is just as much or as little need for this addition to our terminology as there was for Huxley's Pharyngopneusta. Moreover, assuming that the knowledge of these creatures which has accumulated during the last thirty years or so, is not illusory, I think that the conception contained in this term, namely, that gill-slits have the priority of the notochord, will turn out to be well-grounded.

A table, such as the one given here, brings out the dual or overlapping propensities of the various groups in a way which is not possible in an ordinary classification.

\section{MEMORIA TECHNICA}

\section{Relating to the Chordate Series of Animals.}

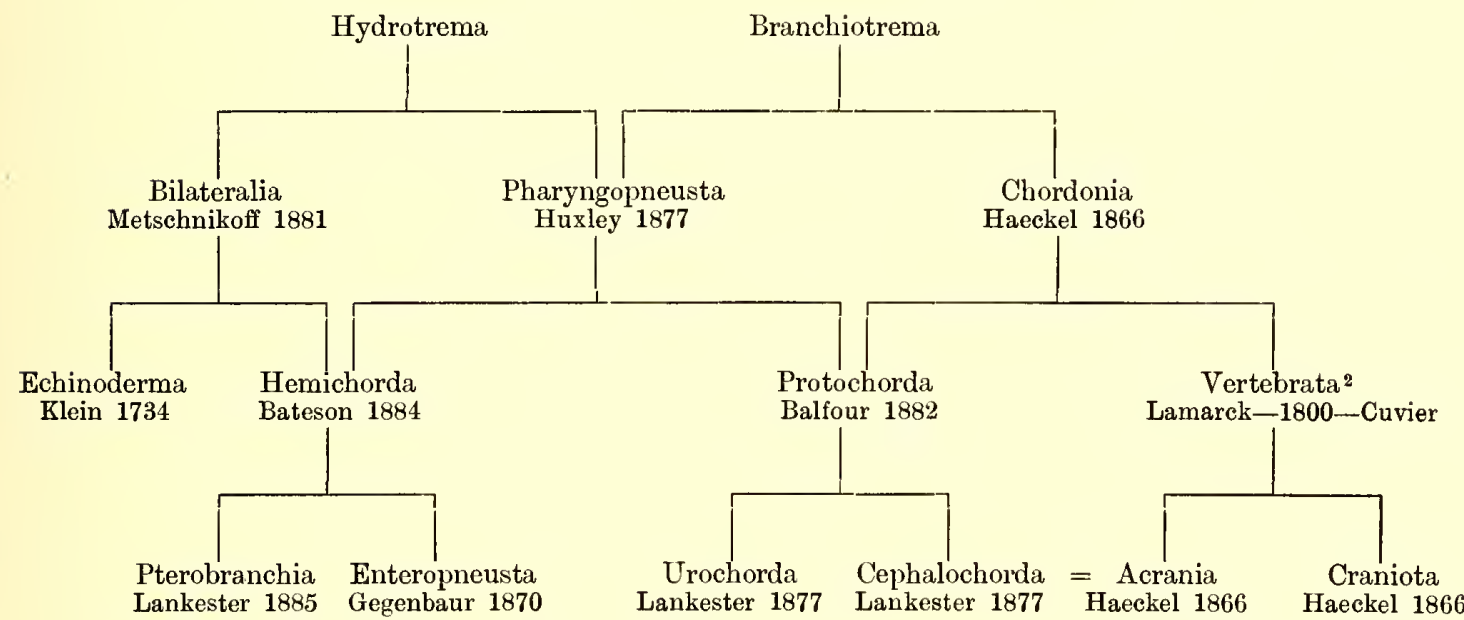

The theory for which I shall proceed to point out the evidence may be briefly stated as follows:-The gonads and gill-slits were primarily unlimited in number and coextensive in distribution, the gonads having a zonary disposition and the gill-slits occupying the interzonal depressions. The primary function of the gill-slits was the oxygenation of the gonads, their secondary function being the respiration of the individual.

Perhaps it will be best to deal with the evidence categorically.

1 E. W. MacBride, “The development of Asterina gibbosa." Q. J. M. S., Vol. 38, 1896.

2 Holochorda of Gadow and Masterman. (H. Gadow, A Classification of Vertebrata, London, 1898. A. T. Masterman, "On the Diplochorda," Quart. Journ. Micro. Sci., Vol. xL. 1897.) 


\section{A. Evidence of Unlimited Gill-slits.}

The evidence is of various kinds and derived from various sources, e.g. number, formation, limitation and vestiges of gill-clefts.

a. Number and formation of gill-slits. It is a fact which sharply distinguishes the Enteropneusta and Cephalochorda from the craniate Vertebrates that new gill-slits are added at the posterior end of the pharynx throughout life.

In spite of this successive addition, at longer or shorter intervals, there is in most cases a maximum which is usually not overstepped before death ensues. In Amphioxus the maximum may be taken as from 90 to 100 gill-slits on each side. In Pt. flava the number of gill-clefts acquired by the macrobranchiate forms may be taken at about 150 pairs. In Pt. aurantiaca, according to Spengel, the gill-slits may reach the impressive total of 700 pairs. In this case it appears to be impossible to assign a maximum. Pt. minuta goes to the other extreme and never has more than 40 pairs (Spengel).

B. Limitation of gill-clefts. The fact of limitation is shown in absolutely unequivocal manner within the group of the Enteropneusta. It is implied in the facts given in the preceding paragraph which might easily be supplemented. It is however sufficient to compare the conditions met with in Pt. flava and Pt. ruficollis respectively. Whereas the length of the pharynx of $P t$. flava varies enormously, namely, from less than a centimetre up to about 3 centimetres, that of Pt. ruficollis is remarkable both for its shortness and its constancy (cf. Pl. XXVI. Figs. 1 and 2; and Pl. XXVII. Fig. 7).

If further demonstration of limitation be required it is furnished in a totally unexpected way by the postbranchial canal of Pt. ruficollis as compared with the corresponding portion of the gut in Pt. flava and Pt. carnosa. In the two lastnamed species the last pair of gill-slits occurs at the dorso-lateral margins of this structure and new slits are duly added in line with the pre-existing slits. In Pt. ruficollis the gill-slits have nothing whatever to do with the vestigial postbranchial canal, the last few pairs opening at the base of it directly into the ventral division of the gut. This faculty of the gill-slits of shifting their position and having their primary topographical relations radically changed is worthy of particular note. At the posterior end of the pharynx in Pt. ruficollis the gill-slits have, in effect, moved from a dorsal to a more ventral position ( $\mathrm{Pl}$. XXX. Figs. 32, 33).

$\gamma$. Vestiges of gill-clefts (see also below p. 321). Under this head are probably to be placed the intestinal pores (Darmpforten) originally discovered in Balanoglossus mereschkowskii by Schimkewitsch, whose observations were greatly extended by Spengel. They occur in certain species only, namely, Schizocardium brasiliense, Glandiceps talaboti, Gl. hacksi, Bal. kowalevskii and Bal. mereschkowskii ${ }^{1}$, and in my Spengelia alba (see

${ }^{1}$ Spengel says Bal. mereschkowskii (the White Sea Enteropneust) is probably co-specific with Bal. kowalevskii. 
above and Pl. XXXII. Fig. 57). Both Schimkewitsch and Spengel admit the possibility of these pores being related in one way or another to gill-slits.

There may be two sets of pores, anterior and posterior. The anterior pores, when present, follow close behind the branchial region and the posterior pores occur at the genito-hepatic transitional region.

Intestinal pores do not occur in the Ptychoderidae.

What we do find, however, in the Ptychoderidae are the remarkable ciliated grooves of the intestine, with their medially placed covering-pads extending (e.g. in Pt. flava) from the anterior end of the hepatic region to the posterior end of the abdominal region, but not into the caudal region. In the subgenus Chlamydothorax (as shown by Spengel in Pt. erythraea and as I have found in Pt. flava), the ciliated grooves are not simple longitudinal furrows but undergo metameric or interannular sacculations. These sacculations often approach very closely to the epidermis. They strongly resemble a gill-pouch before its perforation to the exterior such as I have described in Pt. flava. The medial covering-pad often suggests a tongue-bar. (Cf. Pl. XXIX. Figs. 12-14.)

It is not unlikely that these sacculations of the ciliated apparatus of the gut in the subgenus Chlamydothorax are homodynamous with the gill-pouch diverticula of the gut and, in this quality, are the vestiges of gill-slits which doubtless formerly extended throughout the greater part or the whole of the trunk. Pari passu with the phenomenon of cephalisation, a process which has always been at work in the evolution of Metazoa, the primarily unlimited gill-clefts became limited to the anterior region of the trunk.

\section{B. Coextension of Gill-slits and Gonads.}

The above conception of the limitation of the gill-clefts to the anterior region of the trunk in correlation with cephalisation and regional differentiation is in accordance with what happens in the Craniota. What is not in accordance with craniate traditions is the fact that as a first stage in the process of limitation or localisation of the gonads, they were likewise restricted equally with the gill-slits to the anterior end of the trunk. Whereas in Amphioxus the number of gonads is strictly limited and constant, being laid down once for all during the early adolescent phase of development, in the Enteropneusta the formation of gonads goes on throughout life. As stated by Spengel, the principal point of origin of new gonads of the primary or lateral series is at the posterior end of the gonadial series. As is known new gill-slits arise exclusively at the posterior end of the branchial series.

It is hardly necessary to dwell at length upon the coextension of gonads and gill-slits since it is such an obvious fact, and is practically implied in Spengel's term branchiogenital region. It is none the less remarkable because it is obvious. The reason why we seldom find exact coextension of gill-slits and gonads is because another factor has been at work which has resulted in the more or less complete emancipation of the gonads from the gill-slits (see below). However, there is one admirable example of complete coincidence of branchial and genital regions, namely Balanoglossus canadensis Spengel. 


\section{Annular Ridges and Interannular Depressions.}

The skin of the Enteropneusta is particularly characterised by the thickened glandular epidermal patches which are arranged in a more or less regularly zonary manner so as to produce the appearance of raised glandular annulations separated from one another by interannular non-glandular grooves. These annulations extend from end to end of the trunk.

In the hepatic region of the Ptychoderidae the apparently unimportant, but nevertheless ever-present, epidermal annular ridges are drawn into the service of the hepatic diverticula of the gut, whose outer free edges they bound. The external liver-saccules of the Ptychoderidae are, outwardly, nothing else than products of local hypertrophy of the annular ridges, while the intervals between the successive saccules are the usual non-glandular interannular tracts.

The epidermal zonulation of the Enteropneusta is usually quite unjustly treated as having no deep-lying significance at all.

We have seen what can become of the annular ridges, but it is of more importance for my present purpose to point out some of the potentialities of the interannular grooves or tracts.

The dermal pits of Spengelia are local intergonadial depressions of the interannular tracts.

In $S p$. porosa the last gill-slits open at the base of the most anterior pits. The succeeding pits, although they approach near to the wall of the gut, do not meet it. If they did meet it they would probably fuse with it and form gill-slits.

It would conceivably need but a comparatively slight functional stimulus to induce either a pre-existing gut-sacculation to fuse with the epidermis or a pre-existing dermal pit to fuse with the gut-wall. But when dermal depressions and gut-sacculations coincide, then perforation is almost certain to follow sooner or later. It may readily

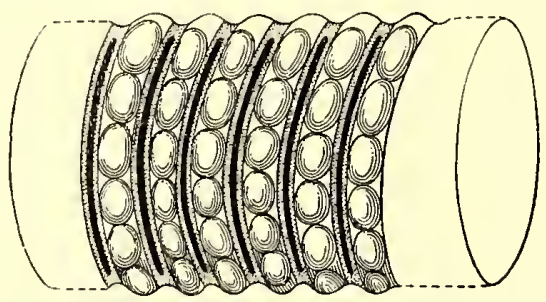

Fig. 6. Diagram to illustrate the theory of the primary intergonadial position of the gill-clefts. No insistence is placed upon the subdivision of the gonads into superposed follicles. They are thus represented in order to illustrate more clearly the principle of zonulation.

be observed that the wall of the gut is thrown into transverse folds producing crests and valleys. This is especially well seen in a large form like Pt. carnosa. The gut of the Enteropneusta is intrinsically straight; at the same time it is necessary to have as large a digestive surface as possible on account of the nature of its food. It effects increase of surface by means of such transverse or circular or zonary plications ${ }^{1}$.

I Spengel points out that in Bal. kowalevsliii and Bal. kupfferi the intestine is considerably longer than the body, and hence has a serpentine course (Schlängelung des Darmcanals). 


\section{Oxygenation of the Gonads.}

By pressing the gill-slits at their first origin into direct functional relation with the gonads we only assign to them their pre-eminent importance in the economy of the higher animals and to that extent we explain their persistency. There is no need to insist upon the truism that the possibility of progressive evolution is dependent upon the gonads being exposed to the best possible physiological conditions.

In my previous paper on Spengelia (loc. cit.) I stated that the dermal pits apparently served for the irrigation of the gonads. At that time I had no idea of framing an elaborate theory of gill-slits.

What induced me to venture upon such treacherous ground was the zonulation of the gonads in the genital pleurae of Pt. flava and the reflection brought home by the exposed pharynx of this species that the septal bars corresponded, in principle, with the annular ridges of the body-wall while the gill-clefts took the place of the interannular depressions ${ }^{1}$ (Pl. XXVI. Figs. 1, 2).

\section{E. Emancipation of the Gonads. Lateral Septa.}

The primary relation of gill-slits and gonads which the present theory assumes is not exactly retained in any existing form that we know, although it is suggested by many tangible facts. The gonads have become emancipated from their direct dependence upon the gill-slits for their oxygenation concomitantly with the elaboration of the vascular system. This emancipation has taken place in two ways, firstly by their relegation to pleural folds of the body-wall and secondly by their recession from the branchial region.

The regional differentiation of the body is one of the cardinal features in the organisation of the Enteropneusta, but it is not complete since the regions tend to overlap. But whereas it is usually possible to define a genital region between branchial and hepatic regions, in the subgenus Chlamydothorax this is not possible; because, although there is a short tract intervening between the pharynx and the hepatic region, the gonads have no more to do with this tract than they have with any other portion of the body proper. In this subgenus the gonads have become abstracterl from the main trunk and are confined to special pleural folds. That the genital pleurae are structures superadded to the main body of the animal is evident from the behaviour of the lateral septa which are an exclusive appanage of the Ptychoderidae.

Where the genital pleurae are at their maximum, namely in Chlamydothorax, the lateral septa likewise have their greatest development. In Pt. flava the lateral septa are coextensive with the genital pleurae because the latter are quite independent of the branchial region. In other forms the lateral septa cease in the posterior portion of the branchial region. The lateral septa are vascular folds of the basement membrane

1 This impression is made all the stronger by the fact, already mentioned, that the tongue-bars are not visible in the external view of the pharynx of preserved specimens owing to their deeper position. Only the septal bars and the intervening slits are visible in such a view. 
which accompany the genital pleurae and carry the genital blood-vessels. They mark out the path of emancipation of the gonads from the gill-slits ${ }^{1}$.

In other existing forms, excepting Bal. canadensis ${ }^{2}$, the genital pleurae have undergone progressive reduction (from before backwards) with the result that the gonads have become to a greater or less extent secondarily restored to the main body of the animal and the gill-slits have been closed in laterally, their external openings being reduced to minute pores placed dorsally on each side of the dorsal nerve-cord.

The gonaducal (submedian, Spengel) line is that in which the genital pores are placed and it coincides with the series of gill-pores except in those Ptychoderidae which possess genital pleurae. The gonaducal line of the Ptychoderidae is further denoted by the peripheral insertion of the lateral septum into the basement-membrane of the epidermis. This line in Chlamydothorax occurs at or near the dorsal free edge of the genital pleurae. In Tauroglossus, where the gonads lie partly in the pleural folds and partly in the main body-cavity, the gonaducal line has shifted from the summit nearly to the base of the genital pleurae ${ }^{3}$. Finally in such a species as Pt. ruficollis, where there are no genital pleurae in the branchial region, the gonaducal line and branchial groove coincide.

Having been secondarily restored to the main body-cavity the gonads have apparently been exposed to the influence of another set of changes tending to their further limitation to a definite genital region.

I refer to the recession of the gonads from the, branchial region. In comparatively few forms do the gonads extend to the extreme anterior end of the branchiogenital region. They do so in Pt. minuta and Pt. flava and a few others; but as a rule they commence at various distances from the posterior rim of the collar. This is best shown in tabular form.

\section{Table showing Recession of the Gonads.}

SPECIES GONADS

Pt. flava......................Coextensive with genital pleurae.

Pt. ruficollis .................First genital duct between 5th and 6th gill-pores.

Pt. sarniensis ..............First genital duct beside the 20th gill-pore, about $4 \mathrm{~mm}$. behind collar. [Spengel.] Pt. aurantiaca ..............Gonads commence some millimetres behind collar; in branchial region they are arranged in a single series and in the genital region in multiple series. [Spengel.]

Sch. brasiliense ............Gonads commence about level of 15th gill-pore. [Spengel.]

Sch. peruvianum ............Gonads not present in fragment in which 70 pairs of gill-clefts occurred. [Spengel.] Gl. hacksi ...................Gonads extend throughout entire branchial region and genital region into hepatic region. In young specimen they commenced at the level of 13 th-14th gill-pores. Thus the most anterior gonads of adult are added secondarily. [Spengel.]

Gl. abyssicola Gonads commence behind the branchial region. In this case alone is the recession complete. [Spengel.]

1 Just as recurrent nerves show divergence from primitive topographical relations.

${ }^{2} \mathrm{Bal}$. canadensis, as described by Spengel, is a most interesting and peculiar species. It possesses two sets of pleural folds which contain the gonads, dorsal and ventral. The genital blood-vessels of this form constitute a system sui generis, and there are no lateral septa.

3 This shifting of the gonaducal line (cf. Pl. XXVIII. Fig. 6 and Pl. XXX. Fig. 23) may also be re. garded as evidence of the possibility of change of function of the genital pleurae (cf. p. 317). 


\section{Summary.}

1. My view is that the gill-slits arose originally as perforations in the interannular grooves for the aeration of the gonads which occupied the dividing ranges.

2. In the existing Enteropneusta the gill-slits no longer serve this primary function directly, since there is an elaborate and highly peculiar vascular system.

3. Consequently in the most primitive forms (e.g. Pt. flava) we find the gonads quite removed from the neighbourhood of the gill-clefts and relegated to pleural folds of the body.

4. When secondarily restored to the main body-cavity owing to reduction and disappearance of the pleural folds, there is a tendency for the gonads to restrict themselves to a special region of the body, or in other words, to withdraw themselves from the branchial region.

5. This withdrawal of the bulk of the gonads from the branchial region manifests itself in different ways:-

(i) By reduction of the ramifications of the gonadic pouches in the branchial region ${ }^{1}$.

(ii) By removal from anterior end of trunk.

6. The theory may be represented in tabular form as follows:-

\section{GILL-SLITS.}

Primary function $=$ Oxygenation of gonads.

Secondary function $=$ Respiration of individual (Primary function superseded by elaboration of vascular system).

Primary position $=$ Intergonadial .

Secondary position $=$ Segmental.

Primary number $=$ Unlimited and indefinite.

Secondary number $=$ Limited and definite.

\section{Gonads.}

Primarily coextensive with gill-slits.
A. Unlimited.
B. Limited.

Secondarily emancipated from gill-slits.

A. Restricted to genital pleurae.

B. Restricted to genital region.

1 Besides Bal. canadensis already referred to, Bal. kupfjeri is exceptional in that the gonads attain their maximum development in the branchial region (Spengel). 


\section{Proboscis-Pores and Anterior Neuropore.}

Spengel rejects the idea of anterior and posterior neuropores and describes instead anterior and posterior epidermal invaginations or pouches (vordere und hintere Epidermistasche) at the two ends of the collar nerve-cord. We will consider first of all the anterior pore alone. "Bei allen Arten der Gattungen Balanoglossus und Glandiceps," says Spengel (Mon. p. 606), "also derjenigen, bei denen bis jetzt kein typischer Axencanal beobachtet worden ist, besteht dorsal von der Ansatzstelle des Eichelhalses an den Kragen eine bald tiefere, bald flachere trichterförmige Einsenkung der Haut, eine blind endigende, von Epidermis ausgekleidete Tasche, welche bis ans vordere Ende des Kragenmarks reicht."....."Was aber mehr als alles andre den Ausschlag zu Gunsten der soeben vorgetragnen Auffassung giebt, das ist der Umstand, dass manchmal in Bereiche dieser Tasche die Eichelporen gelegen sind" [e.g. Bal. canadensis, Gl. talaboti]......" Ein etwas abweichendes Verhalten zeigt die Epidermistasche bei Schizocardium brasiliense. Hier trifft nämlich ihr Ende nicht auf das Vorderende des Kragenmarks, sondern sie erstreckt sich dorsal vom Kragenmark ein Stückchen über diesen Punkt hinaus, so dass das Kragenmark [which here is solid] sich der ventralen Wand der Tasche anheftet. Man könnte auch sagen, die Tasche sei mit einem dorsal vom Kragenmark in die Cölomhöhle hineinragenden Blindsäckchen versehen. Ebenso ist es bei Sch. peruvianum."

My observations on Spengelia alba allow me the satisfaction of admitting that what Spengel says is true. Only it is not the whole truth. The conditions in Sp. alba which I have described above on p. 279 show that the anterior neuropore, as it occurs in most Enteropneusta, is not a simple structure but that it has twofold significance which is frequently masked. When it reveals its double nature indirectly or in half-measures, it is perplexing and tends to lead to confusion. It may be said to have done this in the case of the species named in the passages from Spengel which I have quoted above.

In $S p$. alba we find the double nature of the anterior neuropore exhibited unequivocally, in that a true neuropore (s. str.) coexists, independently, with an anterior epidermal invagination (cf. Pl. XXXI. Fig. 51).

In most cases the neuropore and the epidermal ingrowth coincide (e.g. Pt. flava); in some cases the neuropore is obsolete and only the epidermal pouch remains (e.g. Schizocardium); in rare cases the neuropore and epidermal pouch are both present and distinct from one another (e.g. $S p$. alba); in no case, among the Enteropneusta, can the epidermal pouch be said to be entirely absent simply because there is always a niche formed at the point of insertion of the neck of the proboscis into the dorsal wall of the collar.

Thus we see that there is no fault to be found with the "anterior neuropore" on the one side, nor with the "vordere Epidermistasche" on the other. It is only necessary to bear in mind that there is a neuropore (s. str.) and also an epidermal 
pouch to be taken into consideration. When this has once been recognised it is allowable to use the expression "anterior neuropore," in the wider sense, to cover the two structures which, in the Enteropneusta, usually combine to produce it, but which sometimes assert their independence ${ }^{1}$.

Spengel (Mon. p. 470) points out that where two proboscis-pores occur in the adult it is highly probable that the dextral pore has a secondary origin in an ontogenetic sense, as no Tornaria has ever been found with two water-pores.

This is probably true for those forms which pass through an indirect development. Thus we are, for example, bound to assume that the Tornaria of Pt. flava possesses a single sinistral pore. With those Balanoglossidae which possess two pores, namely, Bal. kupfferi and Bal. canadensis, the matter is different and I should be prepared and even expect to find that in those species, having a direct development, the two pores would arise together as they do in regenerating specimens of Pt. flava. It is sufficiently clear that the paired condition of the pores is phyletically the more primitive, and Spengel intimates that he is likewise of this opinion. We have therefore here a very interesting example of a phyletically older condition being recapitulated as a secondary ontogenetic phenomenon ${ }^{2}$ (cf. above Pt. carnosa).

The comparative morphology of the proboscis-pores is a subject of almost discouraging complexity; and the attempt to elucidate it makes no light task.

Three facts, inter alia, which have come under my observation, have conducted me to certain ideas which, so far as they go, are quite clear and definite in my own mind. These facts are:-

1. The terminal tubular vesicle or end-sac which typically opens internally into the proboscis coelom and externally by the proboscis pore, may be quite shut off from any communication with the coelom; in other words, it may be completely emancipated from the coelom (Pt. flava, Pt. jamaicensis).

2. The end-sac ${ }^{3}$ may have a comparatively long post-trematic coecal extension (Pt. carnosa, Pt. biminiensis, Pt. jamaicensis, Sp. alba).

3. The end-sac may open into the medullary tube behind the anterior neuropore (Pt. carnosa).

If, by a legitimate mental abstraction, we reflect upon the condition in which there is a coecal sac opening into the medullary tube which, in its turn, opens to the exterior by the neuropore, we have before us essentially the combination met with in the Ascidian larva with the difference that, in the latter, the neuropore does not open directly to the exterior but into the dorsally placed mouth.

1 The structure described by Masterman in a species of Actinotrocha as a neuropore is what Spengel would rightly call an "Epidermistasche," and is certainly not a neuropore in the strict sense. (A. T. Masterman, "On the Diplochorda," Q. J. M. S., Vol. 40, 1897, p. 281.)

2 Although paired water-pores have never been demonstrated to exist in Tornaria, they have been observed to have a normal though transitory existence in certain Echinoderm larvae, by Metschnikoff, Brooks, Field and Grave. (See Caswell Grave, "Embryology of Ophiocoma echinata Agassiz," Johns Hopkins Univ. Circ., Vol. 18, Nov. 1898, p. 6.)

${ }^{3}$ By this term I shall, in the remarks which follow, refer to what Spengel calls the "Eichelpforte." 
The theory, as to the broad truth of which I am myself quite convinced and for which I will proceed to produce the available evidence, may be stated briefly as follows :The proboscis pore ${ }^{1}$ of the Enteropmeusta is represented by and is homologous with the inner or cerebral opening of the neuro-hypophysial apparatus of the Ascidian larva; the end-sac of the Enteropneusta typically communicates internally with the coelom, but, within the limits of the group, we find signs of its emancipation ${ }^{2}$ from the coelom; the hypophysial canal of the Ascidian larva has no relations with the body-cavity but it opens at one end into the medullary tube (cerebral vesicle) and at the other into the branchial sac at the base of the buccal cavity. Thus a special significance is given to the peculiar mode of origin of the Ascidian subneural apparatus (gland and duct) and an explanation is forthcoming as to the apparent absence of anything like a proboscis-pore in the Ascidian larva ${ }^{3}$.

a. Evidence of change of function; Excretory system of Enteropneusta. Apart from the evidence as to change of function, or loss of previous function of the proboscispores which is furnished by the fact of their greater or less emancipation from the coelom, there is also evidence of another kind. The proboscis-pores are clearly homodynamous with the collar-pores and the truncal pores (presumed vestiges of which occur in Spengelia). It is to be supposed that these three pairs of regional pores represent the primitive excretory canals of what Masterman (1897 loc. cit.) has called the archimeric regions of the body. But they no longer function as excretory canals since the function of excretion has been relegated to the glomerulus (proboscis-gland of Bateson) which is a structure sui generis. It might be supposed that the proboscispores would at least carry off the products of excretion resulting from the physiological activity of the glomerulus, and it is possible that this does occasionally happen. But if it were their essential function it should invariably happen. But it does not. In Bal. canadensis Spengel has found that the proboscis-pores are quite vestigial and in Pt. flava, as described above, the communication between the end-sacs and the proboscis coelom is sometimes occluded and sometimes quite obsolete.

It will be asked what becomes of the products of excretion if they are not discharged to the exterior, and the answer is that it is not absolutcly necessary, in animals of the grade of organization of the Enteropneusta, that excretory products should be removed from the body (e.g. Ascidians). In close topographical relation with the glomerulus is a capacious vesicle closed on all sides, called the pericardium (Herzblase) on account of its relations to the central blood-space.

The endothelium of this so-called pericardium is subject to remarkable proliferation which varies greatly in its amount in different individuals (perhaps at different periods in one individual). It is quite reasonable to suppose that besides its topographical relations to the vascular complex known as the glomerulus it possesses functional relations with that organ. If this be so, the pericardium of the Enteropneusta in

1 I say nothing as to dextral or sinistral pore or both.

2 Apropos see also Spengel on Bal. canadensis and Bal. kupfferi (MIon. pp. 472-473.)

3 Cf. A. Willey, "Studies on the Protochordata. II. The development of the neuro-hypophysial system in Ciona intestinalis and Clavelina lepadiformis." Q. J. M. S., Vol. 35, 1893, p. 295. 
its capacity of closed vesicle associated with the renal function would be physiologically comparable to the organ of Bojanus of the Molgulidae'.

As for the collar-canals, since the essential organ of excretion is situated in the proboscis it is obvious that some function other than that of excretion must be assigned to them. Spengel gives good reason for supposing that the collar-canals serve for the ingress of sea-water into the collar-coelom for the purpose of procuring turgidity to assist in the peculiar method of locomotion of the Enteropneusta.

It is possible that this also takes place through the proboscis-pores in certain circumstances and in certain species. But whereas the function of the collar-canals, whatever it be, is constant, that of the proboscis end-sacs is as inconstant as they are variable. In all species examined by me the end-sacs of the proboscis taper considerably towards their internal (anterior) end. As we have seen, this tapering is sometimes carried so far as to obliterate the coelomic opening of the sac. The collar-canals maintain their calibre throughout their entire length and open invariably into the collar-coelom by a wide semilunar funnel.

It follows from what has preceded that both the proboscis-pores and collar-pores are vestigial in respect of their primitive excretory function, but whereas the latter have become definitely committed to an important and constant new function, the former are in a completely unsettled state. Their only hope lies in their capacity for forming new associations.

The proboscis-pores and collar-pores of the Enteropneusta considered as homodynamous structures may be contrasted as follows:-

Proboscis-PORES.

Highly variable.

Coelomic opcning reduced or absent.

Function impaired.
COLLAR-PORES.

Remarkably constant.

Coelomic opening wide, semilunar and constant. Function true.

It is a matter of great importance to note the definite fact that a proboscis end-sac can persist as a coecal tube opening to the exterior after the loss of its coelomic opening. The very fact that the end-sac persists under such circumstances is surely evidence that its potentialities are not yet exhausted, and the outlook becomes still more encouraging if it can become associated with the neuropore and with the medullary tube. We have seen that this is a demonstrable possibility (cf. Pl. XXIX. Fig. $17 \mathrm{~A}$ ).

Regional pore-canals can persist as vestiges after the loss of their coelomic openings. Such vestiges, by acquiring new associations, may resume their physiological activity in another sphere, by change of function; or, they may be entirely superseded by a new generation, i.e. by substitution, and so drag out the remainder of their existence in a condition of vestigial degeneration.

\footnotetext{
1 Spengel regards the anterior body-cavity (proboscis coelom) of Enteropneusta as an organ of the left side, its dextral antimere being represented by the pericardium (Herzblase) [Mon. p. 681 et seq.]. Such extraordinary complexity of structure and development as we have to deal with in the Enteropneusta is capable of being regarded from different points of view.
} 
B. Historical. In 1881 Julin published, in the Archives de Biologie (T. II.), his well-known anatomical work on the subneural gland of Ascidians, in which he developed the idea that the subneural gland with its duct which opens dorsally into the branchial sac at the base of the buccal siphon by the dorsal tubercle, is homologous with the hypophysis cerebri of craniate Vertebrates. ${ }^{1}$. This work was followed in 1884 by a memoir published in the fifth volume of the same Archives under the joint names of Éd. van Beneden and C. Julin, in which the authors sought to substantiate their hypothesis by the facts of development.

They described the origin of the subneural gland in a species of Clavelina, from a simple evagination of the wall of the branchial sac, which they called the "caecum hypophysaire." This method of development is of course, in the main, like that followed by the hypophysis of the Craniota and would, if true, no doubt tend to support their hypothesis. It would at the same time rob the Ascidian subneural gland of any morphological interest that might be expected to appertain to it, because it would prove identity where we might reasonably hope to find evidence of change.

In 1892 (Zool. Anz. xv. 1892, p. 332) I showed that in Ciona intestinalis and Clavelina lepadiformis the adult ganglion and the subneural gland arise from a common primordium which I called the neuro-hypophysial canal. This canal opens primarily at its posterior end into the cerebral vesicle, while at its anterior end it secondarily acquires an opening (which may be defined as the rudiment of the dorsal tubercle) into the base of the dorsal mouth. There is good reason, to interpret this secondary communication with the mouth as a re-opening of the neuropore. A similar mode of development has since been described in other forms by Hjort ${ }^{2}$, Salensky and Metcalf.

Meanwhile in 1886, Bateson ${ }^{3}$ compared the proboscis-pore of Balanoglossus with the praeoral pit of the larva of Amphioxus and, on the strength of Julin's anatomical work, with the dorsal tubercle of the Ascidian subneural gland. Bateson's other suggestions on this point were of course made before the development of the subneural gland was known and need not be referred to here. In concluding his remarks on this subject he says (p. 564), "If these views are correct the pituitary body and its pore is to be regarded as the rudiment of a primitive excretory organ which originally opened dorsally." As will be seen, this conclusion is borne out by facts (see below, p. 314).

Strange as it may appear, it is nevertheless true that it has generally been found easier to compare the Urochorda with the Craniota than with the Enteropneusta, i.e. easier to compare them with higher than with more primitive forms.

The idea of the neuro-hypophysial canal does not appear to have gained many adherents, and it is no doubt very right that it should have been so until further information was forthcoming. This information is now to hand and it may be summed up by saying that the pore-canal or end-sac of the proboscis of Enteropneusta is homologous with the primordium of the subneural gland of Ascidians, this primordium being

1 The same suggestion was made in the same year by Balfour in his Comparative Embryology.

${ }^{2}$ Hjort dealt with Distaplia magnilarva, and his preliminary account appeared at the same time as my own (Zool. Anz. xv. 1892, p. 328).

${ }^{3}$ W. Bateson, "The Ancestry of the Chordata," Q. J. M. S., Vol. xxvr., 1886. See also Bateson's previous papers in the same and two preceding volumes. 
the neuro-hypophysial canal; the proboscis-pore of Enteropneusta is represented in the Ascidian larva by the pore leading from the neuro-hypophysial canal into the cerebral vesicle; the anterior neuropore of Enteropneusta is represented in the Ascidian larva by the pore leading from the neuro-hypophysial canal into the mouth.

$\gamma$. Association of mouth and neuropore. We have already dealt with the association of proboscis-pore and neuropore. It now remains to say a few words on the association of mouth and neuropore in order to appreciate the comparison between the anterior trematic complex (mouth, neuropore and proboscis-pore) of the Enteropneusta and of the Ascidian tadpole.

For my part, when I say that the mouth of the Ascidian tadpole is dorsal and the mouth of the Enteropneusta is ventral, I mean that in one case the mouth is on one side of the body, and in the other it is on the opposite side of the body.

The comparison may be tabulated as follows:

\section{ENTEROPNEUSTA.}

1. Mouth ventral.

2. Mouth a vast crescentic or sub-circular orifice facing forwards.

3. Mouth indirectly associated with neuropore in virtue of the projecting collar-flap (Pl. XXVII. Fig. 6 A).

4. Food ingested as the animal burrows through sand, vast quantities of which pass through the alimentary canal where the nutritious matter is extracted and the sand rejected.

\section{Ascidian LaRva.}

1. Mouth dorsal.

2. Mouth a minute circular orifice facing upwards.

3. Mouth directly associated with neuropore, the latter opening into the buccal cavity.

4. Doubtful if larva feeds at all; in many cases it certainly does not. If it does the food (as in adult) is ingested by ciliary currents and consists of micro-organisms and organic débris.

In the locomotion of the Enteropneusta the muscular proboscis is the essential organ of burrowing, and the distensible collar the essential organ of progression ${ }^{1}$.

The passage of the mouth from the ventral position which it occupies in the Enteropneusta to its dorsal position in the Ascidian larva may perhaps be attributed physiologically to the increased importance and efficiency of that association of mouth and neuropore which may be said to be already foreshadowed in the Enteropneusta (see Pl. XXVII. Fig. 6 A). The practical difficulty in the way of this translation of the mouth presented by the proboscis intervening between the latter and the dorsal surface can be supposed to have been, and probably was, surmounted pari passu with the change of function of the proboscis from a muscular burrowing organ to a non-muscular snout or fixing organ. This change would carry with it changes in the entire order of development and the mouth could open dorsally coincidently with the neuropore before the formation of the praeoral lobe. This is essentially what does happen ${ }^{2}$.

1 A remarkably pretty analogous method of locomotion is exhibited by Dentalium, a species of which I had the opportunity of observing at Lifu. Here the muscular foot with its pointed end is the essential organ of burrowing, while the two lateral aliform lobes, which expand at the proper moment, together constitute the essential organ of progression.

2 See A. Willey, "Studies on the Protochordata," I. Q. J. MI. S., Vol. xxxir., p. 317 and III. Ibid. Vol. xxxv., p. 316. My interpretation of the organ of fixation of the Ascidian larva as praeoral lobe has been met with some natural scepticism, but on this point I may say that my views remain unchanged. As it happens, however, this is a point of detail, and we can go a long way without it. 
It is perhaps not out of place to enquire whether there is any parallel instance of a minute, toothless, buccal orifice facing upwards. One of the most remarkable Teleostean fishes I have ever seen, namely, Amphisile strigata Guenther ${ }^{1}$, has the habit which I observed for the first time near Dawson Straits in the D'Entrecasteaux Group (British New Guinea), of swimming in an upright position in the water by means of its pectoral fins. The caudal and pelvic fins are vestigial. The entire ventral surface from tip to tail is as sharp as a knife-edge. The animal is pointed at both ends, about six inches long, one inch maximum height and $\frac{1}{4}$-inch maximum thickness along the back. It cuts through the water with its razor-edge at a great rate, and the mouth is an extraordinarily minute terminal toothless orifice pointing upwards in consequence of the erect swimming attitude.

\section{iII. Regional Pores and Nephric Tubules.}

Bateson was the first to compare the proboscis pore of Balanoglossus with the orifice of the praeoral pit of the larva of Amphioxus, basing the comparison upon Hatschek's account of the origin of the praeoral pit from the left division of the head-cavity. In view of the uniquely amphioxine nature of the origin of such a structure as the praeoral pit, combining the properties of gland and sense-organ, from a coelomic pouch; also in view of recent attempts to discredit Hatschek's discovery, a few general aspects of the question may be brought into view.

In the first place it is quite certain that one's morphological sense of coelomic propriety would never have been offended if the left head-cavity had acquired a communication with the exterior by means of a minute pore (which might perhaps have been difficult to find in section) instead of by a generous embouchure.

In the second place it is well to remember what seems to be usually forgotten, namely, that Hatschek's discovery was the result of unbiassed observation and no theoretical consequences were made to hang upon it until Bateson made the comparison referred to above.

Lastly Hatschek's account of the origin of the praeoral pit, which was based upon observations upon the living embryos, has recently been confirmed in section by MacBride ${ }^{2}$.

It is much easier to unravel the anterior trematic complex of the Ascidian larva than that of Amphioxus. In the larva of Amphioxus we have mouth, praeoral pit ${ }^{3}$, neuropore, and Kölliker's olfactory pit which arises as'an epidermal depression over the neuropore. The olfactory pit is the disturbing element. The most obvious conclusion is that it is comparable with Spengel's anterior Epidermistasche in the Enteropneusta, but I do not think this is quite the right conclusion. Neither do I think that the comparison of the proboscis-pore with the orifice of the praeoral pit is as simple a matter

1 Kindly identified for me by Mr G. A. Boulenger, F.R.S.

${ }^{2}$ E. W. MacBride, "The early development of Amphioxus," Q. J. M. S., Vol. xL., 1898, p. 589.

3 The praeoral pit itself undergoes a certain amount of differentiation, but this does not directly concern us now. 
as might appear. All these structures in animals of the grade of organisation of the Enteropneusta, Cephalochorda and Urochorda are in a more or less primordial condition, and hence appear deceptively simple just as an egg-cell which conceals the potentialities of the future organism may appear a simple mattcr.

In the Enteropneusta there are, as we have secn, dorsal canalicular portions of the proboscis coelom separated from one another by the pericardium. Each of these dorsal coelomic canals may, but usually only one does, open into a tubular end-sac, which in turn opens to the exterior. Bateson found in Bal. kowalevskii that the end-sac arises as an ectodermal ingrowth, and Spengel has found the same in regenerating specimens of Pt. minuta.

We have to consider therefore the possible and particular fate of

1. The dorsal coelomic canals in their capacity as portions of the proboscis coelom or anterior body-cavity.

2. The opening of a coelomic canal into an end-sac, which is equivalent to the opening of the coelom at an ectodermal surface.

3. The end-sac itself.

4. The external orifice of the end-sac.

With regard to the fate of the anterior body-cavity there is one remote though instructive ground of comparison between the Enteropneusta and the Cephalochorda. In the larva of Amphioxus the larger or dextral portion of the head-cavity (usually called the right head-cavity) forms the cavity of the snout or rostrum. In the adult this cavity is lost in the massive development of the laminar tissue (Pouchet) which is characteristic of Amphioxus. Similarly in the Enteropneusta the posterior ends of the coelomic canals of the proboscis lose themselves in and contribute cellular islets to, the chondroid tissue (Marion, Spengel).

It is very important to remember that in dealing with these structures there are two kinds of pores to be accounted for and not one pore only (above Nos. 2 and 4). In the path which has culminated in the Urochorda the coelomic opening (above No. 2) has, I believe, demonstrably vanished. It may not have vanished in Amphioxus; it may have had there another fate, a change of destiny instead of annihilation.

The praeoral pit of the larva of Amphioxus is a portion of the coelom which opens to the exterior, that is to say, which opens at an ectodermal surface. It has been the custom to speak of the right and left head-cavities of Amphioxus. This is correct in one sense, but in one sense only. Ontogeny teaches us (and this is borne out by comparative embryology) that the right and left head-cavities of Amphioxus are subdivisions of one anterior body-cavity ${ }^{1}$, and are not paired structures in the same sense in which the collar-cavities are paired. The praeoral pit therefore should not be defined as the left head-cavity, but as the sinistral portion of the head-cavity which acquires independence and an opening to the exterior.

1 Which has been called "protomere" by Masterman.

W. III. 
I therefore suggest that the orifice of the praeoral pit of the larva of Amphioxus represents the opening of the coelom into the end-sac of the Enteropneusta; the end-sac and its external orifice are represented in Amphioxus by Kolliker's olfactory pit which coincides in its point of origin with the pre-existing neuropore, which herce opens into its base ${ }^{1}$; the coelomic portion of the anterior trematic complex is therefore still existent in Amphioxus, but it is separated from its terminal portion (end-sac) concurrently with the forward extension of the notochord in the same way as the mouth has been dissociated from the neuropore?

Hatschek described, as of mesodermal origin, a subchordal praeoral tube on the left side of the larva of Amphioxus. This has been called Hatschek's nephridium, and its opening into the anterior buccal portion of the pharynx was described and figured by Lankester and Willey ${ }^{3}$. MacBride (loc. cit.) has recently found that at an early stage this tube is in open primary communication with the somite which he has called the left collar-cavity, and in fact that it arises as a canalicular extension of the hollow stalk which connects the left collar-cavity with the archenteron. It only occurs in the larva, is lost during the metamorphosis, and is probably a vestigial structure.

The collar-canals of the Enteropneusta may be said to open into the pharynx through the mediation of the first gill-pouch and of the first gill-cleft (cf. Pl. XXXII. Fig. 52). The inference is obvious that Hatschek's nephridium is an unpaired vestige of the excretory canals of the collar region.

I have already (see pp. 273 and 280) compared the vestigial truncal canals of Spengelia with the atrio-coelomic funnels (Lankester) of Amphioxus.

1 This is in complete accordance with the view which I have expressed on a former occasion, that Kolliker's olfactory pit represents the neuro-hypophysial canal of the Ascidian larva. By the epidermal invagination (at a late stage) which produces Köllikex's olfactory pit the neuropore is carried inwards at its base, and no longer opens flush with the surface of the body. In this way the neuropore acquires a new quality, namely, it becomes the cerebral opening of the olfactory pit or neuro-hypophysis. Thus in Amphioxus, the neuropore and the inner or cerebral opening of the neuro-hypophysis coincide. That there are two structures involved is indicated by the fact that the neuropore exists for a long time in the absence of a neuro-hypophysis (olfactory pit). As described by me in Ciona (loc. cit.) it appears that a large portion of the duct of the adult subneural gland is derived from a secondary evagination of the wall of the buccal siphon at the lips of the primary branchial or buccal orifice of the neuro-hypophysis (see Quart. Journ. Micro. Sci. Vol. xxxv. pp. 305-306). In this way the primary opening of the neuro-hypophysis into the mouth is carried inwards just as the neuropore in Amphioxus is carried inwards by the formation of Kölliker's olfactory pit. Thus the dorsal tubercle of the adult subneural gland is not the same thing as the primitive opening of the neurohypophysis, but it may be said to correspond with the exterual orifice of Kölliker's olfactory pit. The olfactory pit and neuropore in Amphioxus together, represent the neuro-hypophysis of the Ascidian larva; the subneural gland of the adult Ascidian which develops from the neuro-hypophysis is not represented in Amphioxus and is, so far as we know, a purely Ascidian structure.

${ }^{2}$ I offered an explanation of the dissociation of the larval mouth from the neuropore in 1891 (A. Willey, "The later larval development of Amphioxus," Quart. Journ. Micro. Sci., Vol. xxxII., 1891), which has met with some favour.

${ }^{3}$ E. Ray Lankester and A. Willey, "The development of the atrial chamber of Amphioxus," Quart. Journ. Hicro. Sci., Vol. xxxi., 1890, p. 445. 
Thus, if the above comparisons are correct, Amphioxus possesses at some period of its life vestiges of the three pairs of regional or archimeric excretory canals, whose function has been superseded (by substitution) by the nephric tubules.

I have suggested above (p. 281) that the primordia of the nephric tubules may actually be recognised at the dorsal medial angles of the gill-pouches of Enteropneusta (cf. Pl. XXXII. Fig. $55 d g p$ ).

In any case it is quite certain that the topographical coincidence of the nephric tubules with the gill-clefts as described by Weiss and Boveri in Amplioxus is not an accidental association. It evidently means what it appears to mean, namely, that the nephric tubules and the gill-clefts were primarily coextensive ${ }^{1}$.

The nephric tubules of Amphioxus have superseded the regional pores as the essential organ of excretion but in a very different way from that in which the latter are superseded in the Enteropneusta by the glomerulus, which is an organ sui generis. The nephric tubules belong to the same cycle of changes as the regional pores and originate from the same blastema. They replace the regional pores by true substitution, just as in the Vertebrata the mesonephros replaces the pronephros and the metanephros the mesonephros.

Whether or not the regional pores arose as such or have been differentiated from a more indefinite condition as seen in the multiple madreporites of many Echinoderms is not an easy question to decide. The analogy with other cases would lead us to suppose that the ideal condition indicated in the adjoining table is not the primordial condition. We may at any rate formulate provisionally the following sequence of phyletic changes relating to the evolution of the Vertebrate kidney.

I.

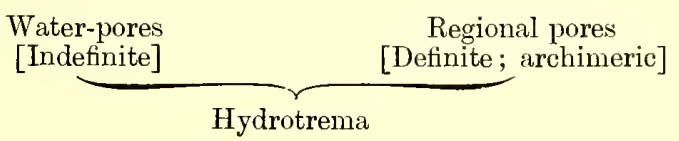

IV.

Pronephric tubules

[Emancipated from gill-clefts]

[Craniate embryos and larvae]
V.

Mesonephric tubules [Opening into coelom] [Anamia]
III.

Nephric tubules [Coextensive with gill-clefts] [Cephalochorda]

VI.

Metanephric tubules [Emancipated from coelom (Wiedersheim ${ }^{2}$ )] [Amniota]

The following table expresses in brief the conclusions to which we have arrived, but it should be taken in conjunction with the text to avoid misunderstanding.

It is intended to show the origin, by substitution, of the Vertebrate excretory system from the archimeric system of excretory canals. Of course the table will only

1 By realising this truth, Paul Mayer's discovery of the six connecting vessels between dorsal aorta and subintestinal vein in embryos of Pristiurus and Rückert's discovery of their topographical coincidence with the pronephric tubules, to which they furnish rudimentary glomeruli, will have assigned to them the importance which is their due.

${ }^{2}$ R. Wiedersheim, "Ueber die Entwicklung des Urogenitalapparates bei Crocodilen und Schildkröten," Arch. f. mikr. Anat., Bd. xxxvi., 1890, p. 410. 
accomplish this object on the assumption that the nephric tubules of Amphioxus (i.e. as we know them in Amphioxus) represent the primordium of the Vertebrate kidney.

\begin{tabular}{|c|c|c|c|c|}
\hline GrodP & $\Delta$ & RCHIMERIC ${ }^{1}$ SySTEM & & Essential Organs \\
\hline Ideal & Protomeric pores & Mesomeric pores & $\begin{array}{l}\text { Opisthomeric } \\
\text { pores }\end{array}$ & Regional pore-canals \\
\hline Enteropneusta & Proboscis pores & Collar pores & $\begin{array}{l}\text { Truncal pores } \\
(\text { Spengelia })\end{array}$ & Glomerulus \\
\hline Cephalochorda & $\begin{array}{l}\text { Praeoral pit }+ \\
\text { olfactory pit }\end{array}$ & $\begin{array}{l}\text { Hatschek's } \\
\text { nephridium }\end{array}$ & $\begin{array}{l}\text { Lankester's } \\
\text { brown funnels }\end{array}$ & $\begin{array}{l}\text { Boveri's nephric } \\
\text { tubules }\end{array}$ \\
\hline Urochorda & $\begin{array}{l}\text { Neuro-hypophysis } \\
\quad\left(\text { in part }{ }^{3}\right)\end{array}$ & & & $\left\{\begin{array}{c}\text { Renal vesicles } \\
\text { Organ of Bojanus } \\
\text { (Molgulidae) }\end{array}\right.$ \\
\hline Vertebrata $^{2}$ & $\begin{array}{c}\text { Hypophysis } \\
\text { cerebri (in part }{ }^{3} \text { ) }\end{array}$ & & . & $\left\{\begin{array}{l}\text { Pronephros } \\
\text { Mcsonephros } \\
\text { Metanephros }\end{array}\right.$ \\
\hline
\end{tabular}

1 In this table I have incorporated the terms archimeric, protomeric, \&c. in the sense in which they were introduced by Masterman ("On the Diplochorda," Quart. Journ. Micro. Sci., Vol. 40, 1897, p. 281). He describes the tripartite division of the coelom as archimeric segmentation, and the three archimeres are (1) Protomere, (2) Mesomere, (3) Metamere. The last is inadmissible because metamere already has a meaning of its own, and I must therefore replace it, for my present purpose, by the term opisthomere.

2 In 1886 Bateson wrote:- " Upon the origin of the excretory system of Vertebrata nothing can be aftirmed from a study of Balanoglossus." I trust the above table will illustrate the progress that has been made in this matter during the last ten or twelve years.

${ }^{3}$ In part because coelomic element is wanting. 


\section{Collar Nerve-cord and Roots.}

Spengel does not regard the collar nerve-cord of the Enteropneusta as the central nervous system but as being only a part of it which has become closed in. This is a highly important view, and it is again with satisfaction that I find myself in agreement with Spengel. He defines the collar nerve-cord (Mon. p. 705) as "die Einsenkung des auf den Kragen entfallenden Theiles des dorsalen Nervenstanmes, der in seiner ganzen Länge vom Grunde der Eichel bis in die Nähe des Afters. bereits vorher nicht nur angelegt, sondern in allen seinen charakteristischen Zügen ausgebildet ist."

The centralisation of the nervous system of the Euteropneusta has not proceeded far. There is concentration along the middle line on the dorsal or sensory side of the body and another concentration along the middle line on the ventral or locomotor side of the body ${ }^{1}$. The dorsal concentration or dorsal nerve-cord of the trunk passes directly into the ventral wall of the medullary tube in the collar region and at the junction of medullary tube and dorsal cord, i.e. at the posterior edge of the collar a circular commissure passes round to unite with the anterior end of the ventral nerve-cord.

Bateson pointed out that the dorsal side of the medullary tube of the collar was the sensory side and received afferent fibres through the so-called dorsal roots or at the two ends of the cord in those forms which do not possess roots; and that the ventral side of the medullary tube from which efferent fibres pass into the muscles, is the motor side. The conclusion he came to was practically the only one possible at that time, namely, that the roots of the collar cord of Enteropneusta "are to be regarded as the homologues of the dorsal roots of other Chordata."

"In Balanoglossus"," says Bateson (1886 loc. cit. p. 558), "we see in the trunk the cord still in the skin, in the collar the cord delaminated", and at the ends of this cord the process of invagination commencing and leading to the presence of a lumen."

This quotation shows that Bateson was alive to the fact that the collar cord is only a local differentiation of the dorsal cord as a whole. This fact is still more clearly expressed by Morgan (Journ. Morph. Vol. Ix. 1894, see p. 74) in the following words, which I heartily endorse:- "We see in Balanoglossus that the invaginated dorsal nervecord can correspond only to the anterior end of the nerve-cord of Amphioxus, and that the superficial dorsal nerve-path, stretching through the gill region thence to the end of the body, must be the homologue of the remainder of the nerve-cord of Amphioxus."

1 The ingenious method of homologising the reverse sides of the body in Vertebrates and Invertebrates by employing the terms "neural" and "haemal" instead of "dorsal" and "ventral" is a gigantesque example of a petitio principii.

2 That is to say Bal. kowalevskii.

3 In Bal. kowalevstii the collar nerve-cord arises in a peculiar manner akin to delamination. In Tornaria as shown by Morgan and in regenerating Ptychodera flava as shown on Plate XXVI. it arises by fusion of medullary folds. 
Baldwin Spencer compared the eye of the Ascidian tadpole with the pineal eye, the most tangible point of resemblance being in the method of formation of the lens, the entire eye, lens and retina being of myelonic origin. This comparison may still hold good so far as it goes. But the full significance of the pineal eye can only be appreciated when we have traced its origin, or at least its affinity, to something which was not an eye at all but a far more generalised sensory apparatus.

Moreover the result of recent work ${ }^{1}$ (Klinckowström, C. Hill, etc.) has been to show that the epiphysial complex is not a simple outgrowth from the roof of the primary fore-brain; there may be more than one outgrowth; there may even be more than one pineal eye with retina and lens complete.

Without going into greater detail, I may refer the reader back to my account of the roots in Pt. flava (p. 234), the intra-epidermal canals in Pt. carnosa (p. 252), and the vestigial root of $S p$. porosa (p. 271).

I have described the remarkable terminal bulb of the vestigial root of Spengelia porosa (Pl. XXXI. Fig. 40) as being in a condition of mucoid degeneration. Whether or not there is any trace of pigment in life I cannot say. Very probably there is some kind of colouring matter. But we do not expect to find any great display of pigment in the Enteropneusta since they are burrowing creatures, living concealed from the light of the sun and belonging essentially to the marine cryptozoic fauna. If $S p$. porosa lived an exposed life the terminal bulb would probably be in a condition of pigmentose degeneration.

An epiphysial structure like an enteropneustic root can be transformed into an epiphysial structure like a pineal eye by losing its primary function, passing through a condition of pigmentose degeneration (or at least developing pigment in its walls) and then being rejuvenated by the acquisition of a new function, the agent of the rejuvenescence being some form of natural selection.

We may therefore infer the following cycle of events:-

I.

Enteropneustic roots

(Ptychoderidae)
II.

Pigmentose condition
III.

Pineal eye or eyes
IV.

Epiphysis cerebri

I will now state with confidence the following proposition.

The medullary tube of the collar of Enteropneusta is the homologue of the cerebral vesicle only of Amphioxus and of the Ascidian tadpole and probably represents no more than the primary fore-brain ${ }^{2}$ (thalamencephalon) of Craniota; the roots ${ }^{3}$ of Ptychoderidae

1 A. Klinckowström, "Beiträge zur Kenntniss des Parietalauges," Zool. Jahrb. (Abth. f. Anat. u. Ont.) vir. 1894, p. 249; Charles Hill, "The epiphysis of Teleosts and Amia," Journ. Morph. Ix. 1894, p. 237; W. A. Locy, "Contribution to the structure and development of the Vertebrate Head," Journ. Morph. xI. 1895; see remarks on the Pineal Sense-organs, p. 561 and bibliography; also A. Prenant, Éléments d'embryologie...des vertêbrếs, Vol. II. p. 566 et seq., Paris, 1896.

2 Whether or not it contains elements of the mesencephalon need not be discussed here. The fundamental truth is that the primitive cerebral vesicle has been closed in phylogenetically in advance of the spinal cord, which meanwhile is represented by the dorsal nerve tract in the skin.

3 I have not considered the origin of these roots themselves. All the facts which are known (e.g. the appearance of a median neural crest in Pt. flava (above, p. 235); the median keel observed by Spengel in 
are genetically related to the epiphysial complex of Craniota; in the crucial nuchal region of the Enteropneusta are therefore to be found not the actual but the nearest possible approximation to the actual primordia of the hypophysis cerebri and of the epiphysis cerebri of Craniota.

\section{Genital Pleurae.}

From the statements and quotations contained in the preceding section it will be seen that there is considerable consensus of opinion in regard to the definition of the collar nerve-cord as the closed-in anterior portion of the dorsal trunk.

Just as the medullary tube of the collar is admittedly an invaginated portion of the dorsal nerve-trunk so the medullary folds which arise and fuse to form the medullary tube are to be regarded as specialisations of the anterior portion of pleural folds which are retained in the Ptychoderidae as the genital pleurae.

In the Craniota there are two principal methods of formation of the medullary tube, namely;-

(1) By medullary folds as in Elasmobranchii, some Ganoids, Amphibia, Sauropsida and Mammalia;

(2) By solid proliferation or delamination as in Cyclostomes, some Ganoids, and Teleostei.

In the Protochorda we find essentially the same two methods in a simplified form, namely ;-

(1) Medullary folds in Urochorda;

(2) A peculiar epithelial delamination in Cephalochorda.

In the Enteropneusta, within the limits of the group itself we find the same two methods, namely;-

(1) Medullary folds as in the Tornaria of Pt. biminiensis (Morgan²) and in regeneration of Pt. flava (above, p. 245);

(2) Delamination as in Bal. kowalevskii (Bateson).

young Pt. minuta; and the remarkable keel also described by Spengel in adult Bal. kowalevskii, etc.) can be brought into accordance with the following definition.

The median roots of the Enteropneusta have arisen as differentiations from the raphe produced by the fusion of the medullary folds over the cerebral portion of the dorsal nerve-cord to form the medullary tube of the collar. This definition is based on the facts of anatomy. According to Morgan's account of the development of the Bimini Tornaria (1894 loc. cit.) it is not borne out by the facts of development. Singularly enough it does seem to be borne out in a remarkable manner in regeneration, which often appears to point the way to a conception where ontogeny fails (see above, p. 246).

1 Cf. section on Regeneration in Pt. flava, above, p. 245, and Figs. 5A-E on Pl. XXVI.

2 This is all the more noteworthy because Pt. biminiensis (see above, p. 291) is one of those species whose medullary cord does not possess an axial canal in the adult. The method adopted in Tornaria agassizii as described and figured by Morgan is also the method of fusion of medullary folds, but by a strange fatality my friend characterises it as being "exactly the same way that the nerve chord of Amphioxus is formed" (T. H. Morgan, "The growth and metamorphosis of Tornaria," Journ. Morph., Vol. v. 1891, see p. 422). 
As is well known it is Gegenbaur's view that the method of delamination is more primitive than the method of fusion of medullary folds. There are others who hold the opposite view. By considering how far the one or the other view will lead him to an appreciation of the subject in hand, the reader may choose for himself between the two views. If he chooses the method of delamination, then he takes upon himself the onus of explaining the meaning of the central canal. For my part I pin my faith to the medullary folds because by their means I see my way to the application of the principle of change of function, and to an approximate conception of the meaning of the central canal.

That the genital pleurae are structures which are capable of undergoing change of function is shown by various indications; perhaps more than anything by the fact that they already serve at least two functions, namely, the supreme function of carrying the gonads and the secondary function of protecting the branchial complex. That they do serve the latter function is quite obvious in a form like Pt. flava, while in a form like Pt. carnosa, where it is less obvious, it is none the less indicated by their capacity of uniting together over the gill-area by a mucous junction (Pl. XXVII. Fig. 6).

The capacity for change of function is also strikingly exhibited at the anterior end of the genital pleurae in species of the subgenus Tauroglossus, where they converge towards one another dorsally in the region of the posterior neuropore and no longer contain gonads in this region (cf. Pl. XXXII. Fig. 61).

Spengel has drawn attention to the more ventral position of the gill-slits in Amphioxus as compared with their more dorsal position in the Enteropneusta, and naturally uses this as an argument in favour of his views. That there is a difference I gladly admit. A process of readjustment has been at work'. The dorsal gill-pores of the Enteropneusta are not present in Amphioxus.

It is a truism to say that change of function of an organ is and must be accompanied by correlated changes of organisation.

To take the particular case under discussion as an example it may be said that the change of function by which the genital pleurae could become converted into medullary folds would be accompanied by their complete emancipation from the gonads and, sooner or later, by the abolition of the dorsal gill-pores", the gill-clefts finding another (ventral) outlet.

Analogous changes have apparently actually taken place in the collar; this is seen in cases of regeneration and may also be inferred on other grounds (see below p. 321).

It now becomes necessary to discuss the organisation of Amphioxus in the light of the above considerations.

We have seen that the pleural folds of the Ptychoderidae possess gonadial, medullary and peribranchial qualities. Taken as a whole therefore they constitute, potentially, a complex primordium. We have already dealt with their gonadial and medullary attributes and it only remains to consider their peribranchial potentialities.

\footnotetext{
1 Compare the excessive readjustment of the gill-clefts which takes place in the ontogeny of Amphioxus.

2 There are two ways of abolishing inconvenient gill-openings, namely, (1) by closure of the slits, (2) by readjustment of the slits. Both these methods are adopted in the larva of Amphioxus.
} 
It is a subject of great complexity, and I can only indicate some of the facts and arguments which must be brought to bear upon it.

1. In virtue of their medullary and peribranchial properties, the pleural folds which are represented in the Enteropneusta by the genital pleurae must contain within them the primordia not only of medullary folds, but also of atrial folds.

2. Although Amphioxus is not the only animal which possesses an atrium, it is the only animal in which the atrium is formed by the fusion of atrial (metapleural) folds.

3. Amphioxus possesses atrial folds, but not medullary folds ${ }^{1}$, the central nervous system forming cenogenetically by delamination.

4. The two halves of the Tunicate atrium are confluent dorsally.

5. The two halves of the atrium of Amphioxus are confluent ventrally.

6. The atriopore of Amphioxus is a neoformation. It is neither an orifice of invagination nor does it arise ontogenetically as a perforation of the body-wall, but it is a foramen remaining after fusion of folds.

7. Several species of the subgenus Tauroglossus are characterised by the presence of deep ventral coecal prolongations of the gill-pouches (Pt carnosa, etc.).

8. In describing the condition met with in Amphioxus, in terms derived from the comparison of Amphioxus with a form like Pt. carnosa, we should say that in Amphioxus the dorsal gill-pores are lost, the gill-pouches of each side are confluent longitudinally, and the gill-pouches of both sides are confluent ventrally, while the atriopore is a neoformation.

9. In order to appreciate the condition met with in a form like Pt. carnosa as compared with Pt. flava, a glance at Pl. XXX. Fig. 22, will show that if the septal walls dividing the successive gill-pouches from one another were to break down, so that the gill-pouches of each side became confluent longitudinally, we should have absolutely the condition which we actually find in Pt. flava (Pl. XXVIII. Fig. 6).

10. The ventral coeca of the gill-pouches of Pt. carnosu and other species are reminiscent of the ventral origin of the genital pleurae (compare Pl. XXX. Fig. 22, and Pl. XXVIII. Fig. 6).

11. Apart from the implication contained in the preceding hypothesis (No. 10), there is every reason to regard Pt. flava as a relatively primitive form.

12. Hence the gill-pouches of the Enteropneusta are structures superadded to the primitive organisation.

The broad generalisation which may be formulated as the summation of the preceding considerations is that the genital folds of Enteropneusta, the atrial folds of Amphioxus, and the medullary folds of Vertebrata belong to the system of pleural folds of the body-wall, and are differentiations from a common primordium.

\footnotetext{
1 An interesting example of compensating growth.
}

W. III. 


\section{Posterior Trematic Complex.}

I have already dealt with what I have called the anterior trematic complex (above, p. 309).

The posterior trematic complex of the Enteropneusta is situated at the posterior end of the collar in the dorsal middle line, and owes its existence to the close association of the posterior neuropore, the collar-pores, and the first pair of gill-pores ${ }^{1}$. It is unnecessary to repeat what has already been said in the account given of Pt. carnosa (see p. 253 and Pl. XXX. Fig. 21) and Sp. alba (see p. 280).

It is, however, very important to recognise the existence of the posterior trematic complex, the position of which in the Enteropneusta is due to the fact that only the cerebral portion of the central nervous system has been closed in as a medullary tube. Therefore while the mouth has relations with and forms part of the anterior trematic complex, the auus has nothing to do with the posterior trematic complex of the Enteropneusta.

As more of the cerebro-spinal axis becomes closed in by the fusion of the medullary folds, the association of pores which primarily constitutes the posterior trematic complex will be dissolved. When the fusion of the medullary folds reaches the anal region, the posterior trematic complex will comprise the association of posterior neuropore and blastopore (primitive anus).

We find here therefore a clue to the meaning of the neurenteric canal, which is due to the association of posterior neuropore and blastopore, and their inclusion within the medullary folds.

If there is any truth in what has been said, it is a matter of such importance that it may be stated categorically that the association of posterior neuropore and blastopore which generally leads to the formation of a neurenteric canal, is the posterior trematic complex of the embryos of Vertebrata.

\section{Stomochord ANd Pygochord.}

The presence of these skeletal products of the gut wall is undoubtedly an expression of the chordate strain in the Enteropneusta, but neither the one nor the other can be homologised with the notochord of the Vertebrata. The pygochord being ventral does not burden the question, but the stomochord is quite another matter. Although there is no question of the pygochord being compared directly with the notochord, yet I think it can be made very suggestive in any attempt to explain the latter.

The position of the stomochord has been compared with the forward extension of the notochord in Amphioxus. I am convinced that this comparison cannot be wholly sustained because the post-cerebral limitation of the notochord as seen in the Urochorda is undoubtedly more primitive than the cephalochordate condition of Amphioxus. Nevertheless, both in Amphioxus and in the embryos of Craniota there is frequently found a disturbance of some kind at the anterior end of the notochord, and this may be due to a local reminiscence of a stomochord.

1 To these must be added, in Spengelia, the truncal pores. 
1 doubt whether the enteropneustic stomochord as a whole can be said to correspond to any definite part of the true notochord. The praeoral extension of the notochord, far beyond the anterior limit of the neural tube in Amphioxus, is due to a forward growth of the pre-existing notochord; whereas the praeoral position of the stomochord in the Enteropneusta is due to a forward projection of a portion of the collar-gut or throat. Spengel calls it the "Eicheldarm," but this word, although intended to be indifferent, is apt to mislead, because the stomochord does not belong to the proboscis at all in its primary quality of integral constituent of the gut, but only in its secondary quality of a skeletally metamorphosed derivative of the gut.

Moreover, whereas the notochord is a uniform, single, indivisible structure, the regional differentiation of the stomochord is, as we have seen, one of its most marked characteristics. It is therefore not sufficient to say that any structure in other forms is comparable to the enteropneustic stomochord, but it must be specified which portion of this structure is referred to.

The cavity of the stomochord is in an obviously vestigial condition. In the days of its functional activity it must have been a portion of the post-oral gut cavity. Its secondary projection in front of the mouth is a fact which can only be explained at present by assuming a precocious segregation of its primordia, such a segregation being indicated by the fact of its developing from an apparently simple rudiment ${ }^{2}$.

As I have dealt with this matter in an article which will shortly appear in the Quarterly Journal of Microscopical Science, I can briefly state the conclusions to which I have come.

1. The "notochord" of Cephalodiscus is related to the vermiform process of the stomochord of Enteropneusta (Spengelidae). This was first suggested by Harmer ${ }^{3}$.

2. The pleurochords described by Masterman in the Actinotrocha of the Bay of St Andrews appear to be vestiges of gill-clefts which still persist in Cephalodiscus These pleurochords occur in the lophophoral (collar) region of the body.

3. The pleurochords of Masterman are related to the lateral pouches of the stomochord of Enteropneusta.

4. Thus the lateral pouches of the stomochord may represent the vestiges of a pair of post-oral, but prae-truncal, gill-clefts; gill-clefts having been abolished from

1 It is this extension of the notochord in front of the cerebral vesicle and neuropore which distinguishes the cephalochordate nature of Amphioxus from the holochordate nature of the Craniota.

2 The terms rudiment and primordium are not capable of rigid definition and they are often interchangeable. The rudiment of a new organ is often the vestige of an ancient one, an old vestige becoming transformed into a new rudiment by substitution and change of function. In such cases therefore rudiment is the converse of vestige. Primordium is an independent term, and whereas every primordium is a rudiment, every rudiment is not a primordium. Of course no line of demarcation can be drawn between primordium and rudiment, nor can any be drawn between embryo and larva. The primordium of an organ is to the rudiment of an organ what the embryo of an organism is to the larval organism.

Mr G. C. Bourne at the meeting of the British Association in Bristol last year, pointed out that the word primordium, in the essential sense in which it is used in the text, originated with William Harvey.

3 S. F. Harmer, "On the Notochord of Cephalodiscus," Zool. Anz. 1897, p. 342.

4 A. T. Masterman, "On the further anatomy and the budding processes of Ceplalodiscus dodecalophus," Trans. Roy. Soc. Edin., Vol. xxxtx. 1898, p. 507. 
the collar region in the Enteropneusta and restricted to the truncal region in correlation with the regional differentiation of the body, and, connected therewith, the limitation of the gill-clefts (above, p. 298)1.

5. The ventral coecum with chordoid walls described by Roule (Comptes Rendus, t. CxxviI., 1898, p. 633) in the Actinotiocha of Phoronis sabatieri is related to the ventral coecum of the stomochord of Enteropneusta.

6. The functional oesophagus of Actinotrocha is represented by the anterior portion of the body of the stomochord in Enteropneusta.

7. Thus Actinotrocha and Cephalodiscus appear to retain in a functional condition a portion of the gut which in the Enteropneusta has become, as such, vestigial. That sessile forms should retain some primitive features in comparison with their freeliving relatives is not without precedent.

The Pterobranchia are to the Enteropneusta what the Ascidians are to Amphioxus.

Apart from its ventral position, the pygochord seems to me to represent what must have been the condition of the notochord at its first inception; namely, the notochord was at first a longitudinal dorsal band-like thickening of the gut-wall with dilated distal border; and the subnotochordal rod represents the longitudinal peduncle of the longitudinal notochord. This explanation of the subnotochordal rod was suggested to me by the behaviour of the pygochord with its constrictions (cf. Pl. XXIX. Fig. 15 and Pl. XXX. Fig. 35), and it is, I think, the third explanation which has been suggested in recent years.

Stöhr ${ }^{2}$ thought that the hypochorda resulted from the fusion of segmental diverticula of the dorsal wall of the intestine. Klaatsch ${ }^{3}$ thinks that the hypochorda is the vestige of the hyperpharyngeal groove of Amphioxus".

\section{Branchial Bars.}

One of the organic changes which accompanied the (hypothetical) change of function of the gill-clefts (i.e. from their primary function of promoting intergonadial currents of water to aerate the gonads to their secondary function of promoting the respiration of the individual) was the development of tongue-bars as the essential organs of respiration. It has already been pointed out that the tongue-bars of Enteropneusta are not (ontogenetically) secondary as they are in Amphioxus.

\footnotetext{
1 The gill-clefts have been limited both anteriorly and posteriorly. The anterior limitation, behind the collarregion, is constant in all Enteropneusta; the posterior limitation is, as we have seen, excessively variable. In connection with the hypothesis that the lateral pouches of the stomochord are the vestiges of a pair of collar gill-clefts, it is useful to remember that in the larva of Amphioxus, the first gill-cleft does actually close up and disappear.

2 Ph. Stöhr, "Ueber die Entwicklung der Hypochorda und des dorsalen Pankreas bei Rana temporaria," Morph. Jahr. xxirr. 1895, p. 123.

${ }^{3}$ H. Klaatsch, "Zur Frage nach der morphologischen Bedeutung der Hypochorda," Ibid. xxv. 1898, p. 156.

${ }^{4}$ According to my view the absence of a subnotochordal rod in Amphioxus is due to abbreviation of development, i.e. it is a cenogenetic loss like the absence of medullary folds, etc. It may be remembered that Eisig compared the subnotochordal rod with the "Nebendarm" of Capitellidae.
} 
By their development, size and vascularity, the tongue-bars of the Enteropneusta obviously constitute, collectively, the essential organ of respiration. In Amphioxus the functional importance of the tongue-bars is greatly diminished; they are smaller in size and lower in vascularity than the primary bars and their development is secondary. In Amphioxus therefore the conditions are reversed, the primary or septal bars constituting, collectively, the essential organ of respiration.

In correlation with the further reduction in the number of gill-clefts and the incorporation of the few that remain into the cephalic complex of cramiate Vertebrates, the nephric tubules have been released from the topographical relation which they bear to the gill-clefts and to the tongue-bars in Amphioxus, and the tongue-bars themselves have disappeared as such. As I have suggested on a former occasion there is reason to believe that the tongue-bars have not vanished without leaving a trace behind, but that their degradation from the position of essential organ of the gill-cleft has culminated in their transformation into the primordial elements of the thymus of Vertebrata ${ }^{1}$. The substance of the tongue-bars has been employed in building up the thymus.

The cycle of phyletic changes undergone by the tongue-bars of the gill-clefts may be epitomised as follows:-

I.

Essential ORgans (Enteropneusta)
II.

SECONDARY BaRS (Amphioxus)
III.

Vestiges

(Embryos of Craniota)
IV.

Thymus

(Adult Craniota)

\section{Parabranchial Ridges.}

In the larva of Amphioxus the endostyle is seen to be composed of two halves, right and left ${ }^{2}$. From the anterior ends of the horns of the endostyle a pair of sharply defined ciliated bands-the peripharyngeal bands-arch round the anterior wall of the pharynx until they reach the dorsal side of the latter, whence they proceed backwards to the end of the branchial region. In the adult the dorsal pharyngeal wall becomes modified into the hyperpharyngeal groove and the ciliated bands merge into the walls of this groove. In the adult therefore it is impossible in surface view to see the dorsal recurrent portion of the bands, but it is, at least in young adults, eminently possible to see the anterior arcuate peripharyngeal portion of the ciliated bands ${ }^{3}$.

The parabranchial ridges (oesophageale Grenzwülste) of the Enteropneusta are likewise ciliated tracts (without the histological differentiation observed in the endostyle) which lie at the base of the gill-clefts and arch round in front to unite in the epibranchial band•(Pl. XXVIII. Fig. $1 \mathrm{~A}$ and Text-fig. 7).

1 A. Willey, Amphioxus and the ancestry of the Vertebrates, 1894, p. 29. Cf. also Pierre de Meuron, Recherches sur le développement du Thymus et de la glande Thyrö̈de. Dissertation. Geneva, 1886. De Meuron gives some admirable diagrams to elucidate the origin of the thymus in different Vertebrata.

2 At first upper and lower owing to the peculiar configuration of the larva.

${ }^{3}$ In preserved specimens the contraction of the body quite obscures the ciliated bands in ninety-nine cases out of a hundred. 
The change of function which would be associated with the transformation of the relatively undifferentiated parabranchial ridges into such a highly specialised organ as the endostyle is not easy to define ${ }^{\mathbf{1}}$, and I limit myself to pointing out the similarity in topographical relations.

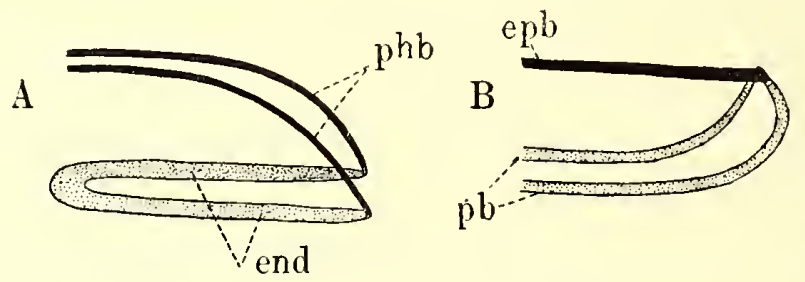

Fig. 7. Diagrams to illustrate the comparison of the specialised ciliated tracts in the pharynx of Amphioxus $(A)$ and Enteropnedsta $(B)$.

end Endostyle. $p h b$ Peripharyngeal bands. $p b$ Parabranchial ridges. epb Epibranchial band.

It is satisfactory to know that there exists something in the Enteropneusta which may be related to the endostyle but which nevertheless is not one.

The phyletic series of changes relating to the endostyle may therefore be tabulated as follows:-

I.

Parabranchial RIDGes

(Enteropneusta)
II.

Endostyle

(Cephalochorda and Urochorda)
III.

THYROID

(Vertebrata)

1 Of course it would be connected with changes in the entire habit of life, method of feeding, and quality of food.

ZoOLOGICAL Laboratory,

New Museums, Cambridge, May 1st, 1899. 
Wiliey Zoological Reisults.
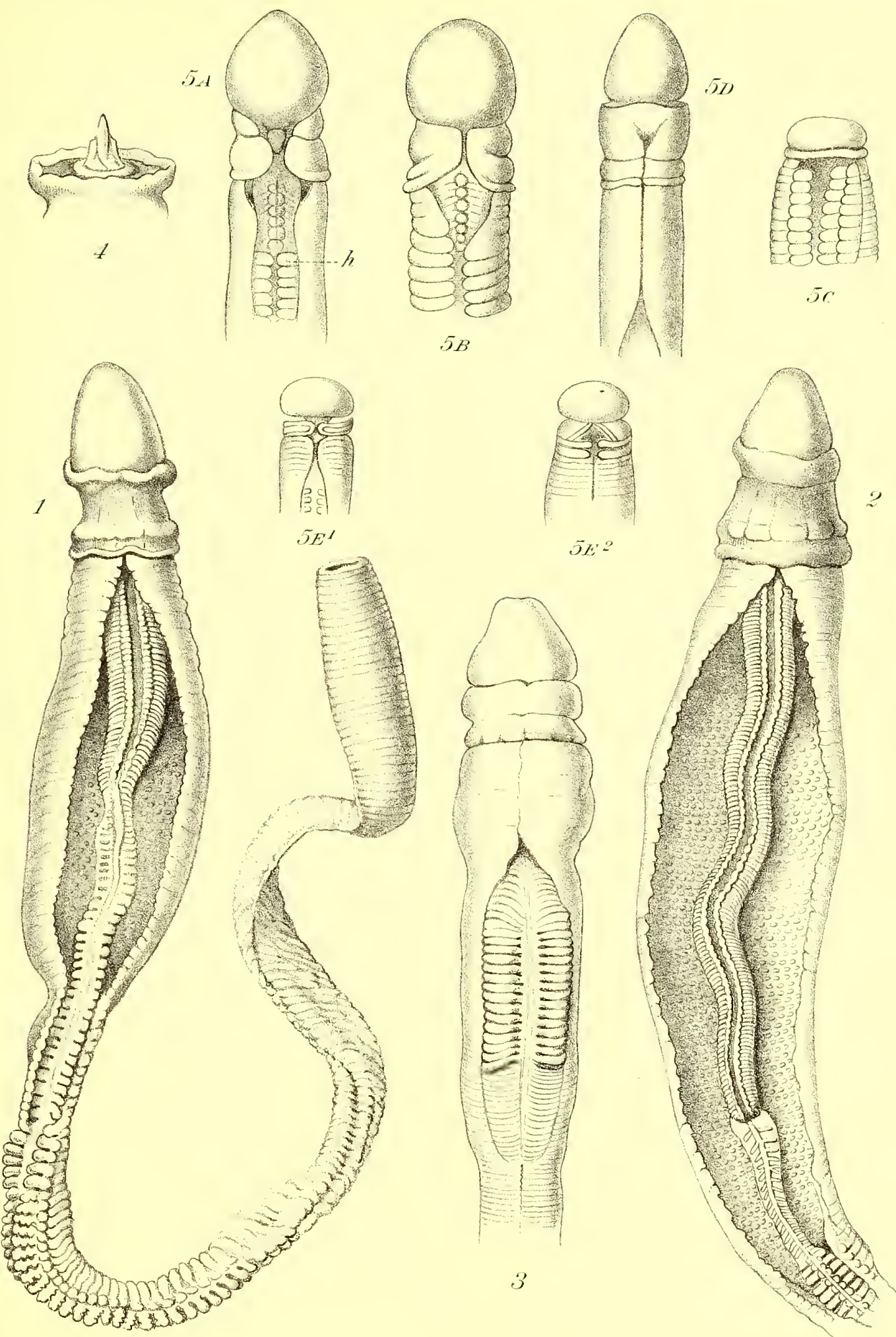
, 


\section{EXPLANATION OF PLATES XXVI-XXXII.}

The material was chiefly preserved in Mayer's Picro-Nitric solution and in a ChromeOsmic mixture which was recommended to me specially for preserving Enteropneusta by Mr J. P. Hill. It gave excellent results and is the most reliable fluid for unique specimens. The following proportions are employed:-

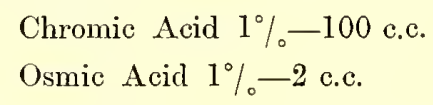

Objects may be left in this fluid for 12 hours (overnight) and then washed out in water. Specimens preserved in $4-5 \%$ formalin are useful for dissection.

\section{REFERENCE LETTERS.}

a. Artefact.

$a d v$. Advehent dermal vessel of proboscis.

ag. Accessory gonads.

an. Anterior neuropore.

b. Blood-space.

bm. Basement membrane.

br. Branchial sac.

bs. Central blood sinus.

c. Collar coelom,

ca. Ciliated apparatus (ciliated grooves of intestine).

cc. Collar canal.

cf. Collar funnel.

$\mathrm{cm}$. Circular muscles.

cp. Collar pore.

ct. Fold in wall of collar canal.

$d g p$. Dorsal diverticulum of gill-pouch.

dn. Dorsal nerve-cord.

dp. Dermal pit.

$d r v$. Dorsal recurrent dermal vessel of proboscis.

ds. Dorsal septum (Mesentery in Pl. xxx. Fig. 32).

$d v$. Dorsal vessel.

$e i$. Epidermal involution.

ep. Epidermis.

epb. Epibranchial tract.

$\left.\begin{array}{c}e p . e \\ e p . i .\end{array}\right\}$ Outer and inner epidermis of collar-flap.

ept. Epidermal tract.

et. Anterior epidermal involution (Epidermistasche).

$e v$. Efferent vessels of proboscis.

g. Gonads.

gd. Genital duct.

gl. Glomerulus. $g p^{1}$. First gill-pouch.

gpc. Coecum of gill-pouch.

gs. Gill-slit.

$g s^{1}$. First gill-slit.

h. Perieardium (not in Pl. XXVI. Fig. 5A,q.v.)

hg. Hind-gut.

$i$. Intestine.

ic. Inner circular muscles of collar.

iec. Intra-epidermal canal.

il. Inner longitudinal muscles of collar.

l. Hepatic saceule.

$l g$. Lateral gonad.

lm. Longitudinal muscles.

lp. Left proboscis pore.

lps. Lateral pouch of stomochord.

ls. Lateral septum.

lv. Lateral vessel.

mc. Medullary canal or cord (collar nerve-cord).

mg. Medial gonad.

$m s$. Median septum of proboscis.

oc. Outer circular muscles of collar.

oe. Oesophagus.

ol. Outer longitudinal muscles of collar.

p. Proboscis coelom.

$p b$. Parabranchial ridge.

pbe. Postbranchial canal.

pc. End-vesicle or end-sac of proboscis (Eichelpforte)

$p h$. Perihaemal cavity.

pnp. Posterior neuropore.

pph. Peripharyngeal cavity.

ptv. Post-trematic portion of end-sac (also pc.).

py. Pygochord. 

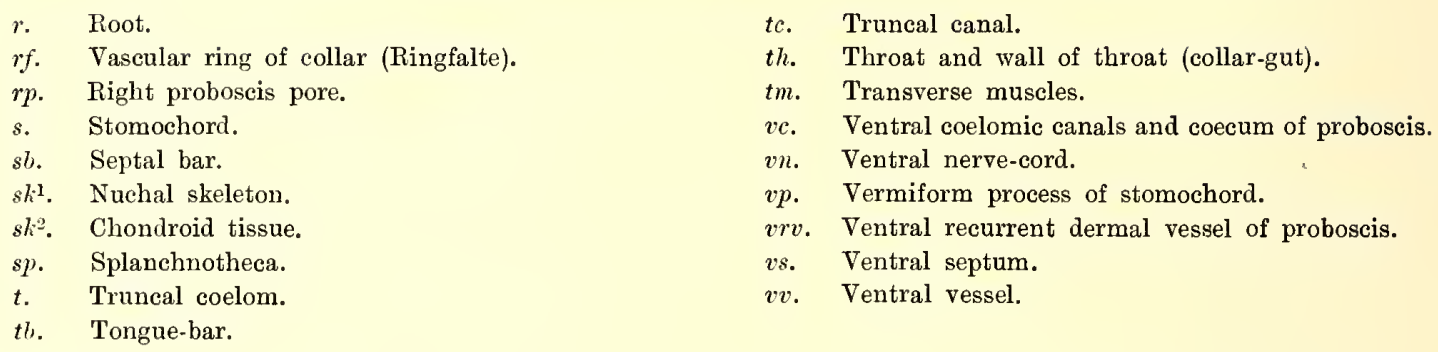

\section{PLATE XXVI.}

All the figures on this plate refer to Pt. flava.

FIG. 1. Dorsal view of normal specimen with genital pleurae divaricated and exposing the free pharynx. $\times 3$.

FIG. 2. Similar view of anterior portion of macrobranchiate variety with fully expanded genital pleurae. The oval bodies disposed in zones on the inner surface of the genital pleurae are glandular dermal islets. $\times 3$.

FIg. 3. Similar view of brachybranchiate variety. The genital pleurae are closely approximated in the branchial region so as to cover in the pharynx. The hepatic tract is sharply defined, the saccules being arranged like the leaves of a book. $\times 6$.

FIG. 4. Anterior end of specimen from which the whole of the pre-nuchal region of the proboscis had been removed, showing the central complex projecting freely as a rigid body, hard to the touch. $\times 3$.

FIG. $5 A-E$. The anterior ends of a series of regenerating individuals from the dorsal side (except $E^{2}$ ).

A. The medullary folds are wide apart, exposing the base of the collar nerve-cord throughout its entire length. The triangular body seen at the base of the collar groove in its anterior half is due to the vaulted floor of the groove (cf. Pl. XXXII. Fig. 66). The hepatic saccules commence at $h$ and the entire pre-hepatic portion of the specimen measured $3.25 \mathrm{~mm}$. in length.

B. The medullary folds are still open but closely approximated. At the anterior end they are fused (see Pl. XXXII. Fig. 68). Proboscis + collar $=3.5 \mathrm{~mm}$.

$C$. A rudimentary proboscis and collar have been added immediately in front of the hepatic region. $\times$ about 4.

D. The medullary folds have completely closed over the collar nerve-cord, but there remains a deep dermal groove in the posterior half of the collar in the middle line. $\times$ about 3 .

$E^{1}$ and $E^{2}$. A regenerating individual from dorsal and ventral aspects to demonstrate the homodynaniy of the zones of the collar with the annulations of the trunk. $x$ about 4 . 


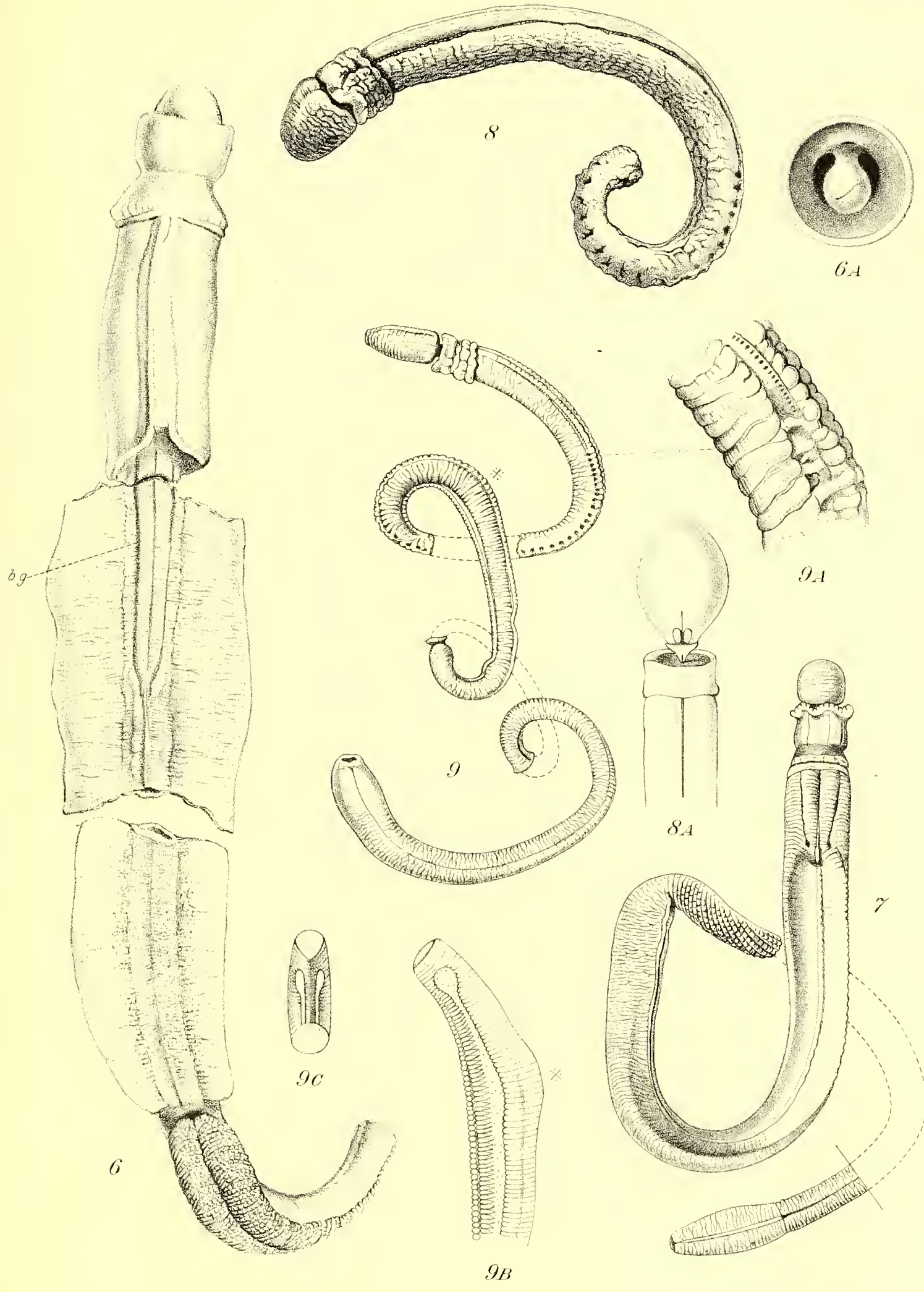

Edi:m Wilson, lith Cambridge. 



\section{PLATE XXVII.}

Fig. 6. Dorsal view of $P$. carnosa n. sp. to the end of the hepatic region; abdominal and caudal regions omitted. From preserved specimen, natural size. In front of the first fracture the genital pleurae are united together across the middle line by a mucous junction.

Fig. $6 \mathrm{~A}$. Frontal view of the head of Pt. carnosa. There is a scar across the small proboscis which probably indicates that the latter was recovering from an injury. The anterior neuropore is indicated in the dorsal angle made by the junction of the proboscis and collar, and below this are seen the lateral portions of the large buccal orifice.

Fig. 7. Pt. ruficollis, n. sp. The hepatic region is denoted by the diagonal markings which commence shortly behind the termination of the genital ridges. The posterior end of the body is represented in ventral view to show the transition from the abdominal to the caudal region. $\times 2$.

FiG. 8. Spengelia porosa in lateral view. From a photograph (x about 2) taken by Mr Grant in the Physiological Laboratory at the University, Sydney, N.S.W.

Fig. $8 \mathrm{~A}$. Sp. porosa. Ventral view of anterior end of macerated specimen showing the cupule and keel of the nuchal skeleton; the two horns of the glomerulus and the vermiform process of the stomochord projecting into the proboscis.

FIG. 9. Sp. alba, n. sp. The entire animal in three fragments; the dotted lines show where the fragments should join on to one another. $\times 1 \frac{1}{2}$.

FI๔. 9 A. Sp. alba. Enlarged view of branchiogenital transition. $\times 6$.

Fig. $9 \mathrm{~B}$. Sp. alba. Enlarged view of genito-hepatic transition and portion of hepatic region, to show smooth ventro-lateral epidermal tract. The dark line showing through in the posterior part of the drawing is due to the lateral blood-vessel of the hepatic region. The asterisk marks the corresponding points in Figs. 9 and $9 \mathrm{~B}$.

Fig. $9 C . S p$. alba. Ventral view of genito-hepatic transition to show the dilated ends of the ventro-lateral epidermal tracts.

\section{PLATE XXVIII.}

Fig. 1 a. Pt. Alava. Collar and anterior end of pharynx opened up by a ventral incision. It shows the parabranchial ridges passing round into the epibranchial tract; also the racemose organ underlying the body of the nuchal skeleton immediately in front of the divaricating cornua of the skeleton. The lobulation of the racemose organ varies greatly in extent, the condition here represented being somewhat beyond the average.

Fig. 1 b. Pt. carnosa. Similar view. Collar-flap projects far in front of insertion of proboscis; an epithelial pad underlies the nuchal skeleton in front of and below the point of bifurcation (cf. Pl. XXIX. Fig. 18). 
Fig. I c. Pt. ruficollis. Collar opened by ventral incision. The projecting knob at the base of the proboscis is formed by the ventral coecum of the proboscis like the racemose organ in Pt. flava.

Fig. 1 d. Sp. porosa. Similar view of macerated specimen. The alary processes and keel of nuchal skeleton are seen as well as the cornua of the skeleton reaching beyond the middle of the collar nearly to its posterior margin.

The remaining figures on this plate refer to Pt. flava; all sections are transverse unless otherwise stated.

FIG. 2. Section through base of proboscis at the level of the proboscis-pores. The unequal size and wide openings of the pores may be noted. The section involves the free edge of the ventral septum of the proboscis, and the cupule of the nuchal skeleton. The dotted line in the epidermis indicates the line of demarcation between the nucleated and fibrous (nervous) layers of the epidermis.

Fig. 3. Portion of section through the region of insertion of proboscis into collar, passing through the anterior neuropore. In this specimen the racemose organ $(v . c)$ was slightly lobulated.

Fig. $4 a-c$. Sections through collar nerve-cord (medullary tube) showing central cana] and hollow roots. arises.

Fig. $4 a$ shows the first root meeting the epidermis and the basal crest from which it

Fig. $4 b$ shows the hollow neural crest between the first and second roots.

Fig. $4 c$ shows the second root arising by constriction from the neural crest and meeting the basement membrane of the epidermis.

Fig. 5. Portion of section through the region of transition from collar to trunk, passing through the posterior neuropore (below which the dorsal vessel is seen); a collar-canal on the left and a collar-pore on the right, opening into the first gill-pouch.

FIG. 6. Section through the branchial region showing genital pleurae and lateral septa. The gonads have been omitted from one side in order to show the lateral septum (which is perforated by the genital ducts) more clearly. A tongue-bar is shown on the right side of the figure, and a septal bar with cut ends of synapticula on the left side.

Fig. 7. Section through the branchiogenital transition shortly behind the terminal gillslits, showing the postbranchial canal.

FIG. 8. Inner view of the basal portions of three gill-slits. Reduced from the Quart. Journ. Micr. Sci., Vol. 40, Pl. 5, Fig. 3; it shows the wide tongue-bars and narrow septal bars united by synapticula or cross-bars.

FIG. 9. A group of gonads containing ova as seen in situ in the genital pleura. (1bid. Pl. 5, Fig. 5.)

Fig. 10. Similar view of a single male gonad (Tbid. Fig. 4a.)

FIG. 11. Nutritive bodies from gonads with darkly stained inclusions. The central body of the smaller cell shows refringent contents. Zeiss Oc. 3, Obj. J, water imm. 
Willey Zoological Results.

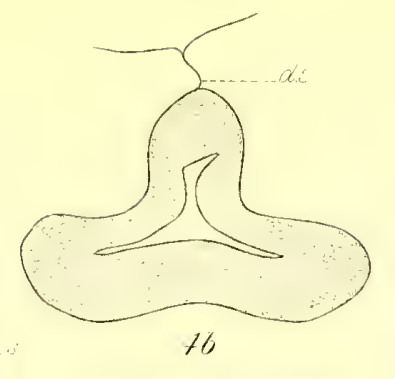

PLATE XXVIII.
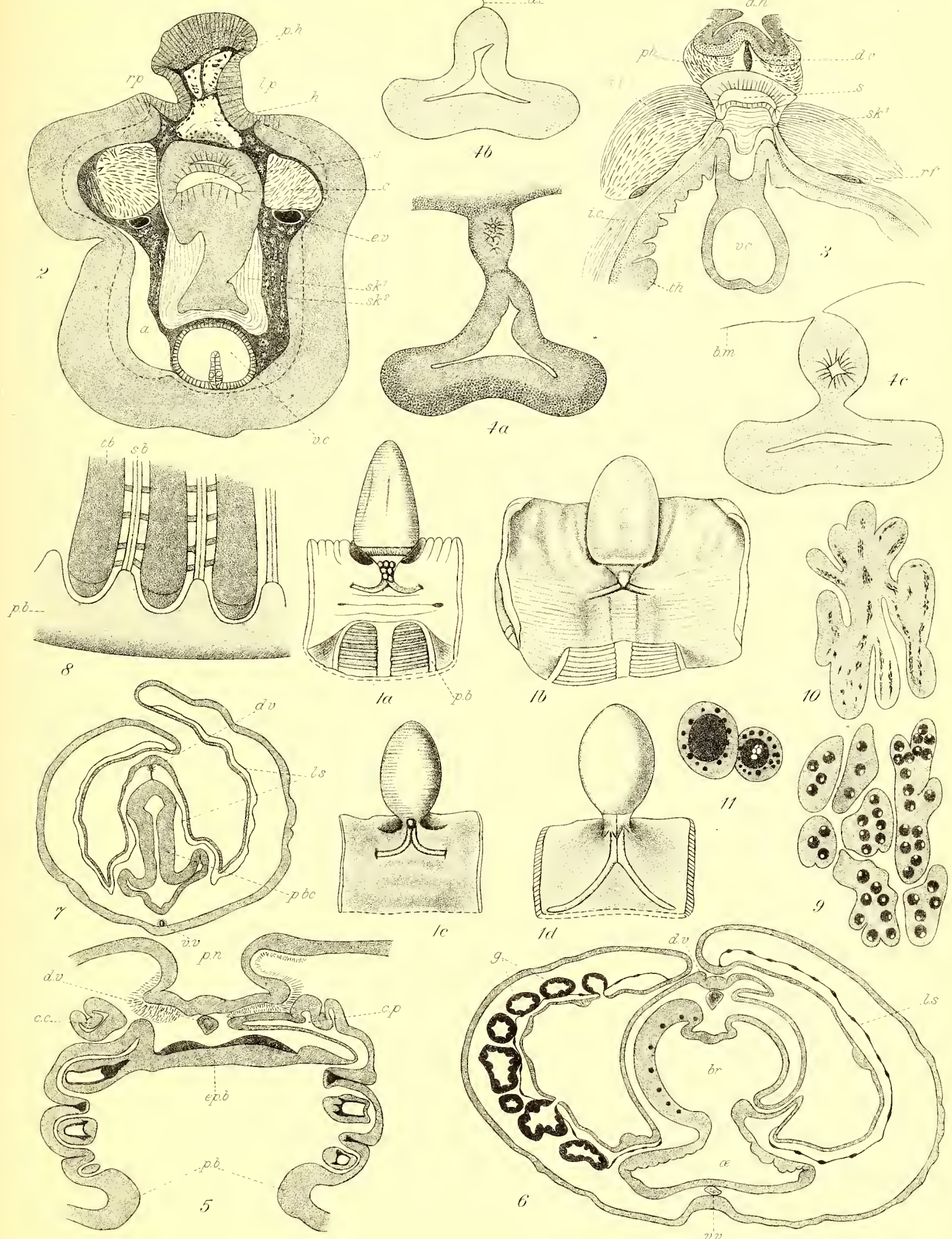

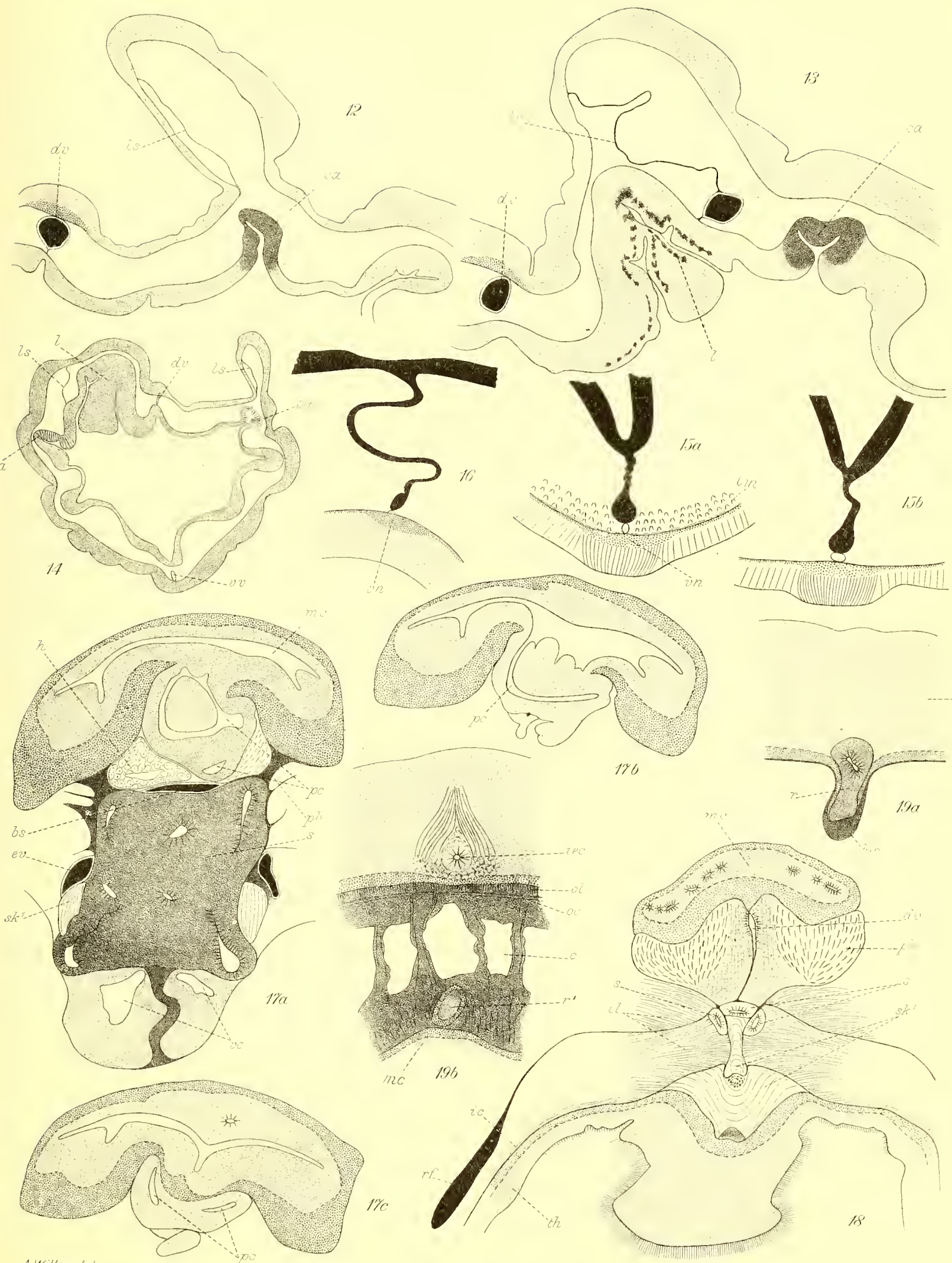

WILILEY. ENTEROPNEUSTA 
$\checkmark$ 


\section{PLATE XXIX.}

Figs. 12-15 refer to Pt. flava.

Fig. 12. Portion of section through hepatic region passing through an intersaccular interval showing sacculation of ciliated groove of intestine.

FIG. 13. Similar section passing through a liver-saccule.

FIG. 14. Entire section through hepatic region involving a liver-saccule on the left and an intersaccular interval on the right.

Fig. $15 a-b$. Ventral portions of sections through caudal region to show the pygochord in its moniliform and simple aspects. The dilated ventral border of the pygochord abuts upon the ventral vessel.

Figs. 16-19 refer to Pt. carnosa, n. sp.

Fig. 16. Ventral portion of section through caudal region to show the narrow lamelliform pygochord.

Fig. $17 a-c$. Portions of sections through the region of insertion of proboscis into collar, involving the posterior part of the proboscis end-sac (Eichelpforte).

FIG. $17 a$. Shortly behind the anterior neuropore, showing the end-sac lying below the medullary tube. The lumen seen in the ventral wall of the end-sac is a diverticulum from the main lumen. The body lying inside the sac is a tangential section through the duplicature of the wall of the sac, described in the text. The section passes through the middle of the coecal or pouched region of the stomochord; above the ventro-lateral pouches are seen the forward prolongations of the cupule of the nuchal skeleton.

Fic. $17 b$. Section through the medullary tube posterior to preceding, showing the endsac opening by the proboscis-pore into the medullary tube (see Text).

Fig. $17 c$. Similar section still farther back, showing the coecal (post-trematic) extensions of the end-sac.

This section passes near the termination of the anterior transverse lumen of the medullary tube, and a minute cavity, forming one of the system of separate medullary cavities into which the primitive lumen is subdivided, is seen in the dorsal wall of the tube.

FIG. 18. Portion of section through the collar-region, about half-way between the anterior neuropore and the buccal orifice of the stomochord. It passes through the middle of the nuchal portion of the stomochord, which is here fragmented into three divisions.

The section also passes shortly behind the end of the ventral coecum (coelomic canal) of the proboscis, and the alary processes of the nuchal skeleton have united behind the coelomic canal to form the keel. The small dorsal moiety of the skeleton is the body. Below the keel is a thick epithelial pad, projecting from the roof of the mouth (cf. Pl. XXVIII. Fig. $1 b)$.

Fig. $19 a-b$. Dorsal portions of sections through the collar.

FIG. $19 a$ shows the distal end of the first root entering the epidermis.

FIG. $19 b$ shows the proximal or basal portion of the first root close to the dorsal wall of the medullary cord shortly in front of its origin from the latter; and the intra-epidermal canal proceeding from the second root. The collar coelom is seen to be traversed by radial trabeculae enclosing radial muscles. 


\section{PLATE XXX.}

Figs. 20-23 refer to Pt. carnosa.

FiG. 20. Section through collar-canal.

FIG. 21. Dorsal portion of section through region of transition from collar to trunk, passing immediately in front of, and cutting tangentially the lip of, the posterior neuropore. To the left of the point of junction of medullary-tube and epidermis is seen the posterior end of the dorsal septum of collar. The collar canals are fused at one side with the wall of the first gill-pouch on each side, and with the basal angles of the medullary tube at their mesial sides. This association of collar-pores, first gill-pores and posterior neuropore constitutes the posterior trematic complex of Enteropneusta (see p. 320).

Fig. 22. Section through anterior branchial region, showing the absence of gonads and the ventral coecum of the gill-pouch. On the left side the section passes through a tonguebar and on the right through a septal bar; on the right of the figure the section is diagrammatically made to pass exactly between two successive gill-pouches so that nothing is seen of them. The thin layer of circular muscles which occurs outside the longitudinal muscles is not shown in the figure.

FIG. 23. Section through the branchiogenital transition shortly behind the terminal gillpores, showing the post-branchial canal (cf. Pl. XXVIII. Fig. 7).

Figs. 24-35 refer to Pt. ruficollis, n. sp.

Fig. 24. Section through anterior end of central complex of proboscis in front of the stomochord, showing the bifurcation of pericardium with the radial vessels of the glomerulus. Between the two halves of the pericardium is seen the median septum of the proboscis, containing dorso-ventral muscles.

FIG. 25. Section through the dilated region of the stomochord with its lateral pouches. Above the stomochord are seen the dorsal coelomic canals separated by the pericardium.

The coelomic epithelium overlying the efferent vessels of the proboscis is ciliated. Above the dorsal border of the pericardium are the two primary branches of the advehent dermal vessel of the proboscis. Between pericardium and stomochord is the central blood-space; and below the stomochord are the ventral coelomic canals separated by the ventral septum of the proboscis.

Fig. 26. Section shortly posterior to preceding, showing the lateral pouches of the stomochord uniting across the middle line to form the ventral coecum of the stomochord which overhangs the ventral coelomic canals. On each side are seen the anterior rami of the cupule of the nuchal skeleton.

FIG. 27. Section through the region of the proboscis pore, showing the efferent vessels lying in the scanty chondroid tissue and the alary processes of the nuchal skeleton arching over the united ventral coelomic canals (ventral coecum of proboscis).

FIG. 28. Section through region of anterior neuropore, i.e. through the region of the insertion of proboscis into collar, showing the lobe-like ventral coecum of proboscis below the keel of the nuchal skeleton. 


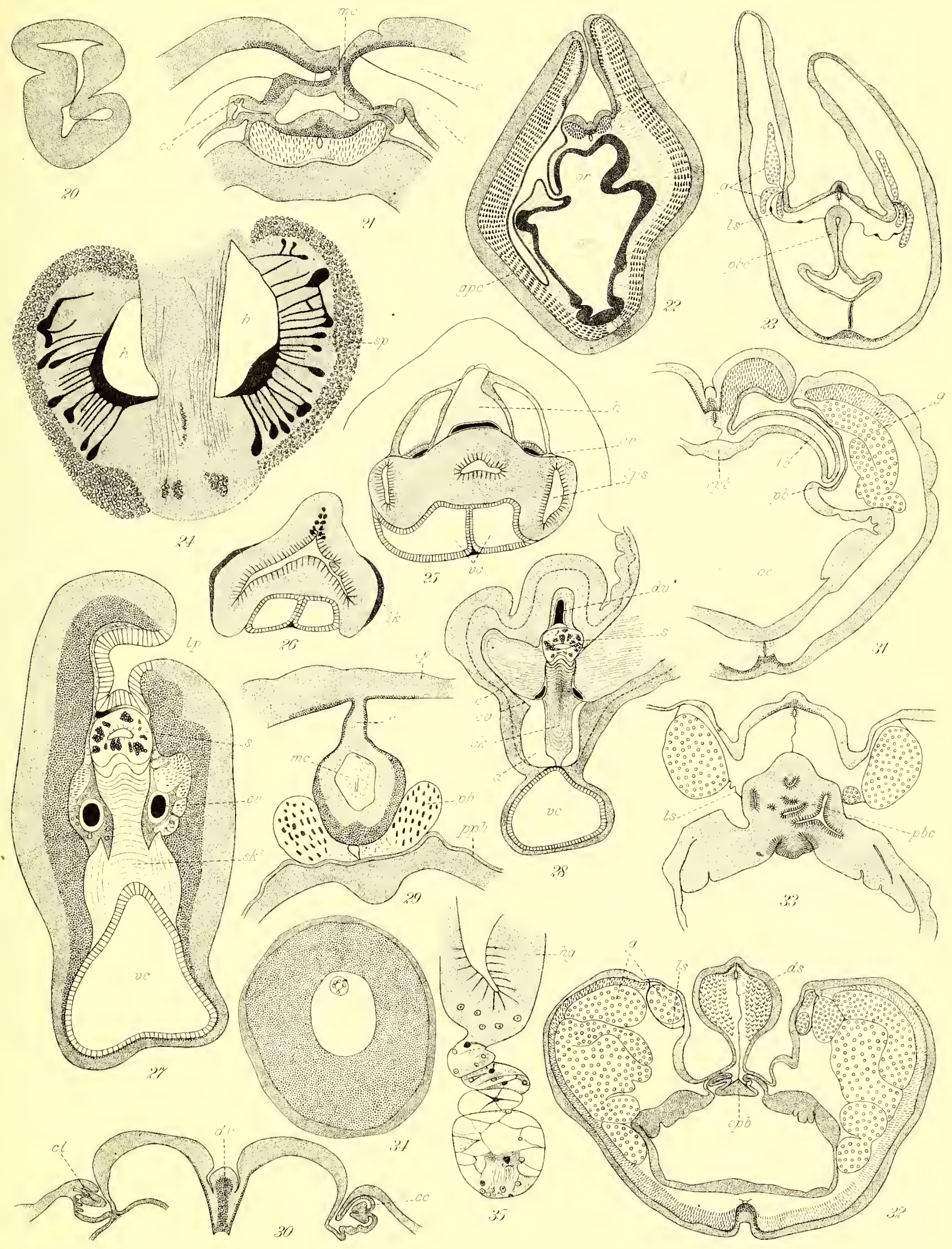



The dorsal vessel is cut approximately at the point whence it is continued forwards into the central blood-space, and where it gives off, dorsally, the advehent dermal vessel of the proboscis.

FIG. 29. Dorsal portion of section through the collar, showing the medullary tube, somewhat flattened laterally, with central canal and solid root passing direct to the epidermis.

FIG. 30. Dorsal epidermal portion of section through branchial region immediately behind collar, showing the posterior ends of the collar-pores. On the left the second gill-pore is cut tangentially and is seen to be overhung by the tongue-like fold of the collar canal. On the right of the figure the section passes between the first and second gill-pores, and shows the raphe in the middle of the tongue-like fold of the collar-canal (see Text).

FIG. 31. Portion of section through branchial region, showing the gonad attached by a genital duct to the epidermis at the outer side of the branchial groove.

FIG. 32. Section through the posterior end of the branchial region, showing the local depression of the branchial grooves and reduction of the branchial portion of the gut. The penultimate gill-pouches are seen at the bases of the grooves. At the outer and upper sides of the grooves are seen the anterior portions of the lateral septa (close to their anterior termination), enclosing the medial branches of the gonads.

FIG. 33. Section shortly behind preceding, sbowing the anterior portion of the postbranchial canal with its subdivided lumen, and below it a pair of grooves continued back from the last pair of gill-slits.

FIG. 34. Section through mature ovarian ovum, showing refringent inclusions in the nucleolus of the germinal vesicle. Highly magnified.

FIG. 35. Ventral portion of section through hind-gut, showing the pygocliord with its vacuolated cells.

\section{PLATE XXXI.}

Figs. 36-45 refer to Spengetia porosa.

Fig, 36. Central portion of section through proboscis in front of the central complex, showing the vermiform process lying in the median septum, through which pass the dorsoventral muscles. On each side of the median septum is the central cavity of the proboscis, the dorsal side of which is bounded by decussating conjunctive fibres.

FIG. 37. Section through the commencement of the central complex, showing the anterior projecting horns of the glomerulus, between which lies the vermiform process of stomochord.

FIG. 38. Section through the posterior end of the dilated region of the stomochord, shortly behind the glomerulus, showing the basal organs of the proboscis enveloped in chondroid tissue. The epidermis is omitted. The lower division of the stomochord is the ventral coecal dilatation, which projects backwards into the cupule of the nuchal skeleton and so appears in section at this level separate from the smaller dorsal division. On either side of the dorsal division of the stomochord are seen the dorsal coelomic canals $(p)$, of which the left is the larger in this region (on the right of the figure), and communicates at a slightly anterior level with the end-sac, which is seen above the pericardium. The ventral coelonic canals are nearing their termination in the chondroid tissue. 
FIG. 39. Section passing through the proboscis-pore (external opening of end-sac). It may be noted how the substance of the nuchal skeleton grades off into the chondroid tissue. Above the stomochord the dorsal vessel is seen to give off the advehent dermal vessel of the proboscis, on either side of which are the anterior extremities of the perihaemal cavities.

FIG. $40 a-c$. Sections through the vestigial root of $S p$. porosa.

FIG. $40 a$ shows the distal terminal vesicle with its thick wall enclosing mucoid contents. Zeiss Oc. 3, Obj. D.

FIG. $40 b$ (posterior to preceding and less highly magnified) shows the root itself abutting upon and terminating in the clistal vesicle, the wall of which is cut tangentially, and encloses a homogeneous mass of darkly staining matter.

Fir. $40 \mathrm{c}$ (still farther back) shows the basal portion of the root and its origin fronl the dorsal wall of the medullary cord.

FiG. 41. Section through the middle of the collar nerve-cord (medullary cord), showing medullary cavities and distribution of fibrous layer.

FIG. 42. Section through collar-canal.

Fig. 43. Cross-section of the skeletal rod of a septal bar with blood-vessel at inner end; taken from a horizontal section through the pharynx.

FIG. 44. Section through posterior end of collar with posterior neuropore, showing the truncal canals in the perihaemal cavities. On the left the figure shows the truncal canal opening into the first gill-pouch at the level of the collar-funnel; on the right the truncal canal is seen at a more anterior level, and the posterior end of the peripharyngeal cavity of that side is seen lying against the wall of the throat (collar-gut), while imbedded within the wall is the posterior extremity of one of the cornua of the nuchal skeleton.

FIG. 45. Section through the branchial region, showing medial gonads, inner circular muscles and oesophageal portion of gut. On the right is shown a tongue-bar and on the left a septal bar with the cut ends of the synapticula.

Figs. $46-51$ refer to $S p$. alba, n. sp.

FiG. 46. Portion of section through proboscis in front of central complex (cf. Fig. 36).

Fig. 47. Portion of section through conmencement of central complex. The section passes immediately in front of the anterior end of the pericardium, and shows the two anterior horns of the glomerulus on either side of the stomochord. Above the latter is seen the vascular complex which constitutes the dorsal recurrent dermal vessel of the proboscis.

Fig. 48. Section through base of proboscis passing through the pouched region of stomochord, shortly behind the glomerulus, the continuation of which into the efferent vessels is seen below the ventral epithelium of the dorsal coelomic canals (cf. Pl. XXX. Fig. 25). The pericardium is seen to be traversed by transverse fibres, and above it are the two primary branches of the advehent dermal vessel. The dorsal and ventral coelomic canals are separated by the lateral pouches of the stomochord.

FIG. 49. Section through the neck of the proboscis in the region of the proboscis-pore, passing in front of the posterior termination of the ventral coelomic canals. The chondroid substance is homogeneous, and is characterised by the relative scarcity of cellular islets. 


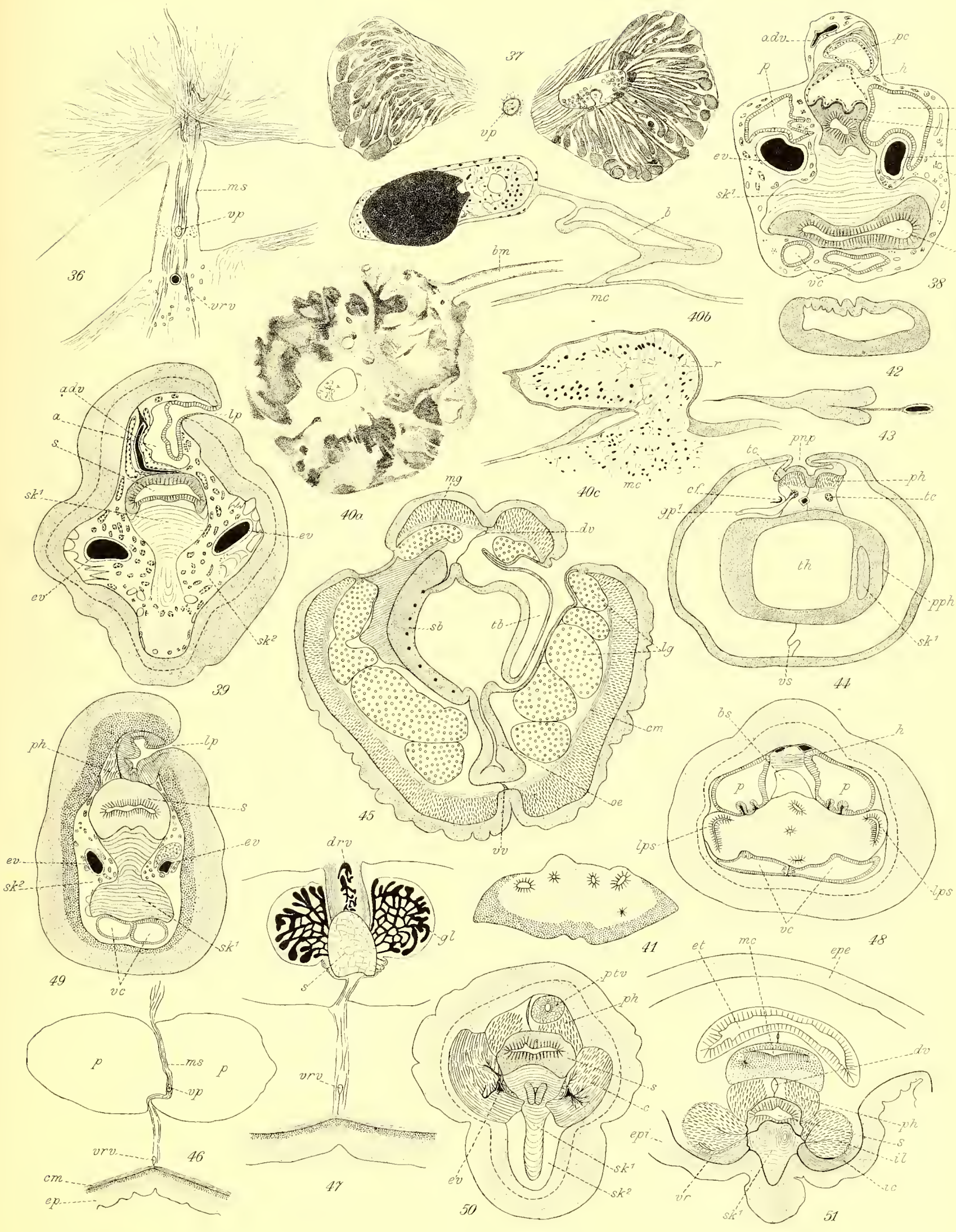


$$
\text { . }
$$ 
FIG. 50. Similar section at a more posterior level (behind the ventral coelomic canals), showing the post-trematic coecal projection of the end-sac into the anterior end of the left perihaemal cavity. This section with the next shows the inclusion of the fused anterior portions of the cornua of the nuchal skeleton within its body, which presumably takes place concomitantly with the progressive growth in length of the animal.

Fia. 51. Portion of section shortly behind the insertion of proboseis into collar, showing the medullary tube (which opens at a slightly more anterior level, independently, by the anterior neuropore) and the anterior epidermal involution (anterior Epidermistasche), formed by backward extension of the angle of insertion of proboscis and collar, dorsal to the medullary tube with which it is united by a short septun.

\section{PLATE XXXII.}

Figs. 52-60 refer to $S p$. alba.

Fic. 52. Portion of section through region of transition from collar to trunk, but in front of the posterior neuropore. On the left of the figure the truncal canal is seen communicating with the first gill-pouch at the commencement of the first gill-slit and at the level of the collar-funnel. On the right of the figure the section passes in front of the truncal canal of that sicle.

FIG. 53. Section through one of the perihaemal cavities immediately in front of a truncal canal. At $x$ is seen a distinct loculus for the reception of the truncal canal; this loculus extends over several sections.

FIG. 54. Section through the same perihaemal cavity at a level intervening between Fig. 52 and Fig. 53, showing the truncal canal as an independent tube.

Fia. 55. Section through branchial region. On the left a tongue-bar is shown, and on the right the figure shows the entire half of a gill-slit between septal bar and tongue-bar. Note absence of medial gonads, presence of inner circular muscles and of a minute dorsal. diverticulum of the gill-pouch $(d g p)$.

FIG. 56. Upper half of section through the branchiogenital transition, showing accessory gonads and last gill-slit.

FIG. 57. Similar section through posterior end of genital region (genito-hepatic transition), showing intestinal canals and pores (vestigial gill-slits). Owing to the overlapping of these canals, as described in the text, portions of no less than five of them are seen to the left of the figure and two on the right. They consist of ectodermal and endodermal portions, and occur at the dorsal angles of the gut, in the same position as the terminal true gillslits (cf. preceding figure).

FIG. 58. Section through the hepatic region, showing the gonads continued into this region, the internal hepatic saccules (that on the right cut tangentially), an intersaccular epidermal involution, the lateral longitudinal vessels and the ventro-lateral epidermal tracts.

FIG. 59. Portion of section through epidermis of genital region, to show the depth of the dermal pits in this species and individual.

FIG. 60. Ventral portion of section through caudal region, to show the thickened median ventral wall of hind-gut representing the pygochord. 
FIG. 61. Pt. biminiensis, n. sp. Dorsal view of anterior end, showing convergence and overlapping of genital pleurae at anterior end of trunk.

FIG. 62. Same. Section through body of stomochord in front of the pouched region, showing wide cavity.

FIG. 63. Same. Section through anterior portion of the coecal region of stomochord in front of the pouches.

FIG. 64. Same. Section through neck of proboscis in region of proboscis pores (see Text). Between the right and left end-sacs is seen the anterior extrenity of the right perihaemal cavity, and below the right end-sac (left of tigure) the solid posterior extremity of pericardium. Note dorso-lateral and ventro-lateral pouches of stomochord (cf. Pl. XXIX. Fig. $17 a)$. Above the latter are seen the anterior rami of the cupule of nuchal skeleton.

Fig. 65. Same. Portion of section behind region of insertion of proboscis into collar, showing the post-trematic extension of the left end-sac, the anterior paired lumen of the medullary cord with two separate medullary cavities, the process of skeletal substance enclosed within the stomochord between the dorso-lateral pouches; and the confluent ventral coelomic canals (ventral coecum of proboscis cavity).

FIG. 66. Pt. flava. Section through anterior collar-region of regenerating specimen shown in Pl. XXVI. Fig. $5 \mathrm{~A}$, to show formation of medullary tube by medullary folds. The section cuts the anterior border of buccal orifice of stomochord tangentially.

FiG. 67. Same. Similar section through middle of collar-region of same specimen as preceding, showing appearance of medullary groove at this level.

FIG. 68. Same. Portion of section through extreme anterior end of collar region of regenerating individual shown in $\mathrm{Pl}$. XXVI. Fig. $5 B$, to show the fusion of the medullary folds over the medullary tube at this level. Posterior to this point the medullary canal is still unclosed in this specimen.

FIG. 69. Pt. ruficollis. Dorso-lateral portion of section through genital region of mature female, to show the wide gaping of the genital duct. 

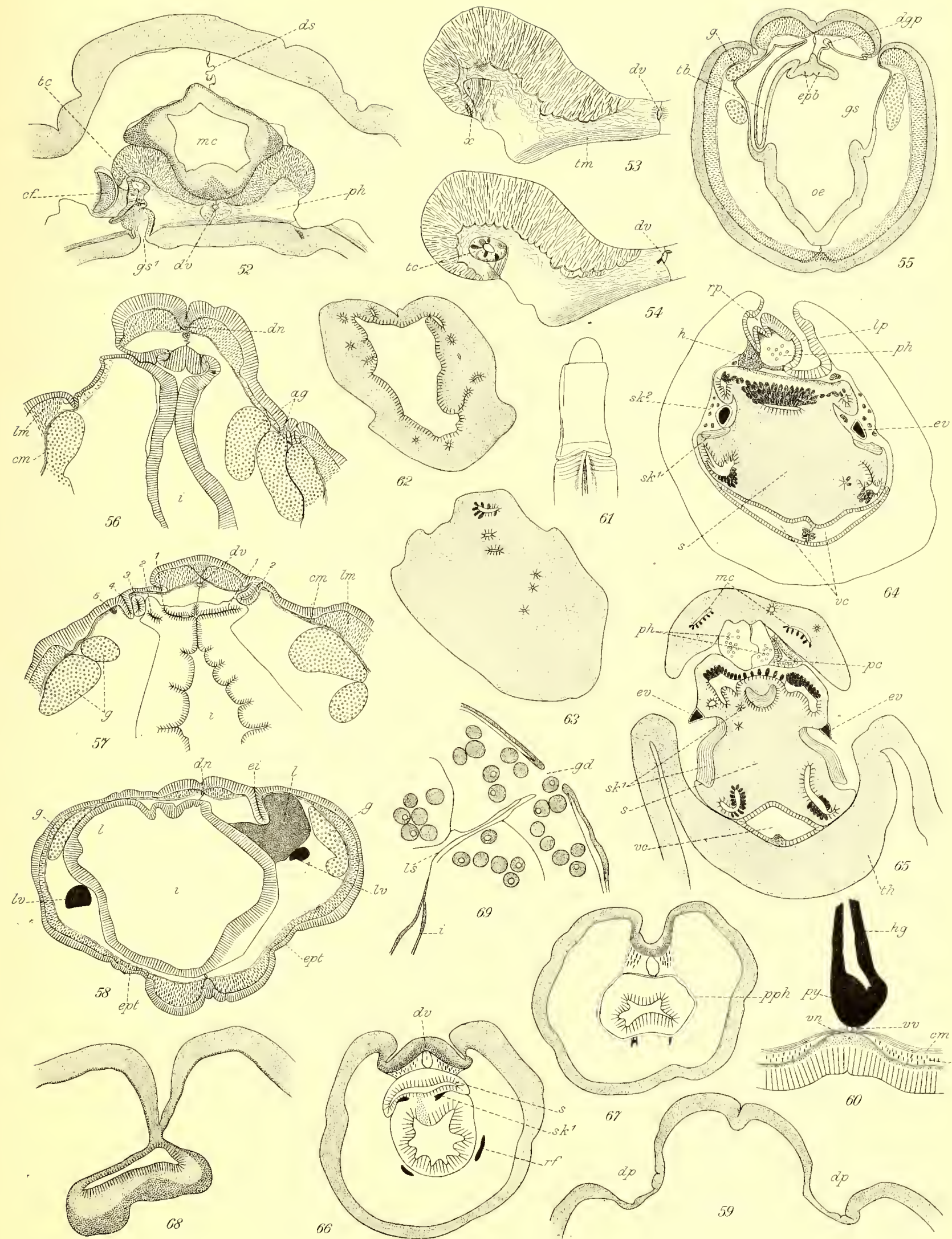

. 


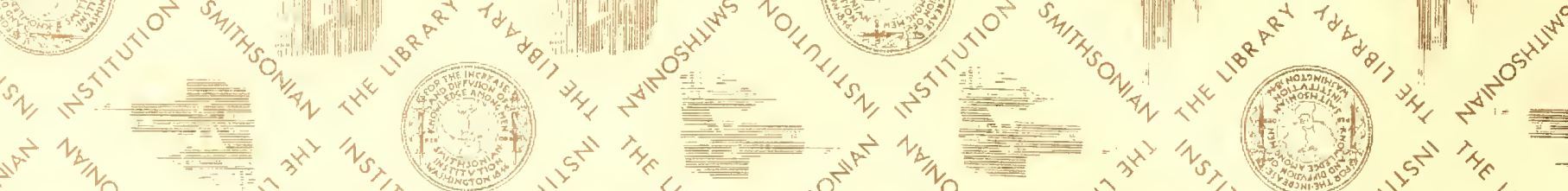

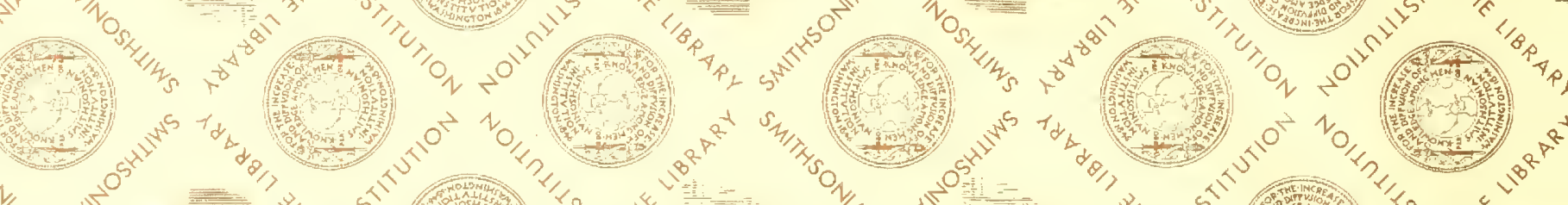

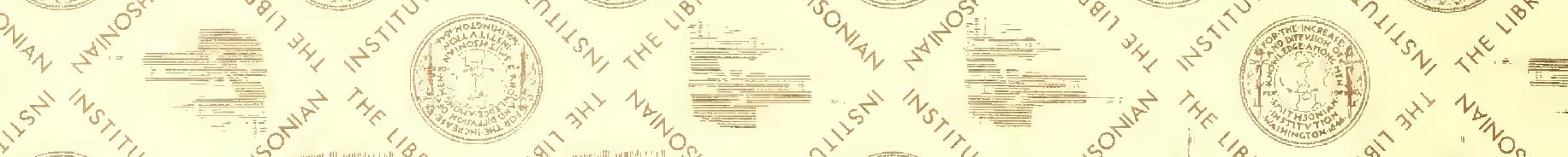

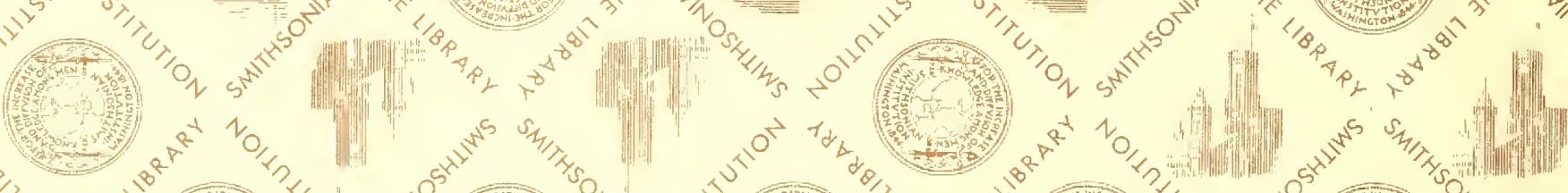

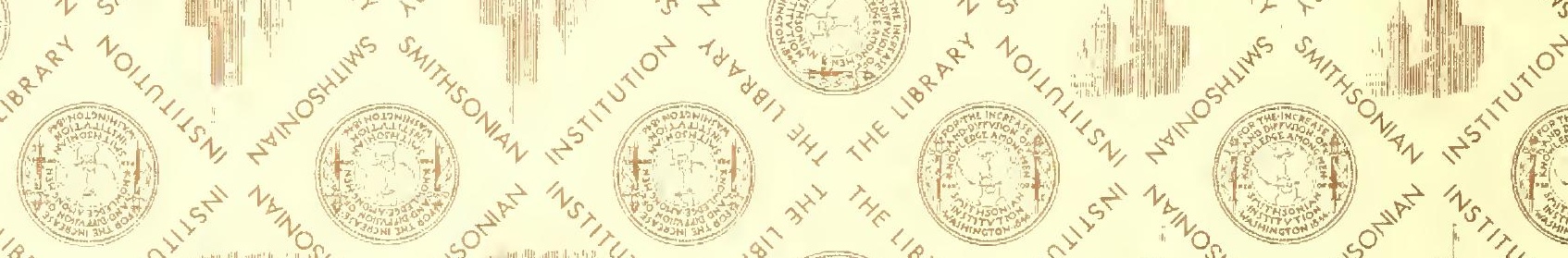

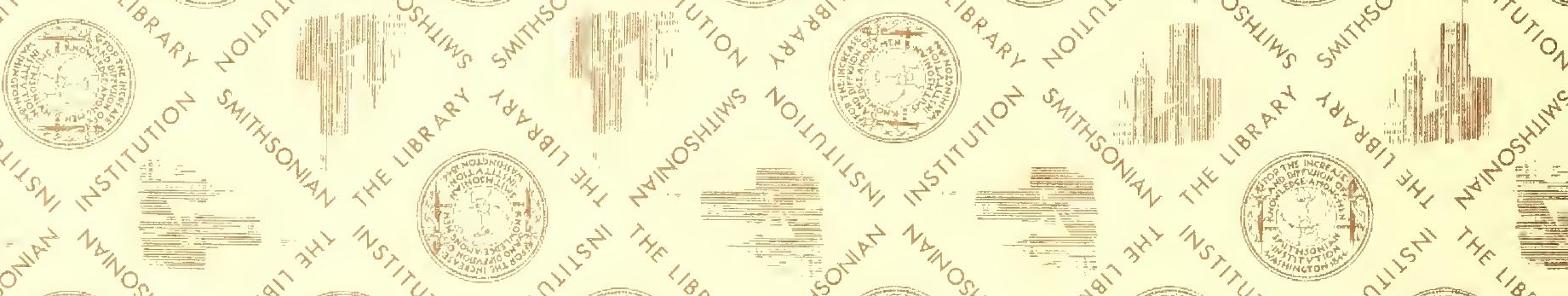

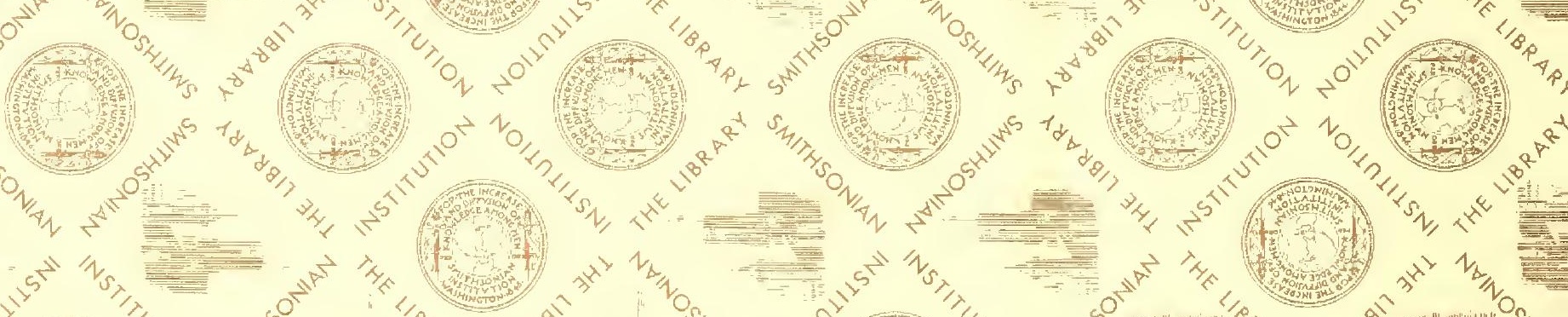

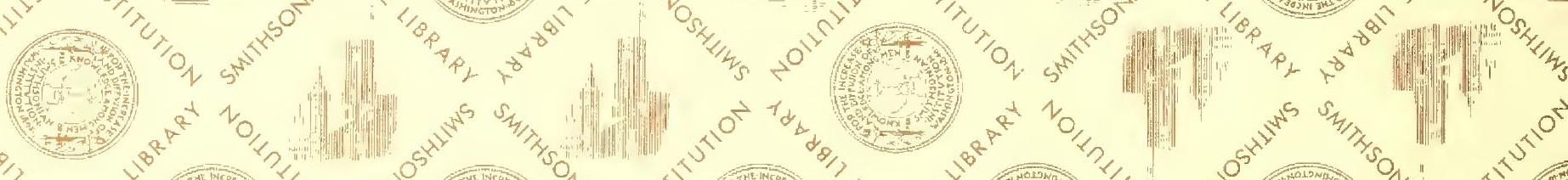

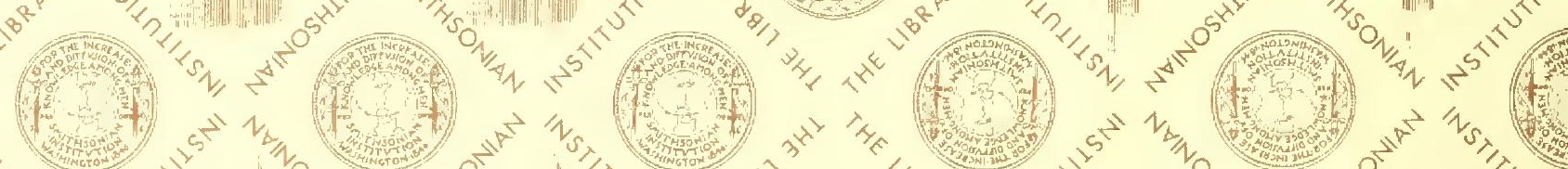
-
(
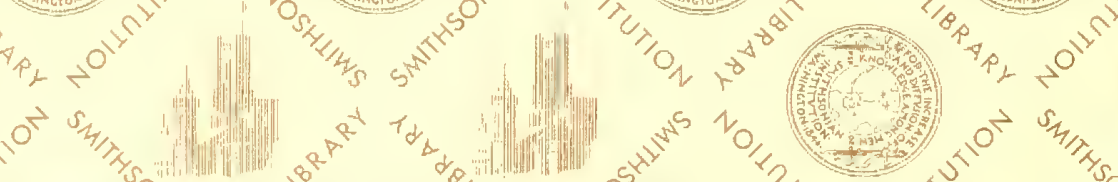
Af

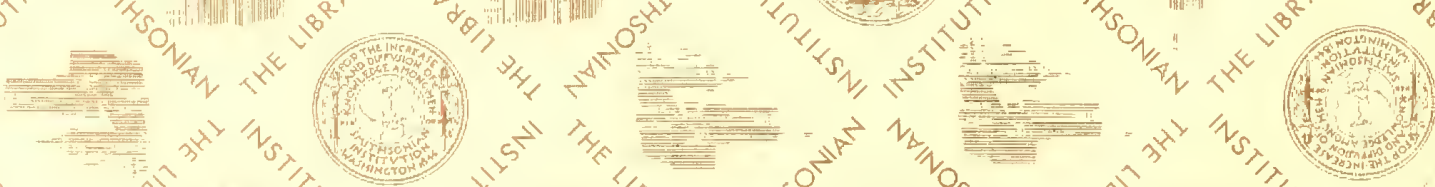

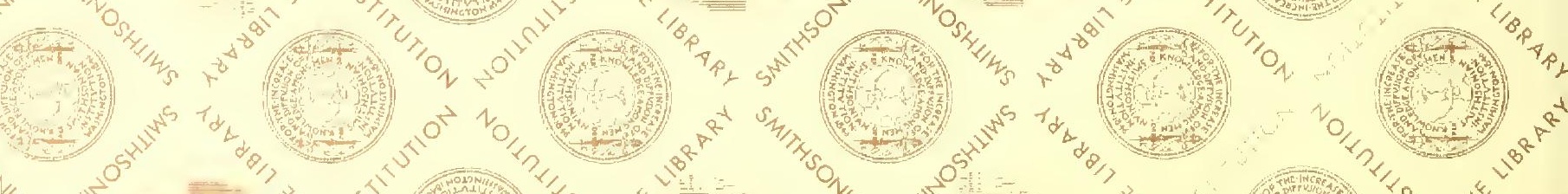


